\title{
The nature and consequences of school choice
}

Citation for published version (APA):

Zölitz, U. N. (2014). The nature and consequences of school choice. [Doctoral Thesis, Maastricht University]. Maastricht University. https://doi.org/10.26481/dis.20140207uz

Document status and date:

Published: 01/01/2014

DOI:

10.26481/dis.20140207uz

Document Version:

Publisher's PDF, also known as Version of record

\section{Please check the document version of this publication:}

- A submitted manuscript is the version of the article upon submission and before peer-review. There can be important differences between the submitted version and the official published version of record.

People interested in the research are advised to contact the author for the final version of the publication, or visit the DOI to the publisher's website.

- The final author version and the galley proof are versions of the publication after peer review.

- The final published version features the final layout of the paper including the volume, issue and page numbers.

Link to publication

\footnotetext{
General rights rights.

- You may freely distribute the URL identifying the publication in the public portal. please follow below link for the End User Agreement:

www.umlib.nl/taverne-license

Take down policy

If you believe that this document breaches copyright please contact us at:

repository@maastrichtuniversity.nl

providing details and we will investigate your claim.
}

Copyright and moral rights for the publications made accessible in the public portal are retained by the authors and/or other copyright owners and it is a condition of accessing publications that users recognise and abide by the legal requirements associated with these

- Users may download and print one copy of any publication from the public portal for the purpose of private study or research.

- You may not further distribute the material or use it for any profit-making activity or commercial gain

If the publication is distributed under the terms of Article $25 \mathrm{fa}$ of the Dutch Copyright Act, indicated by the "Taverne" license above, 
CUlf Zölitz, Maastricht 2014

www.ulfzoelitz.com

All rights reserved. No part of this publication may be reproduced,

stored in a retrieval system, or transmitted in any form, or by any means, electronic, mechanical, photocopying, recording, or otherwise, without the prior permission in writing, from the author.

Published by Maastricht University, Postbus 616, 6200 MD Maastricht Printed by Datawyse - Universitaire Pers Maastricht.

ISBN: 9789461593061 
The Nature and Consequences of School Choice 


\title{
The Nature and Consequences of School Choice
}

\author{
DISSERTATION \\ to obtain the degree of Doctor at \\ Maastricht University \\ on the authority of the Rector Magnificus, Prof. dr. L.L.G. Soete \\ in accordance with the decision of the Board of Deans, \\ to be defended in public \\ on Friday February 7, 2014, at 12:00 hours \\ by
}

Ulf Nikolaus Zölitz 
Supervisor:

Prof. dr. Lex Borghans

Co-supervisor:

Dr. Bart Golsteyn

Assessment Committee:

Prof. dr. Andries de Grip (chairman)

Prof. dr. Pierre Koning

Dr. Trudie Schils 


\section{Table of Contents}

Chapter 1 Page 7

Introduction to the Thesis

Chapter 2 | Page 15

School Choice in the Netherlands and the United States

- A Literature Review

Chapter 3 | Page 29

Parental Preferences for Primary School Characteristics

Chapter 4 | Page 61

School Quality and the Development of Cognitive Skills

Between Age Four and Six

Chapter 5 | Page 97

Does Information Provision Affect School Choice and Educational Attainment?

- A Design for a Field Experiment in the Netherlands

Chapter 6 | Page 133

Bad Apples and Blinding Lights - On the Nature of

Peer Effects in Academic Achievement

Chapter 7 | Page 161

Conclusions

References | Page 167

Dutch Summary | Page 172

Acknowledgements | Page 175

Curriculum Vitae | Page 176 

Chapter 1

\section{Introduction to the Thesis}





\section{1 | Motivation}

Free school choice provides parents with the opportunity to choose the school for their child that they believe suits its needs best. When parents choose a school for their children they make a fundamental decision about many important aspects which will potentially shape the future development of their children. Choosing a school means making a choice about the quality of education, the daily commuting distance and the kind of classmates and peers a child will have. These peers themselves might also have an influence on educational attainment, social behavior and the formation of personality. Choosing a school with a religious affiliation or a particular teaching concept also means making a choice about the norms and values a child will internalize and therefore it might also affect future educational and occupational choices.

In a system where school choice is free, parents can choose the school that they believe provides the best education. This also means that schools, if they want to maintain in the "education market", have incentives to increase the quality of the education that they offer. Increased school choice have been argued to raise student achievement by putting schools in a more competitive and incentive compatible environment.

\section{2 | Aim}

The aim of this thesis is to identify the determinants of school choice and to provide evidence on which aspects of the school environment influence students' cognitive development and educational achievements. In order to set a foundation for this research we review in chapter 2 the existing literature on how parents choose schools and how the introduction of free school choice policies affected student performance. We focus on school choice in the US and the Netherlands and aim to compare choice mechanisms and the different consequences of school choice. The aims of chapter 3 and 4 are respectively to provide a better understanding of how parents choose schools and to investigate how school quality shapes the early cognitive development of children. Based on the insights of this analysis we develop the design of a field experiment in chapter 5 where information about school attributes is provided to parents in the city of Rotterdam. The aim of this experiment is to identify how information provision affects parental school choice behavior. In chapter 6 we 
investigate how one specific institutional factor - peer quality - contributes to student achievements. Chapter 7 concludes and summarizes the findings of this thesis and provides a plan for future research in the field.

In the following I will preview the main findings of the thesis in more detail: what we currently know about school choice, what parental choices reveal about their preferences and how choosing a school affects children's development. I will then address whether providing information about schools could change school choice and to which degree peers affect student outcomes.

\section{3 | Outline and Main Results}

Although all chapters are written to be comprehensible independently from each other, they build upon the foundations set in earlier chapters.

\section{Chapter 2 - What we currently know}

Chapter 2 of this thesis summarizes the literature on the reasons of school choice and the existing evidence on the consequences of choosing a particular school. We review research on primary and secondary school choice in the Netherlands and the United States. We first provide an introduction to the Dutch education system, the mechanism of school choice and potential concerns about segregation effects. We then turn to the evidence on parental preferences for school quality and other school characteristics. The second part of the review summarizes the current state of research on school choice and its effects in the United States. We focus on discussing the research that evaluates the effects of recent policies aimed to increase school choice opportunities. Finally, we review experimental and quasi-experimental evidence that allows for a clearer identification of causal effects. The results of the review show that the currently existing literature provides mixed evidence. While some crosssectional studies in the US find that attending higher performing schools seems to cause better outcomes, others do not confirm this finding and attribute higher test scores to self-selection into schools. Experimental evidence and evidence based on random lottery assignment that provides clearer identification suggest that parental choice behavior is likely to be influenced by providing easy to understand information about school quality. 


\section{Chapter 3 - What parental choices reveal}

In chapter 3 we investigate how parents choose schools in the Netherlands and show how preferences for school quality, proximity and the type of education can be identified by analyzing revealed choices. Using data collected by the Maastricht University research institute Kaans - a large and representative data set of over 15,000 Dutch primary school starters - we estimate models of school demand that incorporate heterogeneity in school preferences. We present evidence that preferences for school quality are heterogeneous among socio-economic subgroups and that some parents strongly prefer specialized schools with a particular teaching concept. Specifically, families from a lower socio-economic background seem to choose schools of lower educational quality. In a broader sense our results could point to the idea that free school choice might not only foster competition, but also provide incentives for schools to specialize to meet the demands of a heterogeneous society.

\section{Chapter 4 - How school choice affects children's development}

Chapter 4 provides evidence on the effect of school quality on the early cognitive development of primary school starters. Since abilities develop in a cumulative, dynamic process it is important to understand to what extent schools contribute to the development of young children's cognitive ability. In this chapter, we use a panel data set containing cognitive test scores of 4-6 year olds from South Limburg, the Netherlands. School quality is measured by school average achievement test scores at age 12 (school average CITO scores). ${ }^{1}$ The results of this chapter indicate that children in high-quality schools develop their skills substantially faster than those in low-quality schools. Our results further show that the effect is heterogeneous. Children with lower initial levels of cognitive ability benefit more from being in a high-quality school as measured by an above median CITO score. There are two main contributions of this chapter. Firstly, whereas many studies have explored the effects of early intervention programs on later outcomes, no study to the best of our knowledge has examined the effects of school quality on the early development process of children's cognitive skills. Our results reveal that the effect of school quality is already visible during the first year of preschool and continues into the second year.

\footnotetext{
1 The CITO score is a Dutch equivalent of the SAT.
} 
Secondly, our findings contribute to the literature on the formation of cognitive skills by showing that school quality is an important environmental factor that influences the development of cognitive skills at ages 4-6. Our findings suggest that some parts of the later observed heterogeneity in student outcomes may already be established at an early stage of life due to differences in school quality.

\section{Chapter 5 - Could providing information help?}

Chapter 5 proposes the design of a field experiment which investigates whether systematic provision of information about schools has an effect on parental school choice behavior. Making school information easily available could be a policy tool to make school quality more transparent and lead to a better informed decision making procedure of parents in the short run. In the long run better informed choice will potentially lead to higher educational attainments.

In the experiment that we design, half of the primary school-starter cohort is provided with multidimensional information on school options in their neighborhood. The other half of the cohort serves as the control group which receives no information about school characteristics. The information provided is a school comparison table that contains easy to understand information designed to reach all parts of the population. It contains simplified statistics on student achievements, the assessment outcome of the Dutch inspectorate of education, the distance to schools, the educational philosophy, religious affiliation and parental satisfaction with different aspects of the school. In order to provide insights into the potential effects of the experiment we conduct a simulation. Based on administrative data on observed school choices in the past and information on parental background and housing locations we estimate the expected changes in student numbers at the school level due to increased transparency about school average student achievements.

\section{Chapter 6 - How do peers affect students?}

Chapter 6 provides evidence on the importance of classroom peers. One potentially important channel for the effect of school quality on student performance that we identified in chapter 4 is peer interactions. Since it is almost impossible to empirically disentangle peer effects from selection at the primary school level, we study peer effects in a different environment: in Maastricht University 
tutorial classes. In this chapter we explore the fact that students are randomly assigned to classes within a course (conditional on scheduling constraints). Using data on approximately 8,000 economics and business students we show that being assigned to class peers with higher ability, as measured by past GPA, leads on average to a very small, but statistically significant increase in student grades. These average effects however hide substantial heterogeneity. It is especially the low ability students that benefit from high ability peers. Chapter six further tests the "one bad apple" and "one shining light" concepts of peer effects which state that students at the lower (upper) tail of the peer ability distribution have a particularly negative (positive) effect on the learning of classmates. We find evidence that contradicts the "shining lights" model and is consistent with the idea that one "bad apple" reduces class learning. Taking together, this means that if a class inherits fewer outliers in terms of ability, overall student achievements are higher. One potential explanation of this finding could be that if the best and worst students have abilities closer to the class mean, teachers might be better able to tailor their teaching style and content fitting to the needs of their students. 

Chapter 2

School Choice in the Netherlands and the United States - A Literature Review 



\section{1 | Introduction}

Free school choice means that parents are given the right to choose the school they prefer for their children. School choice stands in contrast to school assignment, where children are automatically assigned to a school based on their residential location. Milton Friedman (1955) created a basis for the literature on school choice. He argued that a state monopoly in education without parental choice gives little incentives for schools. Without choice, schools have no reason to specialize on the needs of its children, provide a high quality of education or to meet the expectations of parents. He envisioned school choice to be a mechanism that i) provides equal opportunity in the access to education and ii) increases competition, specialization and educational quality by the introduction of market forces.

During the last 20 years a large number of school choice policies has been introduced in the United States and many other countries around the world. Following the introduction of new school choice policies, there has been a discussion about the positive and negative effects of increased parental choice. Advocates argue that parental choice increases educational quality through the channel of school competition. Critics say that the introduction of increased choice opportunities will lead to more segregated schools and therefore more inequality in outcomes.

This chapter provides a literature review on how parents choose schools and how increased choice policies affect student performance. We review the current state of research and elaborate on what has been done in this emerging field of economics. Our review focuses on school choice in the US and the Netherlands. Historically these two countries have followed quite distinctive patterns in school choice policies. In the Netherlands free choice has been introduced more than 100 years ago. It can therefore be assumed that parental school choice behavior is close to some form of general equilibrium. The United States have been gradually moving to a system with increased school choice throughout the last twenty years. These often locally differing policies offer promising research opportunities since little is yet known about the long run effects of increased school choice. 
This chapter proceeds as follows. Section 2 introduces the Dutch education system and the mechanism of school choice. Section 3 reviews the literature on segregation effects of school choice. Section 4 summarizes the evidence on parental preferences for school quality. Section 5 gives an overview of research on school choice in the US where we put a focus on how school choice relates to future educational attainments. At the end of section three we review experimental evidence in which parents are provided with school quality information. The final section four concludes and gives a research outline for future studies.

\section{2 | The Dutch framework}

\subsection{School choice in the Netherlands}

The Netherlands provide a unique setting to investigate school choice behavior, since Dutch parents have the right to freely choose which elementary school their child will attend. Primary and secondary schools enjoy a large degree of organizational autonomy, which means that parents can freely choose from schools with different religious affiliations and diverse educational concepts that fit their personal values and preferences best. There are two main types of primary schools. The category "openbaar onderwijs" represents schools that are not exclusively dedicated to one particular denomination or follow a particular ideological world-view. Opposed to that, schools in the category "bijzonder onderwijs" always have either a religious affiliation ("confessioneel bijzonder") or are dedicated to a particular ideology or teaching concept ("algemeen bijzonder"). Examples of these schools are Catholic, Hindu, Islamic, and Protestant schools, but also "Dalton", "Jenaplan", "Montessori" and "Vrije" schools. The category "openbaar onderwijs" is not exclusively for specialized schools. There are also for example "openbare jenaplanscholen" or "openbare montessorischolen". In addition to that, parents also have the constitutional right to found a new school that matches their personal values and beliefs if they reach the required minimum number of students. ${ }^{2}$

\footnotetext{
2 The exact number of student depends on local environment and population density. The minimum requirement in a remote area in the countryside can be much lower than the requirement in highly urbanized areas.
} 
In order to maintain certain minimum standards in this diverse system of schools the educational quality is monitored by the Dutch Inspectorate of Education which assesses all schools with regular visitations and by evaluating schools' student achievements.

For both primary and secondary schools there are no home-schools, to which a child will be assigned by some default or which are based on residential location or school district. Parents do not have to apply to be eligible for school choice nor face complex admission lotteries except for some schools in Amsterdam and a few other municipalities. In the Netherlands the population density is with 494 people per squared kilometer ${ }^{2}$ very high which means that for most families a number of schools is usually available within walking distance. ${ }^{3}$ The most obvious costs that parents face when they choose a more distant school are the opportunity costs of time. Both parents and their children will spend more time on traveling since the school and the future classmates of their children will on average be located further away.

\subsection{Dutch institutional detail}

In international studies that compare student achievements, the Netherlands perform very well. In the PISA 2009 secondary education study the Netherlands are ranked tenth for reading and eleventh for mathematics and science. Compared to other European countries they are among the top five.

Primary education in the Netherlands starts at the age of four and lasts for eight years. In the first two years children mainly engage in preparatory activities. At the end of primary education a nation-wide standardized achievement test - the "CITO Eindtoets", is conducted. The outcome of this test together with the recommendation of the teacher determines for which of the four secondary school tracks the child is eligible. Switching between the secondary school tracks Gymnasium, Atheneum, HAVO and VMBO is possible at different points throughout the school career. Admission to scientific studies at universities is only possible with a VWO diploma.

\footnotetext{
${ }^{3}$ Statistics Netherlands, STATLINE (2011).
} 
School fees in the Netherlands are virtually non-existent and all public and private schools receive full government funding if they fulfill certain minimum requirements. Schools that serve students from a more disadvantaged background receive additional funding in order to compensate for the increased challenges of the education process.

Capacity constraints and waiting lists seem to restrict choices of parents in big northern cities: Amsterdam, The Hague and Utrecht. As long as capacity limits do not apply, schools have to accept all students that want to enroll. If a school is oversubscribed and has to make a selection among the applicants the selection criterion has to be made public. In Amsterdam admission lotteries are used for some secondary schools. Unfortunately there is no official data available to which degree Dutch primary schools are subject to capacity constraints and oversubscriptions. The data we analyze in the following chapters of this thesis were collected in South Limburg where these constraints are virtually nonexistent.

\section{3 | Concerns about segregation}

In the discussion about the effects of free school choice the issue of potentially increased ethnical and socio-economics segregation has been raised repeatedly. Ladd, Fiske and Ruijs (2010) argue that parents with "out-group avoidance" will choose the schools where their subgroup is represented with the biggest fraction of the student population and therefore free school choice will lead to more segregation at the school level. The authors also argue that differences in preferences for educational quality might lead to a state where certain subgroups that have stronger preferences for school quality cluster at particular schools. They also present some empirical evidence on how residential segregation levels have increased in some neighborhoods of larger cities of the Netherlands. However they do not present any empirical evidence that subgroups choose schools based on different characteristics or that the segregation level at schools has currently increased.

Karsten et al. (2003) investigate closer whether subgroups choose schools based on different characteristics and assessed reasons for school choice in the Netherlands. Their results show that white parents perceive non-white schools to be 
unsuitable for their child because of the ethnical compositions and vice versa. The main findings are consistent with a model of "in-group favoritism". Such a model predicts that parents prefer schools with a high share of people that belong to their social group. However the results of this study have to be interpreted with caution since the data analysis of this study fully relies on the stated reasons for school choice and does not take into account actual traveling distance to the schools or any objective measures for the schools' quality - characteristics which also might have played a role during the choice process.

Denessen, Driessena and Sleegers (2005) also investigate parental preferences for school choice using data from the Dutch primary education cohort study PRIMA. When answering the questionnaire, the five reasons that parents attribute the highest importance for school choice to, are "Quality of education", "School climate", "School pays attention to the child", "Order and discipline" and, ranked fifth, "School is within easy reach". The authors further show that the indicated reasons for school choice are heterogeneous among some subgroups. More religious families indicate that they place a higher importance on the religious affiliation of the school. In particular Islamic and orthodox Protestant parents state that they selected a school for religious reasons. The authors do not find evidence for reasons for school choice being related to the socio-economic background of the parents.

There are some general problems that arise when analyzing school choice behavior purely based on questionnaire data. Firstly, the non-response of particular socio-economic subgroups can bias the results and makes it questionable whether the findings can be generalized. Secondly, parents may rationalize their choice ex post or give more socially desirable answers. A solution for this problem could be the estimation of revealed parental preferences based on actual school choice data from administrative sources. This approach might give different results than studies which fully rely on questionnaire answers and shed more light on the actual mechanism at work during the choice process. 


\section{School choice and the demand for school quality}

Koning and van der Wiel (2013) investigate how parents in the Netherlands react to publicly available quality information about secondary schools. They show that the "Trouw" school ranking that is being published in local newspapers is significantly related to future student enrolment: Negative school quality scores decrease the number of enrolments and positive scores increase the number of students choosing that school. The largest effect was found in the response to scores about academic secondary schools ("VWO"). This suggests that parents of children who are eligible for this track either care more about educational quality or are more likely to read the newspaper in which the results were published. The authors conclude that the size of the estimates suggests that the impact of the "Trouw" publication is generally small compared to the impact of the overall reputation of a school track or to the impact of school's distance from home. The implied willingness to travel for attending a wellperforming school rather than an average secondary school is only about 220 meters. Even if parents are well informed, distance to different school options seems to remain the strongest choice driving factor. ${ }^{4}$

Koning and van der Wiel (2012) also investigate whether schools respond to the "Trouw" newspaper rankings by improving their educational quality. They show that schools who receive the worst ranking (double minus) improve in their student performance measures by about .1 to .3 standard deviations within the next year. They also show that the most positively ranked schools rarely maintain their high educational quality.

More recently Ruijs and Oosterbeek (2012) investigate secondary school choice behavior in of Amsterdam using administrative data. The authors develop conditional and mixed logit models to estimate parental preferences for school characteristics such as distance from home to school, the existence of an ad-

\footnotetext{
${ }^{4}$ Whether Dutch parents also have preferences for school quality in primary school choice has previously not been investigated. This issue is being closer investigated in chapter 3 of this thesis.
} 
mission lottery, school quality measured as student attainments ${ }^{5}$ and the amount of peers from primary education that prefer the same school. The authors find that parents on average prefer secondary schools close to their home and schools that have a large percentage of primary school peers. The mixed logit estimation that the authors apply allows for heterogeneity in the preference for peers parameter. The results show that between 10 and 17 percent of the population prefer schools with a lower percentage of peers from primary education.

In the same paper school quality and the existence of an admission lottery in the last year is found to be an inconsistent predictor of choice. The authors conclude that proximity to schools and peers are more important determinants of school choice than quality. These findings are not consistent with studies from the United States which find that parental preferences for secondary school quality are weak and therefore low quality schools face little incentives to improve their educational quality.

\section{5 | School choice in the United States}

In comparison to the Netherlands, parents in the US have historically enjoyed little freedom in choosing which school their child attends. If parents want to get access to better schools they have to change their residential location. Higher school quality has been found to translate into substantially higher housing prices. Only more recently educational reforms in the United States like the "No Child Left Behind Act", a number of private school voucher programs, the introduction of charter schools and different choice plans have aimed to increase the freedom of parental school choice. In particular within their school districts parents are being given the increased freedom to choose between schools that differ in their educational quality.

\footnotetext{
5 More precisely Ruijs and Osterbeck use the "Trouw" score as a quality measure. Inputs for this score are final exam grades, the percentage of students receiving a degree without ever repeating a grade and performance in lower school grades.
} 


\subsection{Choice as a lifting tide?}

Hoxby (2003) advocates increased choice and describes free school choice as a "tide that lifts all boats" - a mechanism that benefits the educational attainments of all students. Parents who have preferences for schools with better student achievements put market pressure on lower achieving schools, since the parental taste for quality is reflected in the school choices they make. One requirement for this system to work well is that parents know and care about the differences in educational quality when they choose a school for their child. Given these two assumptions increased school choice can be seen as a policy tool to increase school competition and thereby increase student achievements and school quality in the long run. The idea is that lower performing schools will attract fewer students and therefore have to improve their educational quality if they want to remain in the market. Higher achieving schools will attract more students, since they provide a larger "added value" to the attainments of the children that attend them.

\subsection{Preferences for school quality}

Hastings, Kane and Staiger (2009) provide evidence for heterogeneous preferences in the demand for school quality. They show that ethnical minorities put lower expressed weights on school achievements when indicating their first, second and third most preferred school in the school district.

They further find that white parents and children not eligible for free lunch seem to care or know more about the schools' quality than non-white and free lunch receivers. In contrast to that, higher income families have stronger preferences for schools with high student achievements. The authors conclude that lower performing schools have weak incentives to improve because they provide education to the children of parents that care less about quality. At the same time, high quality schools perceive more competitive pressure, because the parents with a higher socio-economic status that choose these schools are sensitive to differences in average student achievements. They argue that black families face the tradeoff between distance and quality to a much larger degree than white families, who already live closer to the good schools. They find evidence for some heterogeneity in parental school proximity preferences. Longer traveling distances seem to be more costly for non-white and free-lunch eligible families. 
A disadvantage of the data used in their paper is that they were collected during a phase of major school choice policy changes. Increased freedom of school choice was introduced together with new desegregated bussing plans. Nearly half of all students received a new default school, from which they now had the option to deviate. These policy changes themselves might introduce temporary heterogeneous preferences and choice behavior that is not yet in its steady state. More disadvantaged parents might take more time to learn about the differences in educational quality of the new school options in their district. In addition to that, predictions about the future quality of a school might be difficult to make if a large fraction of students changes schools and future individual performance is also dependent on the peer composition.

\subsection{Charter schools}

In the 1980s publicly funded charter schools were sequentially introduced by different US states. They enjoy greater organizational autonomy, but also have a higher degree of accountability for their students' achievements. Parents can choose to send their child to a charter school as an alternative to a regular public or private school. Charter schools have spread fast all over the US and 41 of the federal states have passed charter school laws. Many charter schools are regularly oversubscribed and use admission lotteries. Charter schools usually differ from regular public school in a more selective teacher-hiring, stricter behavioral norms and an atmosphere of higher work norms and aspirations. Abdulkadiroğlu et al. (2011), Angrist et al. (2011) and Hoxby (2000) provide evidence that charter schools attendance causes higher student achievements. In contrast to that, Hanushek et al. (2007) and Booker et al. (2007) do not find a significant positive effect of attending a charter school on student achievements. Besides the direct effects on enrolled students, charter schools might also indirectly affect the local education market by introducing more competition for students. The presence of a charter school might a) induce the regular public schools to either compete and increase the educational quality or b) lead to an increased specialization of the traditional schools. 


\subsection{School admission lotteries}

In the literature on the effects of school quality and increased freedom of choice, school admission lotteries have been used repeatedly. They provide quasi-experimental exogenous variation in the access to schools and allow a causal interpretation of the identified school effects. An example is Cullen, Jacob and Levitt (2006) who study the effects of high school admission lotteries in Chicago. In contrast to the findings of Hastings et al. (2008, 2009) they do not find an effect of attending the "better" school of choice on individual academic achievements. Nevertheless the results show that children who were admitted to a school with higher student test scores were less likely to participate in crime and had a lower truancy rate.

More recently, Hastings et al. (2012) find that winning the school admission lottery decreases the truancy rate before the start at the new school of choice. Winning the school admission lottery therefore appears to increase intrinsic motivation at least in the short run. The authors further find that being granted access to a charter or magnet school also increases math and reading testscores.

\subsection{Experimental evidence on school choice}

Some current field experiments in the United States have found that school choice can be affected by providing parents with information about schools. In addition to that, children also seem to benefit in terms of school achievements when their parents made better informed choices and they received access to higher-achieving schools.

Hastings, van Weelden and Weinstein (2008) investigate how information provision about school quality influences school choice and student outcomes in Charlotte, North Carolina (US). Information about test scores and admission chances was provided to a group of randomly selected parents. The control group did not receive any school information. The results show that the provision of information on school test scores had an influence on parental choice behavior. Parents who received information were more likely to choose a school with higher student attainments. The treatment effect was largest for parents who had higher scoring school alternatives relatively nearby. 
Parents seem to weight the benefits of choosing a higher performing school against the direct and indirect costs of increased traveling distance to a school. The paper further investigates whether the experiment lead to an increase in student performance. The results show that the students attending a higherachieving school benefit in terms of their math and reading test scores. The results also reveal that children from lower income families benefit less from attending a higher performing school. This result could explain previous findings that parents with a lower socio-economic status put lower expressed weights on academic achievements when choosing a school. They might have weaker preferences for school quality since their children's performance is less dependent on the quality of the school they attend. An alternative explanation for the findings of Hastings et al. (2008) could also be that lower SES parents seek a match between the abilities of their child and a schools' performance, while middle and high educated parents choose schools on the basis of the absolute academic performance. One underlying mechanism could be that lower educated parents do care about quality in the sense that they want their children at a school where they can perform comparatively well given their abilities.

\section{6 | Conclusion}

This chapter provides an overview about the current state of research on school choice. Evidence from the US suggests that parents have heterogeneous preferences for school quality. In particular families from a lower socioeconomic background seem to choose schools of lower educational quality, measured by average student achievements. Whether these families have a weaker preference for quality or are just less informed about differences in quality characteristics has not yet been clearly disentangled. Experimental evidence suggests that informing parents about differences in educational quality results in stronger expressed preferences for higher-achieving schools.

The research that investigates the effects of school choice on student performance in the US shows mixed evidence. While some cross-sectional studies find that attending higher performing schools causes better outcomes, others do not confirm this finding and attribute higher test scores to self-selection into schools. Experimental evidence and evidence based on random lottery assignment that provides clearer identification shows that 1) parental choice behavior 
can be influenced by providing easy to understand information about school average student test scores and 2) student achievements can be raised by getting access to the preferred school of choice.

The aim of the following two chapters in this thesis is to provide evidence on how parents choose schools in the Netherlands and how school choice affects educational attainments of children. In the Netherlands much less research on the topic of school choice has been done. Evidence from the Dutch context is an interesting case for policy makers since free school choice has a longstanding tradition in the Netherlands. This evidence is of particular importance for countries that plan to increase the freedom of school choice since it can provide insights into the long term effects of free school choice. Evidence from countries where increased school choice has been introduced more recently does not provide an answer to whether the observed short run gains from the introduction of choice policies are actually sustainable. The Dutch evidence that is available so far is at best mixed. Whether parents choose schools under quality considerations and thereby put pressure on schools to improve their educational quality remains unclear. It also remains an open question whether parental behavior is actually rational from an individual perspective and beneficial for the development and attainments of a child in the Dutch context. 


\section{Chapter 3}

\section{Parental Preferences for Primary School Characteristics ${ }^{\star}$}

* This chapter is based on joined work with Lex Borghans and Bart Golsteyn. We thank Ellen Greaves, Margriet van der Sluis, Benedikt Vogt, Inge de Wolf and seminar participants at the ESPE (2013), IWAEE (2013) and ORD (2013) for valuable comments. We further thank Paul Jungbluth for generously sharing data and for providing valuable background information. 



\section{1 | Introduction}

Policies that aim to raise school quality, like the no child left behind act in the US, focus on increasing the freedom of school choice. The idea behind these policies is that schools will have to provide higher quality education if they have to compete for students with other schools.

The key underlying assumption for school competition to raise the quality of education is that the quality of a school is an important choice criterion for parents. Parental preferences however are unlikely to be one-dimensional. Parents may also value other characteristics of schools such as the teaching philosophy, religious affiliation or geographical proximity. If parents have weak preferences for school quality relative to other school characteristics, quality competition between schools is likely to remain low, even when parents are given more opportunities to choose. In this case, free choice may stimulate schools to specialize by offering specific features instead of improving the quality of their program. Estimates of parental preferences for primary school quality (measured by test scores) are scarce ${ }^{6}$ and the relative importance of other school characteristics has mostly been neglected.

This chapter provides an elaborate picture of parental primary school preferences by investigating heterogeneous preferences for school quality and a variety of additional school characteristics such as school denomination, teaching philosophy, and peer preferences. The measures for school quality that we use are the assessment outcome of the Dutch Inspectorate of Education and school average test scores (CITO scores). Our study complements previous research by investigating to which extent school quality and these additional characteristics form preferences for schools and by studying how these preferences vary across parents. ${ }^{7}$

6 Important estimates of parental preferences for school quality are provided by among others Koning and van der Wiel (2013) Hastings, Kane, and Staiger (2010) and Jacob and Lefgren (2007).

7 The effects we identify might not necessarily be caused by the quality indicators that we investigate, but could also be driven other unobserved quality attributes that strongly correlate. We therefore aim to investigate whether they are consistent with observable quality indicators. 
We use a combination of administrative and survey data on over 15,000 Dutch parents of primary school students to estimate conditional and mixed logit models of school choice. The latter model allows estimates to vary across the population of choosers which is central to the identification of heterogeneity in preferences for school characteristics.

The Dutch context is of particular interest since, in contrast to other countries that have introduced free school choice more recently, it provides a case where school choice has traditionally been unrestricted. The observed patterns in school choice can be assumed to represent a general equilibrium and behavior will not be driven by recent policy changes or other interventions.

Our results firstly show that school quality matters: parents prefer schools with higher average student test scores and schools with a positive quality assessment of the Dutch Inspectorate of Education. We find heterogeneity in the response to the outcome of the Inspectorate's assessment. Parents with a higher education levels are more sensitive to the Inspectorate's assessment than lower educated families. Similarly, schools with higher student achievements are on average more popular, but there is substantial variation in this preference among the group of lower educated people. About 32 percent of the lower educated families prefer schools with lower average achievement test scores over higher achieving schools. There are two potential explanations for these findings: (1) parents are unaware of quality differences at the school level or (2) they put a low weight on characteristics related to school quality when choosing a school. ${ }^{8}$

Secondly, our results show that the schools' denomination and the practice of an alternative teaching philosophy are important school characteristics that matter for choice. Parental preferences are also heterogeneous with regard to these other school characteristics such as whether a school is public, Catholic, Islamic, is dedicated to Montessori education or follows the educational philos-

\footnotetext{
${ }^{8}$ It is important to keep in mind that the results are subject to reverse causality. The school average test scores and the Inspectorates assessment themselves could also be affected by the type of socio-economic subgroups that select into specific schools.
} 
ophy of Rudolph Steiner. Even within specified socio-economic subgroups of the population, parents have varying preferences for particular school attributes. While some parents are willing to accept long daily travel distances to a school with a particular specialized profile, other parents avoid this school although it is in their immediate vicinity. Examples of these specialized schools are Islamic schools, which are very unpopular for most parts of the population but very attractive to about 10 percent of the population. ${ }^{9}$ Similarly, nonmainstream schools with an alternative teaching philosophy are on average less popular, but some higher educated parents strongly prefer these schools. Our estimates show that 26 percent of the higher educated parents prefer schools with alternative teaching concepts over mainstream education and are willing to accept a three to four times longer daily traveling distance for attending such a school.

Our findings with respect to the preferences for school quality are in line with previous research that has shown that parents with a lower socio-economic background put lower weights on observable school quality indicators. Hastings et al. (2010) use data from Charlotte, North Carolina to show that black and lower income families have weaker preferences for primary and secondary schools with higher student achievements. The authors conclude that lower quality schools have weak incentives to improve because they attract the parents that care less about quality. The authors further argue that high quality schools perceive more competitive pressure, because the higher SES parents that choose these schools are more sensitive to differences in average student achievements.

This chapter is related to research that has focused on estimating parental preferences for secondary schools. Koning and van der Wiel (2013) investigate how parents in the Netherlands react to publicly available quality information about

\footnotetext{
${ }^{9}$ It is important to point out that the assumption of a normally distributed mixing distribution for the preferences of Islamic school is not necessarily given. A bimodal distribution would appear more realistic in this case.
} 
secondary schools. ${ }^{10}$ They show that newspaper published school rankings significantly predict future student enrolment: negative school quality scores decrease the number of enrolments and positive scores increase the number of students choosing that school. The largest effect was found in response to scores about the highest secondary school track $(V W O)$. However, the size of the estimates suggests that even if parents are well informed, the effect of published quality indicators is generally small compared to the impact of other characteristics such as the overall reputation of a school track or the distance from home to school.

We show that quality indicators such as school average achievement test scores and the online published assessment outcome of the Inspectorate of Education matter for primary school choice. Besides school quality, the school's denomination, teaching concept and proximity are important determinants for primary school choice. Preferences are strongly heterogeneous across parents.

The remainder of this chapter is structured as follows. Section 2 provides background information on the Dutch education system. Section 3 discusses the data. Section 4 describes our identification strategy. Section 5 shows the estimation results. Section 6 concludes.

\footnotetext{
${ }^{10}$ Ruijs and Oosterbeek (2012) also investigate secondary school choice behavior in the city of Amsterdam and conclude that proximity to schools and peers are more important determinants of school choice than quality.
} 


\section{2 | The Dutch education system}

The Netherlands have a longstanding tradition in free school choice. Since 1917, parents can freely choose between state funded private and public schools. In contrast to other countries where free school choice policies are introduced more recently, the Netherlands provide a case to study school choice behavior that can be assumed to be closer to a "steady-state". The results presented in this chapter can therefore be interpreted as evidence about how parental school choice preferences are shaped in a stable system without major policy discontinuities. This can be of particular interest for policy makers who are interested in the persistence of observed short run effects of free choice.

Dutch parents can in theory choose among all schools in the Netherlands. There are no school catchment areas or choice restricting school districts. School tuition fees are small or non-existent and therefore do not restrict school choice. The most obvious costs that parents face when choosing a more distant school are the opportunity costs of time. Both parents and their children will spend more time on traveling if they choose a more distant school since the school and the classmates of their children will be located further away. Due to the high population density in the Netherlands, a number of schools is usually within walking or cycling distance. ${ }^{11}$

Dutch parents can choose from schools with a variety of different religious affiliations and diverse educational concepts that fit their personal values best. Besides public schools (“openbare scholen") there are schools with denominations like Catholic, Hindu, Islamic, and Protestant schools. Schools who focus on a specific pedagogical concept are the "Brede school", "Dalton school", "Freinetonderwijs", "Iederwijs", "Jenaplan", "Montessori" and "Vrije scholen". The three most prevalent schools types that are usually within reach are catholic, protestant and public schools.

11 The population density is about 487 people per square kilometer (if only the land area is being counted). 
All school types are publicly funded, proportional to their student numbers. Schools that serve students from a more disadvantaged parental background receive some additional funding.

Oversubscriptions are mostly a problem in larger cities in the western part of the country and are usually solved with admission lotteries. In the most southern province Limburg, where the data for this chapter was collected, oversubscriptions and capacity constraints do not play a role for choice considerations. This is an important aspect since if there would be capacity constraints we could no longer assume that the most preferred school is identical to the indicated school of first choice.

\subsection{Primary education}

Primary education in the Netherlands starts at the age of four and is compulsory from the age of 5. It lasts for eight years, where the first two grades consist mostly of preparatory activities and can be compared to kindergarten in the US. At the end of grade eight a nationwide standardized central exam is taken - the so-called CITO test. The outcome of this test together with the teacher's recommendation determines the secondary school track. There are three different types of secondary education tracks that vary in their degree of difficulty and educational focus. Only the highest track (VWO) permits access to studies at the University level.

Figure 1 shows the distribution of the end of primary school student achievement tests and the recommended thresholds for secondary school tracking. The figure shows that the variation in the average achievement test scores across schools is substantial. ${ }^{12}$ If a school is to the right of the solid vertical line, the average student at this school goes to the highest secondary school track. The average achievement test score of a school is generally not publicly known, however some schools publish their score on their websites for marketing reasons.

\footnotetext{
12 One interesting question from an economic perspective is why these differences in school quality maintain in a system of free choice. Market forces should lead to an equilibrium where all schools converge to a certain quality level. A potential answer could lie in the heterogeneity of preferences.
} 
Figure 1: Distribution of school aggregated SAT score averages

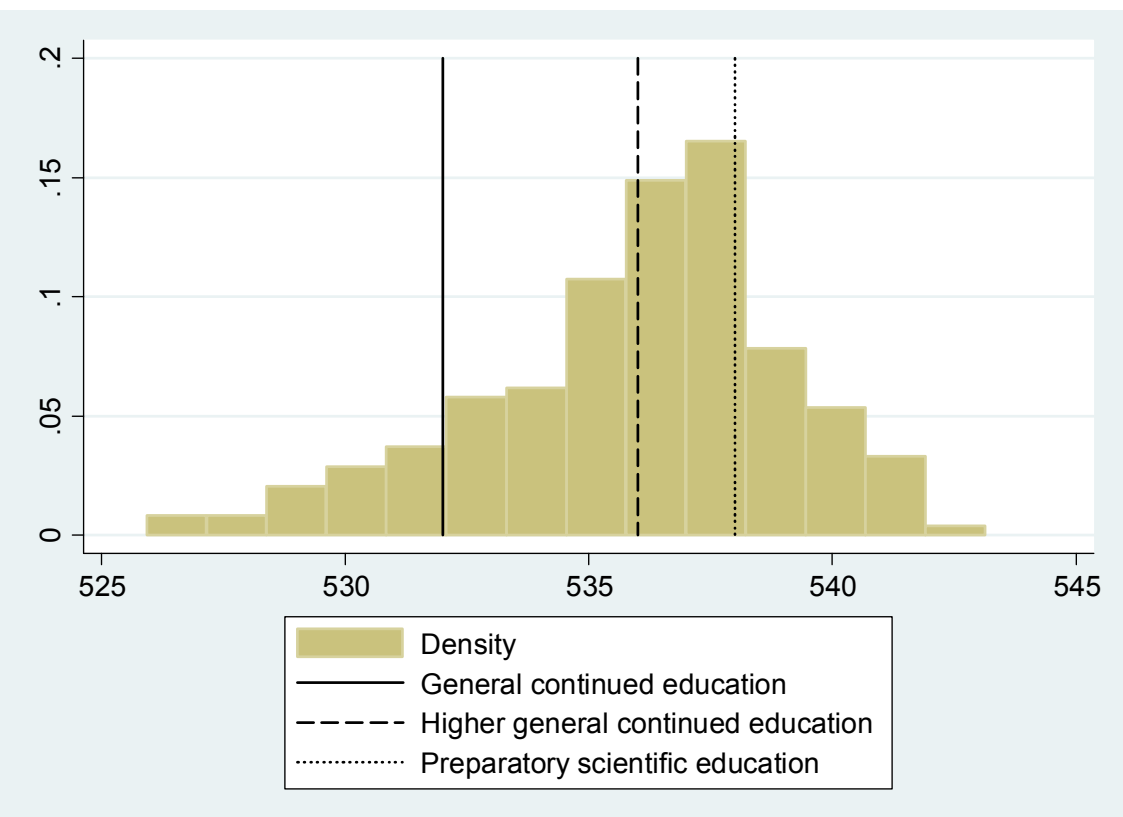

Notes: These are school level averages of national-wide end of primary education achievement tests (CITO scores). The student specific achievement test score ranges between 500 and 550. The vertical lines mark the recommended thresholds for secondary school admission. $\mathrm{N}($ schools $)=183$.

\subsection{Inspectorate of Education}

In order to maintain certain standards at the school level, the educational quality is monitored by the Dutch Inspectorate of Education which assesses all schools through regular visitations and by evaluating student achievements. The Inspectorate's assessment consists of class observations, and meetings with pupils, parents, teachers and the school management team. In addition, the Inspectorate investigates whether the school is able to perform a reliable selfevaluation and whether the school complies with statutory rules and regulations. One additional factor in the process of evaluation is the schools' average achievement test score (CITO score). ${ }^{13}$ There are three final outcomes of these

13 About 90 percent of all schools use the "CITO" test for student assessment. 
quality assessments: "trusted", "weak" or "unsatisfactory". About five percent of the primary schools receive the label "weak" and less than 1 percent are "unsatisfactory". The quality assessment of the Inspectorate is published online and parents can look up the rating of a specific school or compare the schools in the neighborhood. If schools continue to provide unsatisfactory quality or do not comply with the Inspectorate, they can be sanctioned by the Minister of Education. The most extreme measure is cutting off a school's funding.

\section{3 | Data}

The school choice data analyzed in this chapter was collected by the Maastricht University research project Moelejaan in the southern part of the Dutch province Limburg. South Limburg is an urbanized area of 661 square kilometers and a population of about 620,000 . It is surrounded by Belgium and Germany and only the north is connected to the rest of the Netherlands.

The data we use are a combination of administrative student data from schools and survey data from a questionnaire among the parents at these schools. 200 primary schools in this area participated in the study and provided student level data. This is about 97 percent of the primary schools in the region South Limburg. The data consist of 16,852 children from three different cohorts that started school in 2007, 2008 and 2009. For the analysis, 1,065 children are dropped from the sample due to missing or non-existent home addresses. 13 schools are excluded because of missing end of primary school achievement test scores (CITO scores). ${ }^{14}$ The final sample consists of 15,000 students from 183 schools. For about 64 percent of these children we have information about the education level of the parents from survey data, which we use for some parts of our analysis.

Table 1 shows descriptive statistics for five different school types. The table gives a first impression of how parents at various schools differ in terms of observables. Column (5) shows that schools with an alternative teaching con-

\footnotetext{
14 These schools did not participate in the CITO test. They conducted a non-comparable end of primary education achievement tests.
} 
cept attract particular students. Students at these schools travel a substantially longer distance from home to school and have on average higher educated parents. The performance of these schools is relatively weak in terms of student achievement and the schools are also more likely to be assessed as "weak" by the Inspectorate.

Table 1: Descriptive statistics

\begin{tabular}{lcccccc}
\hline & $(1)$ & $(2)$ & $(3)$ & $(4)$ & $(5)$ & $(6)$ \\
Type of school & Public & Catholic & Protestant & Islamic & Alternative & $\begin{array}{c}\text { All } \\
\text { schools }\end{array}$ \\
\hline & & & & & & \\
Percentage of parents & 0.30 & 0.27 & 0.33 & 0.59 & 0.23 & 0.16 \\
lower educated & {$[0.15]$} & {$[0.16]$} & {$[0.22]$} & - & {$[0.14]$} & {$[0.00]$} \\
Percentage of parents & 0.30 & 0.37 & 0.32 & 0.20 & 0.35 & 0.35 \\
middle educated & {$[0.09]$} & {$[0.11]$} & {$[0.16]$} & - & {$[0.13]$} & {$[0.11]$} \\
Percentage of parents & 0.40 & 0.37 & 0.34 & 0.22 & 0.41 & 0.37 \\
higher educated & {$[0.16]$} & {$[0.16]$} & {$[0.17]$} & - & {$[0.21]$} & {$[0.16]$} \\
Percentage with "weak” & 0.10 & 0.08 & 0.11 & 0.00 & 0.14 & 0.09 \\
Inspectorate evaluation & {$[0.30]$} & {$[0.28]$} & {$[0.33]$} & - & {$[0.36]$} & {$[0.29]$} \\
& & & & & & \\
Std. school average SAT & 0.02 & 0.08 & -0.12 & 2.93 & -0.68 & 0.03 \\
$\quad$ (CITO) & 0.76 & 0.97 & 1.05 & - & 0.95 & 0.98 \\
Student distance & 0.993 & 0.713 & 0.854 & 2.628 & 1.457 & 0.83 \\
(in kilometers) & 1.13 & 0.77 & 0.98 & 3.10 & 1.87 & 1.01 \\
Distance rank school & 3.438 & 2.094 & 3.475 & 11.16 & 5.781 & 2.66 \\
& 4.56 & 3.21 & 4.64 & 11.02 & 7.07 & 4.15 \\
Number of schools & 31 & 145 & 9 & 1 & 14 & 200 \\
Average number of & 264.2 & 193.7 & 56.6 & 102.0 & 71.9 & 189.5 \\
students & & & & & & \\
\hline
\end{tabular}

Notes: The school type "Alternative" refers to schools with a particular teaching concept. Schools in this category are Montessori, Jenaplan and "vrije" schools. Standard deviations in brackets.

The table also shows the average distance rank of the students that attend a particular school type. The average distance rank of all schools is 2.66 , which means that the average student has 1.66 school options that are closer to their home location, but which they do not choose to attend. For schools with an alternative teaching concept, the average student-school distance rank is 5.78 . 
The table shows that more specialized schools attract students from further away (i.e. that have more other schools closer to their homes).

Figure 2 shows the distribution of the Euclidian distance to the chosen school. The median distance to the chosen school is .525 kilometers. 90 percent of the parents choose a school that is within a 1.785 kilometer radius from home, and few parents choose schools located far away from their home.

Figure 2: Distance to the chosen school in kilometers

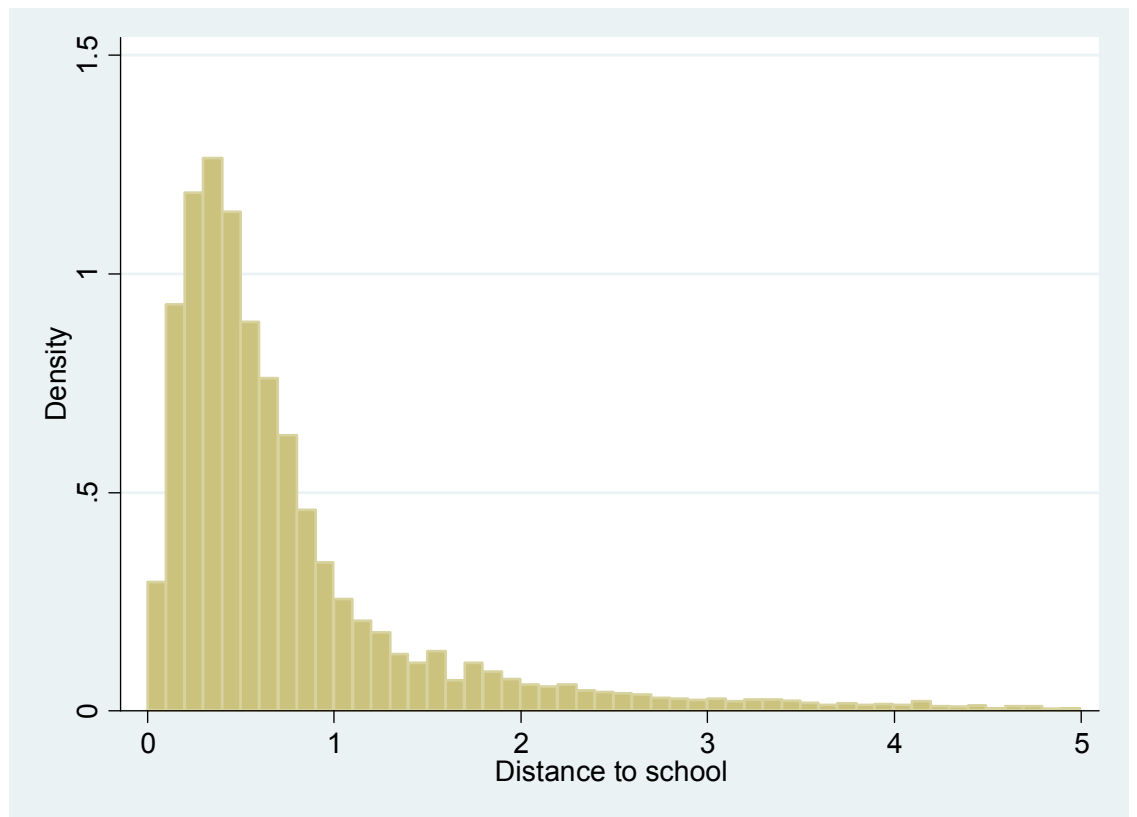

Notes: The figure shows the distribution of the variable "Distance to school". 131 students attend schools further away than 5 kilometers. $\mathrm{N}=15,435$.

\section{4 | Empirical strategy}

In order to investigate how parents choose between different primary schools we apply two different discrete choice models: the conditional logit and the mixed logit model. In the following we will briefly discuss the intuition and limitations of both estimation techniques. 


\subsection{The conditional logit model}

The conditional choice model was developed by McFadden (1973) and first applied to the context of school choice by Glazerman (1998). Intuitively, the conditional logit model compares the characteristics of the chosen school with the attributes of all schools which are not chosen using student fixed effects.

In this model the parents of each child $i$ face the decision to choose between $j$ different schools. Every school is associated with a certain amount of individual specific utility $U_{i j}$. The model assumes that utility $U_{i j}$ can be described as a linear function of a child specific component $W_{i}$, a school specific component $X_{j}$, a school-child specific component $Z_{i j}$ and a non-systematic random component $\varepsilon_{i j}$.

$$
U_{i j}=W_{i}+X_{j}+Z_{i j}+\varepsilon_{i j}
$$

Examples of $W_{i}$ are individual specific characteristics like gender, age or ability. $X_{j}$ are school characteristics that are common to the population of school choosers. Examples of $X_{j}$ are the average test results of a school, the assessment of the Inspectorate or the denomination of a school. An example of $Z_{i j}$ is the distance between the parents' home and the school, the percentage of peers at a given school or the parents' expectation about the child's school specific success given its ability. The characteristics $Z_{i j}$ are school-student specific and represent an interaction between child and school attributes.

The utility that the parents of child $i$ obtain from choosing school alternative $j$ can be written in a linear form as:

$$
U_{i j}\left(X_{j}, Z_{i j}\right)=\beta_{1} W_{i}+\beta_{2} X_{j}+\beta_{3} Z_{i j}+\varepsilon i j
$$

The parameters $\beta_{1}, \beta_{2}$ and $\beta_{3}$ are the focus of our interest, since they determine how differences in the attributes translate into utility differences. We assume that parents choose the school that provides them with the highest level 
of utility. The individual specific error terms are assumed to be random, independently-distributed variables with an extreme value distribution (the Gumbel distribution).

We do not directly observe the utility level $U_{i j}$, but use the observed outcomes of the choice process which are revealed to us in the data. The observed outcome variable $Y_{i j}$ is binary and takes on the value 1 if the school is chosen and zero otherwise. If the parents of a child choose school $J$, it is revealed to us that $U_{i J}>U_{i j-J}$, i.e. that the utility level of the chosen school must have been larger than the utility of any other school in the choice set. Using the observed outcomes of school choice we can estimate how differences in $X_{j}$ and $Z_{i j}$, which vary over different school options, relate to the probability that one given school has the highest amount of utility of all schools in the choice set.

$W_{i}$, the individual specific characteristics do not vary over different choice alternatives. When estimating the model all individual characteristics fall out of the choice probability, since the conditional logit model analyzes within person differences in preferences for schools.

This appears problematic since one of the main research questions of this chapter is how preferences for certain school characteristics vary across different socio-economic subgroups. In the conditional logit framework, estimating heterogeneity with respect to individual characteristics can be elicited by (1) estimating the model for subsamples of the population separately, or (2) including interaction terms between individual characteristics and school specific attributes. $^{15}$

\footnotetext{
15 The latter variant imposes a stronger assumption on the error term than the first variant. The inclusion of interactions implicitly assumes that the error term is equal across the subsamples of interest. Splitting the sample and performing separate regressions allows the error term to vary across subsamples. The downside of this approach is that if the error term varies across subgroups the estimates from separate subgroup regressions become less comparable, because the size of the point estimate in the logit model is always relative to the size of the error term. In our analysis we perform both estimation variants and obtain quantitatively virtually identical results.
} 
One practical problem with the conditional logit estimation is the assumption of independence of irrelevant alternative (IIA). ${ }^{16}$ The IIA property assumes that the probability of choosing a particular alternative does not depend on the characteristics of other alternatives. Mixed logit models do not rely on this assumption.

\subsection{The mixed logit model}

The mixed logit model allows estimating the mean preference for a school attribute and the standard deviation of the mean preference coefficient. This appears particularly attractive for our research question since it allows a more direct estimation of heterogeneous preferences for certain school characteristics. The main advantage relative to the conditional logit model is that we do not need to specify the dimension in which a preference is heterogeneous. Using the mean and standard deviation we can directly infer which share of the population has particular preferences for a specific school characteristic.

The mixed logit is also a convenient solution for avoiding the IIA property of the conditional logit. The mixed logit or random parameter logit that we apply was developed by Train (2009) and allows for random taste variation, unrestricted substitution patterns, and correlation in unobserved factors. The mixed logit model works very similarly to the conditional logit model, but does not only estimate one point estimator that represents the mean preference of the population. Instead the model assumes that coefficients $\beta_{i}$ vary over the population and are drawn from a normal or lognormal distribution.

\footnotetext{
${ }_{16}$ To illustrate the importance of this, suppose parents have the choice between catholic school A, catholic school B and protestant school C. The IIA assumption is that parents who have initially chosen school A would be equally likely to switch to school B and C if their chosen school A is closed and everything else including all school characteristics is held constant. One can expect that the IIA assumption does not hold in this school choice context since we would think that parents who have initially chosen for a catholic school will be more likely to choose a school that is also catholic.
} 
The mixed logit model can be represented in the following way in a random utility framework:

$$
U_{i j}=\beta_{i}^{\prime} X_{i j}+\eta_{i j}+\varepsilon_{i j}
$$

The utility level the individual $i$ obtains from choosing school alternative $\mathrm{j}$ is described as a function of $X_{i j}$ which is a vector of school and/or child specific characteristics, the random parameter $\eta_{i j}$ and the "regular" error term $\varepsilon_{i j} \cdot \varepsilon_{i j}$ has a mean zero and is independent and identically distributed over alternatives ${ }^{17}$, it is unrelated to $\eta_{\mathrm{ij}}$, the parameters in the vector $\beta_{\mathrm{i}}$. The density function of $\eta$ is given as $f(\eta \mid \beta)$ and depends on the parameters of the model. Following Train (2009), the estimated mixed logit probability is a weighted average of the logit equation, but evaluated at different values of $\beta$, with the weights given by the density $f(\eta \mid \beta)$. For a given fixed $\beta$ the probability of choosing alternative $k$, which inherits the highest utility out of $J$ different options is:

$$
L_{i k}\left(\beta_{i}\right)=\frac{\exp \left(x \beta_{i}{ }^{\prime} X_{i k}\right)}{\exp \left(\sum_{\mathrm{j}} \beta_{\mathrm{i}}{ }^{\prime} \mathrm{X}_{\mathrm{ij}}\right)}
$$

Since $\beta$ is not fixed we have to integrate $L_{i k}\left(\beta_{i}\right)$ over all possible variables of $\beta_{\mathrm{i}}$. For this we need the mixing distribution $f(\beta)$. The mixed logit probability is then given as:

$$
P_{i k}=\int\left(\frac{\exp \left(x \beta_{i}{ }^{\prime} X_{i k}\right)}{\exp \left(\sum_{\mathrm{j}} \beta_{\mathrm{i}}{ }^{\prime} \mathrm{X}_{\mathrm{ij}}\right)}\right) f(\beta) d \beta
$$

\footnotetext{
${ }^{17}$ Further it is assumed to be not (auto) correlated and to have the same mean and same variance (homoskedastic).
} 
Equation (5) does not have a closed form solution and the probability $P_{i k}$ can be estimated using simulated maximum likelihood. ${ }^{18}$

\section{5 | Results}

We analyze the preference for distance in section 5.1 and the preference for school quality in section 5.2. Section 5.3 analyzes the heterogeneity of preferences with respect to these indicators and section 5.4 investigates to what extent school popularity varies between socio-economic groups. Section 5.5 and section 5.6 respectively analyze the importance of school denomination and alternative educational concepts.

\subsection{Preferences for distance}

Table 2 shows the estimates we obtain from the conditional logit estimation. The displayed coefficients represent the raw coefficients. Coefficients significantly larger than zero represent a characteristic that is related to an increase in the probability of choice and coefficients significantly lower than zero mean that this school characteristic is unpopular or unattractive among the population of choosers. The table shows that increased distance to a school option is negatively related to the probability of choice. Keeping everything else constant, an increase in distance of 100 meters reduces the probability of choice by 19.0 percentage points. This indicates that parents appear to have a strong preference for choosing a school close to their home location.

\footnotetext{
${ }^{18}$ For the simulated maximum likelihood estimation one needs to generate random draws from $f(\beta)$. For every individual we use 50 draws of $\beta$. Our obtained results were not sensitive to an increase in the number of draws that we use.
} 
Table 2: Preferences for school distance and quality Estimates from conditional logit models

\begin{tabular}{lcccc}
\hline & $\begin{array}{c}(1) \\
\text { Conditional } \\
\text { logit }\end{array}$ & $\begin{array}{c}(2) \\
\text { Conditional } \\
\text { logit }\end{array}$ & $\begin{array}{c}(3) \\
\text { Conditional } \\
\text { logit }\end{array}$ & $\begin{array}{c}(4) \\
\text { Conditional } \\
\text { logit }\end{array}$ \\
\hline Distance to school (100m) & $-0.211^{* * *}$ & $-0.211^{* * *}$ & $-0.211^{* * *}$ & $-0.211^{* * *}$ \\
'Weak' assessment & $(0.002)$ & $(0.002)$ & $(0.002)$ & $(0.002)$ \\
& & $-0.401^{* * *}$ & & $-0.283^{* * *}$ \\
Std. CITO score & $(0.045)$ & & $(0.047)$ \\
& & & $0.144^{* * *}$ & $0.127^{* * *}$ \\
& & & $(0.011)$ & $(0.011)$ \\
Observations & & & 567,703 & 567,703 \\
Number of schools & 183 & 1863 & 183 & 183 \\
Number of students & 15000 & 15000 & 15000 & 15000 \\
\hline
\end{tabular}

Notes: The variable "std. CITO score" represents the standardized three year CITO score average from 2008, 2009 and 2010 at the school level. The variable "weak" Inspectorate assessment includes the one school that was rated as "unsatisfactory". Standard errors in parentheses; ${ }^{* * *} \mathrm{p}<0.01,{ }^{* *} \mathrm{p}<0.05,{ }^{*} \mathrm{p}<0.1$

Figure 3 shows how the probability of choosing a school relates to the distance of a school option and investigates whether this effect is linear. The graph is based on a conditional logit estimation that includes one dummy variable for every 100 meter unit of distance between home and school. The omitted category is having a school option within 100 meters from home. The vertical axis displays the size of the coefficients and their 95 percent confidence intervals. As the distance between the home address and the school increases, the likelihood of choice decreases in a slightly convex trend. The difference between 0 and 1 kilometer reduces the probability of choice more than the difference between 3 and 4 kilometers. The marginal costs of traveling distance decrease slightly with increased distance. 
Figure 3: Probability of choice and distance

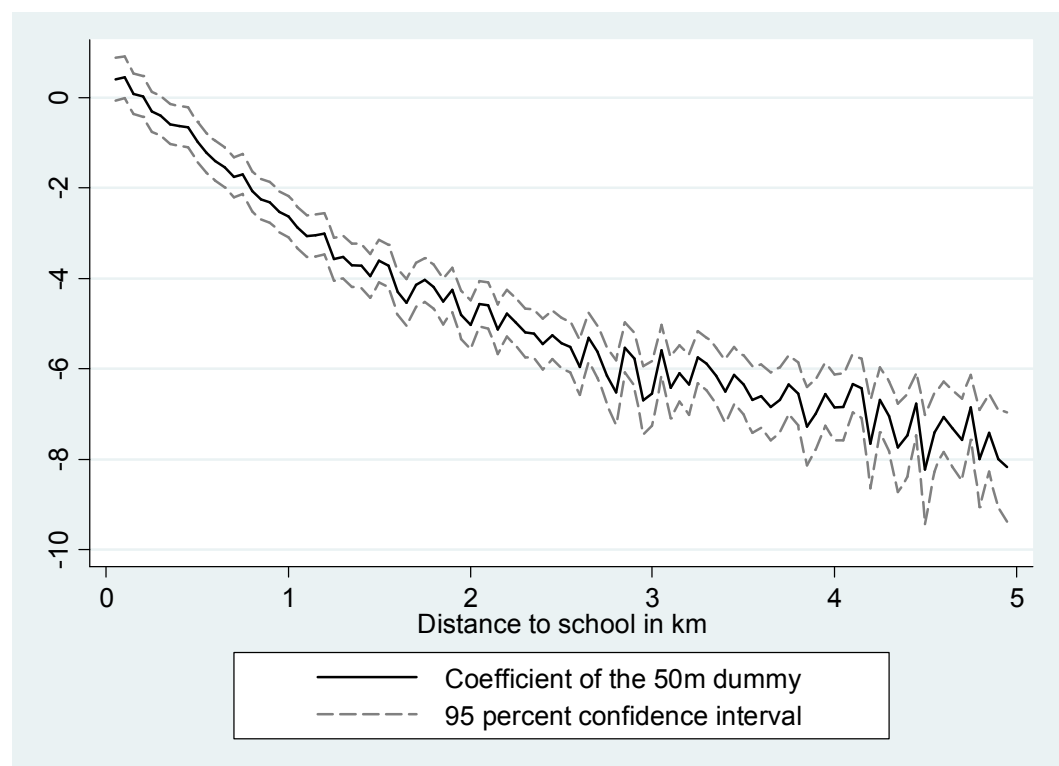

Notes: Development of distance dummies (in 100m steps) from conditional logit estimation and their 95\% confidence intervals. Estimations based on 15,304 students from 192 schools.

\subsection{Preferences for school quality}

The regressions in table 2 also include two measures for school quality: the outcome of the assessment of the Inspectorate, which is published online and the three year school average achievement test score (CITO score), which is not available for all schools. A negative assessment by the Inspectorate of Education is negatively related to the choice probability. Higher average student achievement test scores relate positively to the choice probabilities. These findings support the hypothesis that parents value these two measures of school quality when choosing among the different schools. In relation to the strong effect of distance, the preference for school quality seems to be rather weak. 
According to the estimated model, a school with a "trusted" rather than "weak" assessment outcome increases the willingness to travel further by 190 meters. ${ }^{19}$

Table 3: Preferences for school distance and quality

- Estimates from mixed logit models

\begin{tabular}{lcccc}
\hline & $(1)$ & $(2)$ & $(3)$ & $(4)$ \\
& Mixed logit & Mixed logit & Mixed logit & Mixed logit \\
\hline Means & & & & \\
Distance to school (100m) & $-0.307^{* * *}$ & $-0.308^{* * *}$ & $-0.312^{* * *}$ & $-0.312^{* * *}$ \\
& $(0.004)$ & $(0.004)$ & $(0.004)$ & $(0.004)$ \\
Weak evaluation & & $-0.496^{* * *}$ & & $-0.335^{* * *}$ \\
& & $(0.051)$ & & $(0.053)$ \\
Std. CITO score & & $0.190^{* * *}$ & $0.169^{* * *}$ \\
& & & $(0.013)$ & $(0.013)$ \\
Standard deviations & & & $0.133^{* * *}$ & $0.133^{* * *}$ \\
SD distance to school (100m) & $0.130^{* * *}$ & $0.131^{* * *}$ & $(0.003)$ & $(0.003)$ \\
& $(0.003)$ & $(0.003)$ & & 0.035 \\
SD weak evaluation & & 0.039 & & $(0.161)$ \\
SD std. CITO score & $(0.159)$ & -0.011 & 0.029 \\
& & & $(0.055)$ & $(0.056)$ \\
& & & \\
Observations & & & & \\
Number of schools & 183 & 183 & 183 & 183 \\
Number of students & 15000 & 15000 & 15000 & 15000 \\
\hline
\end{tabular}

Notes: The variable "std. CITO score" represents the three year CITO score average of from 2008, 2009 and 2010 at the school level. The variable "weak evaluation" is one for the school that was rated as "unsatisfactory". Standard errors in parentheses; ${ }^{* * *} \mathrm{p}<0.01,{ }^{* *} \mathrm{p}<0.05,{ }^{*} \mathrm{p}<0.1$

\footnotetext{
19 The implied willingness to travel can be obtained by dividing the "Weak" assessment coefficient by the distance coefficient in table 2. Differently framed example: Parents prefer a school A with a CITO average of 530 over school B with a CITO average of 540 that is $100 \mathrm{~m}$ further away than school A.
} 
The estimates that we obtain from estimating the mixed logit models in table 3 show similar results. In table 3 we report the mean of the logit estimator and the standard deviation of the respective random parameter. The model shows that there is significant variation in the distance parameter, which suggests that some subgroups of the population are more sensitive to an increase in traveling distance than others.

In both types of models, the size of the "weak evaluation" coefficient is smaller when the standardized achievement test score is included. This collinearity between the two quality indicators is partly due to the construction of the Inspectorate's assessment, which is partly built on the achievement test score (CITO).

\subsection{Heterogeneity across socio-economic subgroups}

We now turn to the question whether preferences for school quality are heterogeneous among parents with a different educational background. In order to investigate heterogeneity we split the sample based on the highest obtained educational degree of the father of the child. ${ }^{20}$ Table 4 shows estimates obtained from the conditional logit estimation for the three different subgroups. The estimates indicate that preferences for school quality vary substantially across groups. Higher educated families have about three time stronger preferences for school average achievement test scores (CITO) when compared to middle and lower educated families. These last two groups do not significantly differ in their "taste" for high student achievements.

The interpretation of these coefficients requires some caution. What appears to be a difference in preferences could also be a result of asymmetric information about school quality. The achievement test (CITO) scores may not be known

\footnotetext{
20 The group "higher educated" refers to families where the father holds a degree from higher tertiary education: professional bachelor education (HBO) or university. The middle educated group refers to a degree from high secondary education (VWO) as the highest obtained degree of the father and the "lower educated group" represents families where the father holds a lower secondary or tertiary education level (HAVO/(V)MBO) or no educational degree.
} 
to the public as only some schools publish them on their websites. Lower educated families may in general have less information about school quality or face larger information costs. Besides that, schools with lower average student achievements may be more likely to be located in neighborhoods with more people from a lower socio-economic background. Our findings therefore do not necessarily have a causal interpretation.

Table 4: Heterogeneous preferences for school quality - Estimates from conditional logit models

\begin{tabular}{lccc}
\hline & $\begin{array}{c}(1) \\
\text { Higher } \\
\text { educated }\end{array}$ & $\begin{array}{c}(2) \\
\text { Middle } \\
\text { educated }\end{array}$ & $\begin{array}{c}(3) \\
\text { Lower } \\
\text { educated }\end{array}$ \\
\hline Distance to school $(100 \mathrm{~m})$ & $-0.216^{* * *}$ & $-0.226^{* * *}$ & $-0.212^{* * *}$ \\
& $(0.003)$ & $(0.004)$ & $(0.004)$ \\
Std. CITO score & $0.256^{* * *}$ & $0.086^{* * *}$ & $0.084^{* * *}$ \\
& $(0.023)$ & $(0.026)$ & $(0.028)$ \\
'Weak' Inspectorate evaluation & $-0.811^{* * *}$ & $-0.448^{* * *}$ & $-0.269^{* *}$ \\
& $(0.127)$ & $(0.100)$ & $(0.106)$ \\
Observations & 139,973 & 127,562 & 90,562 \\
Number of schools & 183 & 183 & 183 \\
Number of students & 3687 & 3365 & 2399 \\
\hline
\end{tabular}

Notes: The variable "Std. CITO score" represents the three year CITO score average of from 2008, 2009 and 2010 at the school level. Standard errors in parentheses; ${ }^{* * *} \mathrm{p}<0.01,{ }^{* *} \mathrm{p}<0.05,{ }^{*} \mathrm{p}<0.1$

Table 4 further shows that a "weak" outcome of the Inspectorate's assessment is negatively related to the probability to choose the school. This effect varies across the three subgroups. Preferences for avoiding "weak" schools increase with the education level of the father. Holding everything else constant, higher educated parents would be willing to accept a 375 meters longer way to school if they thereby could avoid sending their child to a "weak" labeled school. For 
lower educated families the respective distance is only 127 meters. ${ }^{21}$ The preferences for school distance appear to be homogeneous across subgroups. In the estimates that represent the preferences for school proximity (distance to school) we observe only minor differences. ${ }^{22}$

Table 5: Heterogeneous preferences for school quality - Estimates from mixed logit models

\begin{tabular}{lccc}
\hline & $\begin{array}{c}(1) \\
\text { Higher } \\
\text { educated }\end{array}$ & $\begin{array}{c}(2) \\
\text { Middle } \\
\text { educated }\end{array}$ & $\begin{array}{c}(3) \\
\text { Lower } \\
\text { educated }\end{array}$ \\
\hline Means & & & \\
Distance to school $(100 \mathrm{~m})$ & $-0.294^{* * *}$ & $-0.346^{* * *}$ & $-0.323^{* * *}$ \\
Std. CITO score & $(0.007)$ & $(0.010)$ & $(0.011)$ \\
& $0.287^{* * *}$ & $0.121^{* * *}$ & $0.144^{* * *}$ \\
Weak Inspectorate evaluation & $(0.026)$ & $(0.030)$ & $(0.033)$ \\
& $-1.036^{* * *}$ & $-0.516^{* * *}$ & $-0.316^{* *}$ \\
Standard deviations & $(0.227)$ & $(0.115)$ & $(0.125)$ \\
SD Distance to school $(100 \mathrm{~m})$ & & & \\
& $0.112^{* * *}$ & $0.148^{* * *}$ & $0.144^{* * *}$ \\
SD weak evaluation & $(0.006)$ & $(0.007)$ & $(0.008)$ \\
SD std. CITO score & -0.016 & 0.017 & $-0.299^{* * *}$ \\
& $(0.073)$ & $(0.065)$ & $(0.090)$ \\
Observations & -0.720 & 0.087 & 0.127 \\
Number of schools & $(0.462)$ & $(0.443)$ & $(0.364)$ \\
Number of students & & & \\
\hline
\end{tabular}

Notes: The variable "Std. CITO score" represents the three year CITO score average of from 2008, 2009 and 2010 at the school level. Standard errors in parentheses; $* * * \mathrm{p}<0.01, * * \mathrm{p}<0.05, * \mathrm{p}<0.1$

21 The implied willingness to travel can be obtained by dividing the "Weak" assessment coefficient by the distance coefficient in table 4 .

22 These differences are small, but significantly different across the three socio-economic subgroups. 
The results we obtain from the mixed logit models in table 5 give similar results about the heterogeneity of preferences for school quality across families with different education levels. The benefit of the mixed logit model is that it allows us to investigate whether preferences are homogeneous within the specified educational subgroups. Table 5 shows that there is substantial variation in the preference for "weak" schools among the group of lower educated. About 14 percent of the lower educated appear to prefer weak schools over non-weak schools. ${ }^{23}$

This finding suggests that a substantial fraction of this subgroup either does not know about the online published Inspectorate's assessment or that they do not care about what the Inspectorate considers poor educational quality. Yet another explanation could be that this subgroup puts more weight on other school characteristics that negatively correlate with the Inspectorate's assessment. One obvious candidate for such a characteristic would be the fraction of peers with a similar socio-economic background at a given school. Including the percentage of peers at a given school as an additional school characteristic introduces potentially severe endogeneity problems and the interpretation of peer preference estimates is not straightforward.

Figure 4 displays the relationship between school popularity and school average student achievements in a different way. Controlling for distance to the school we estimate a conditional logit model with a specific dummy variable for each school. The size of the estimated dummy coefficients can be interpreted as its relative popularity relative to other schools given their geographical characteristics. Figure 4 plots the coefficient size of these school dummies against the achievement test (CITO) score of the respective school. The vertical axis represents the size of the school dummies from a conditional logit model. The horizontal axis displays the school average CITO score of the respective school.

The slope of the fitted values line is positive and significantly different from zero, which means that the school's "attractiveness" relates positively to the

23 This percentage for a given variable $\mathrm{X}$ can be obtained by applying the formula: $1-\Omega\left(\widehat{\beta_{x}} / \widehat{S D}_{x}\right)$; where $\Omega$ describes the cumulative standard normal distribution.

52 | Parental Preferences for Primary School Characteristics | Chapter 3 
average student achievements of the school. However, it is apparent from the graph that student achievements alone are rather weak or noisy predictors of school popularity.

Figure 4: Choice probability and student attainments (CITO)

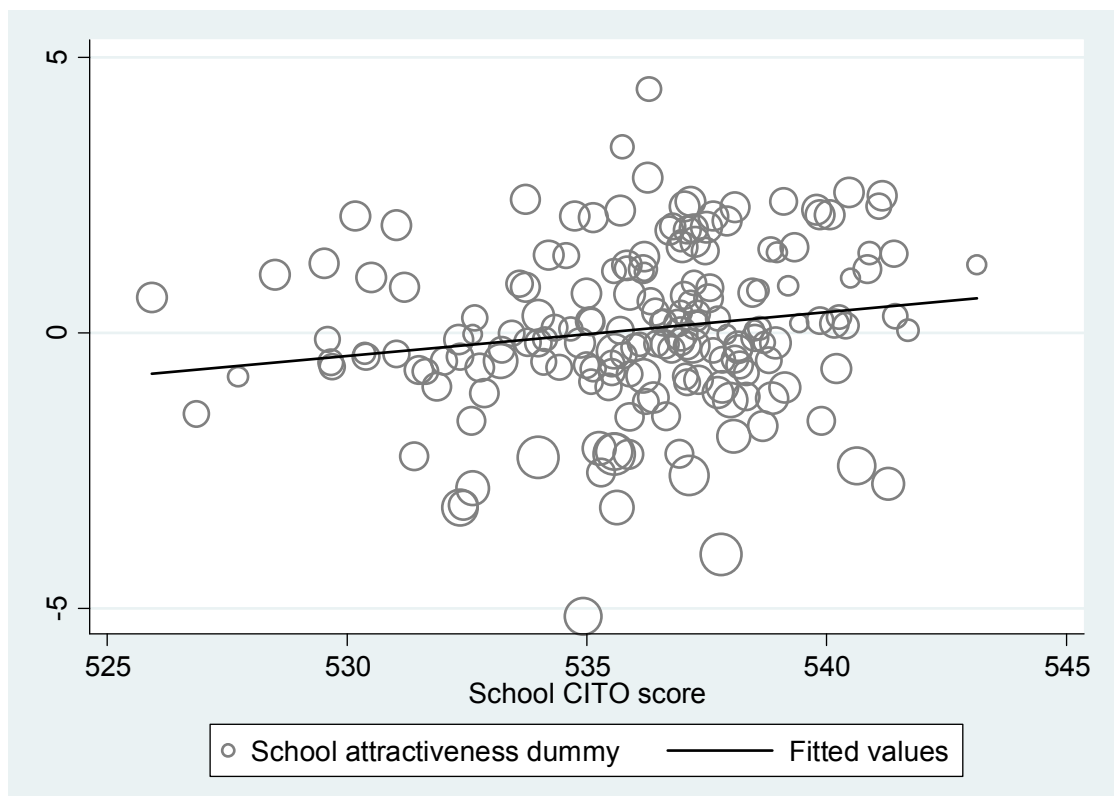

Notes: The radius of the circle represents the size of school dummy standard error. The slope of the line is significantly positive $(\mathrm{P}>|\mathrm{t}|=0.023)$. The figure is based on 183 schools. Nine schools were dropped from the sample due to a missing achievement test (CITO) score.

\subsection{Consistency of school popularity across subgroups}

In the following we investigate whether different subgroups of the population find a given school similarly attractive. Analogue to the approach in the previous section we estimate a conditional logit model with a specific dummy variable for each school and control for distance. We conduct separate regressions for three educational subgroups. Based on the highest obtained degree of the father we split the sample into higher, middle and lower educated families. 
The attractiveness of a given school in one socio-economic subgroup can now be compared to the revealed preference for this school in a different subgroup. Figure 5 shows the consistency of school popularity across subgroups. Figure 5 a displays the size of the school "attractiveness" dummy for the higher educated on the vertical axis and the size of the same school dummy for middle educated on the horizontal axis. With fully homogeneous preferences for schools the slope of fitted values should be identical to a 45 degree line. The slope of the fitted value line is .93 and not statistically different from one. This implies that high and middle educated parents find the same schools attractive and have very similar revealed preferences. In contrast to that, higher and lower educated families find very different schools attractive (Figure 5b). The correlation of revealed school attractiveness dummies is only .41 and statistically different from one. In figure $5 c$, where we compare the revealed preferences of middle and lower educated parents, the slope of the fitted value line is only .36, but statistically significantly different from zero. This comparison between middle and lower educated parents shows that preferences for schools are quite different between these two groups.

Figures 5: Do different SES subgroups find the same schools attractive?

Figure 5a: Higher educated vs. middle educated

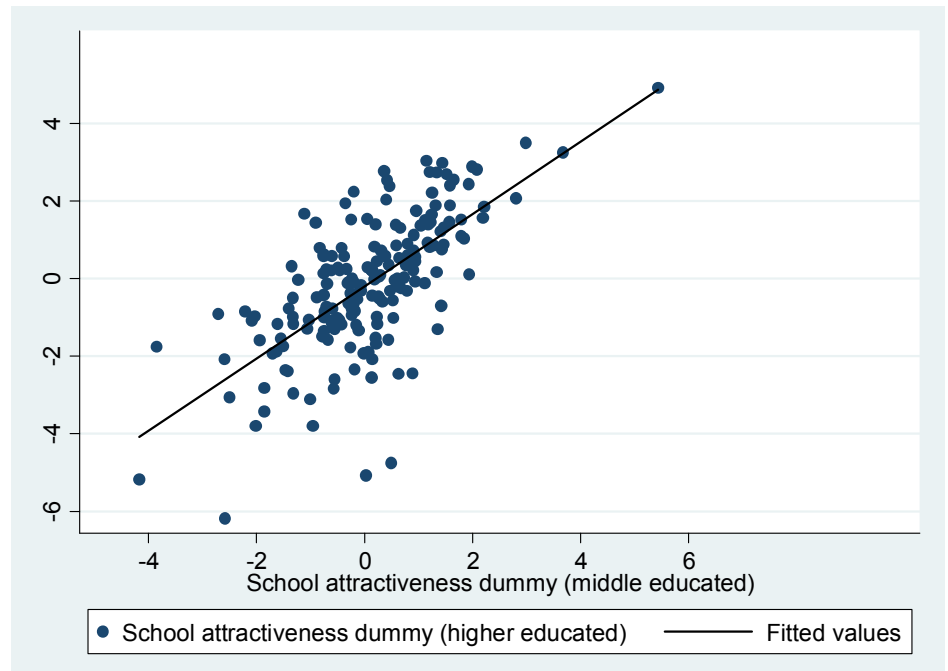

Note: The slope of the fitted values line is $.932^{* * *}$. 
Figure 5b: Higher educated vs. lower educated

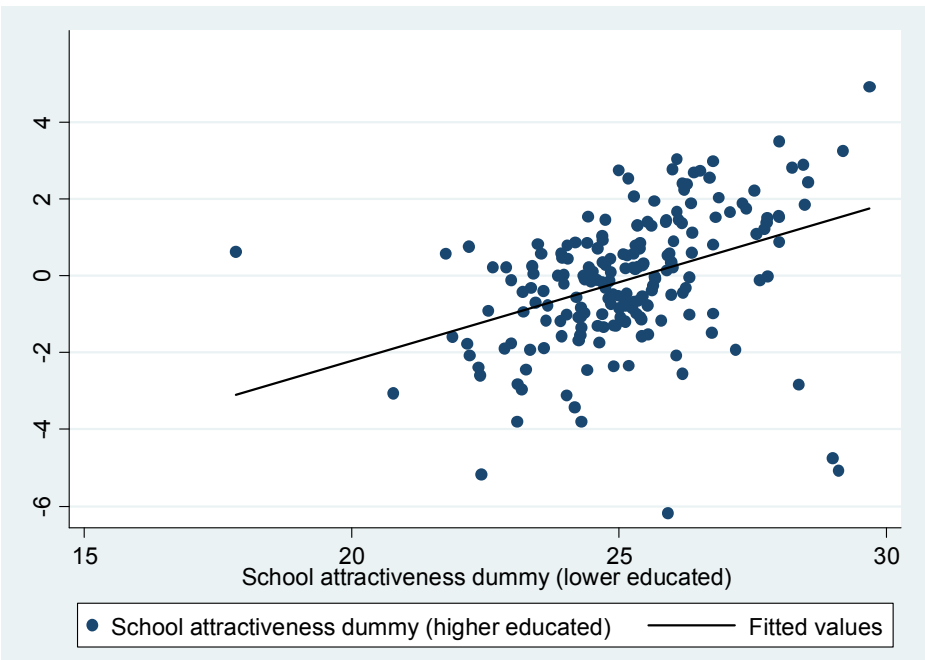

Note: The slope of the fitted values line is $.410^{* * *}$.

Figure 5c: Middle educated vs. lower educated

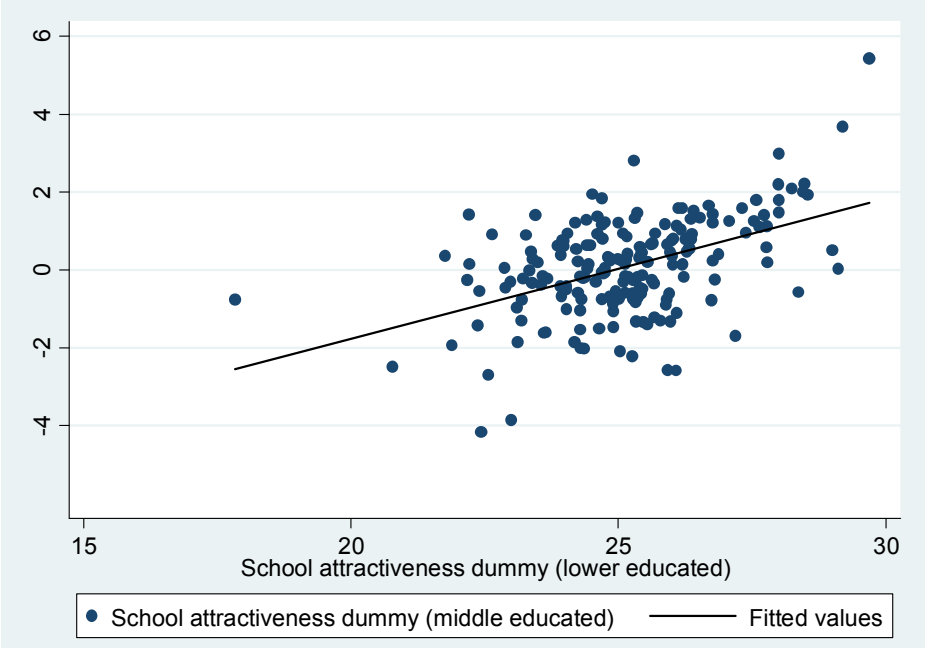

Note: The slope of the fitted values line is .361***. 


\subsection{Preferences for school's denomination}

We now investigate whether a school's religious affiliation and educational concept matter for parental choice behavior. The mixed logit models in table 6 shows the most complete model of school choice. As in the previous regressions we include distance and two indicators for school quality. In addition to that, we also include three dummies for Public, Protestant and Islamic schools. The omitted reference category is Catholic schools.

Column (1) in table 6 shows that public schools appear on average equally attractive as catholic schools, but there is substantial variation in the preference parameter. About half of the population prefers one of the two types. Looking at the group of middle educated parents we see that about 40 percent prefer catholic over public schools. Protestant schools have on average a lower probability of being chosen than catholic school for higher and middle educated parents. About 15 percent of the higher educated prefer protestant schools over catholic schools. About 20 percent of the middle educated prefer protestant schools over catholic schools.

The one Islamic school in our dataset is on average very unpopular for most parents, but this preference varies substantially over the population as the estimate for the standard deviation shows. About 10 percent of the parents have orthogonal preferences and find the Islamic school attractive.

\subsection{Preferences for alternative educational concepts}

The regressions in table 6 also include a dummy that specifies whether the school is devoted to an alternative teaching concept. Schools that belong to the "alternative teaching concept" category are Montessori, Jenaplan and Vrije schools. These schools usually grant their students a larger degree of individual freedom during the learning process and put more focus on fine arts, cultural, and artistic education. The reference group in the regressions is schools with a mainstream educational concept. The mean preference shows that schools with an alternative teaching philosophy are generally less popular. However, there is substantial variation in the mean preference for these schools. About 26 percent of the higher educated parents prefer these schools over mainstream schools. Middle and lower educated families seem to largely avoid these schools. 
Table 6: Heterogeneous preferences for school characteristics - Estimates from mixed logit models

\begin{tabular}{|c|c|c|c|c|}
\hline & $\begin{array}{l}(1) \\
\text { All }\end{array}$ & $\begin{array}{c}(2) \\
\text { Higher edu- } \\
\text { cated }\end{array}$ & $\begin{array}{c}\text { (3) } \\
\text { Middle edu- } \\
\text { cated }\end{array}$ & $\begin{array}{c}(4) \\
\text { Lower edu- } \\
\text { cated }\end{array}$ \\
\hline \multicolumn{5}{|l|}{ Mean } \\
\hline Distance to school (100m) & $\begin{array}{c}-0.337 * * * \\
(0.006)\end{array}$ & $\begin{array}{c}-0.325^{* * *} \\
(0.010)\end{array}$ & $\begin{array}{c}-0.369 * * * \\
(0.012)\end{array}$ & $\begin{array}{c}-0.336 * * * \\
(0.012)\end{array}$ \\
\hline Std. CITO score & $\begin{array}{c}0.253^{* * *} * \\
(0.021)\end{array}$ & $\begin{array}{c}0.411 * * * \\
(0.034)\end{array}$ & $\begin{array}{c}0.151^{* * * *} \\
(0.038)\end{array}$ & $\begin{array}{c}0.146^{* * *} \\
(0.039)\end{array}$ \\
\hline Weak Inspectorate evaluation & $\begin{array}{c}-0.458^{* * *} \\
(0.081)\end{array}$ & $\begin{array}{c}-1.057^{* * *} * \\
(0.268)\end{array}$ & $\begin{array}{c}-0.389 * * * \\
(0.125)\end{array}$ & $\begin{array}{c}-0.311^{* *} \\
(0.131)\end{array}$ \\
\hline Public school & $\begin{array}{c}-0.135^{* *} \\
(0.060)\end{array}$ & $\begin{array}{l}-0.013 \\
(0.098)\end{array}$ & $\begin{array}{c}-0.444 * * * \\
(0.118)\end{array}$ & $\begin{array}{c}0.107 \\
(0.095)\end{array}$ \\
\hline Protestant school & $\begin{array}{c}-0.731 * * * \\
(0.177)\end{array}$ & $\begin{array}{c}-1.053^{* * *} \\
(0.406)\end{array}$ & $\begin{array}{c}-0.924 * * * \\
(0.331)\end{array}$ & $\begin{array}{c}-0.628^{* * *} \\
(0.189)\end{array}$ \\
\hline Islamic school & $\begin{array}{c}-16.956^{* * * *} \\
(3.702)\end{array}$ & $\begin{array}{c}-7.950 * * * \\
(3.056)\end{array}$ & $\begin{array}{c}-30.454^{*} \\
(18.347)\end{array}$ & $\begin{array}{c}-39.880^{* * * *} \\
(13.329)\end{array}$ \\
\hline Alternative teaching philosophy & $\begin{array}{c}-0.262 * * * \\
(0.084)\end{array}$ & $\begin{array}{c}-1.056^{* * *} \\
(0.301)\end{array}$ & $\begin{array}{l}-0.245^{*} \\
(0.145)\end{array}$ & $\begin{array}{c}-0.473 * * * \\
(0.157)\end{array}$ \\
\hline \multicolumn{5}{|l|}{ Standard deviations } \\
\hline SD Distance to school (100m) & $\begin{array}{c}0.141 * * * \\
(0.004)\end{array}$ & $\begin{array}{c}0.130^{* * *} \\
(0.007)\end{array}$ & $\begin{array}{c}0.160^{* * *} \\
(0.008)\end{array}$ & $\begin{array}{c}0.149^{* * * *} \\
(0.009)\end{array}$ \\
\hline SD std. CITO score & $\begin{array}{c}0.076 \\
(0.069)\end{array}$ & $\begin{array}{c}0.01 \\
(0.160)\end{array}$ & $\begin{array}{c}0.034 \\
(0.086)\end{array}$ & $\begin{array}{c}0.311^{* * *} \\
(0.112)\end{array}$ \\
\hline SD weak Inspectorate evaluation & $\begin{array}{c}0.238 \\
(0.275)\end{array}$ & $\begin{array}{l}0.920^{*} \\
(0.503)\end{array}$ & $\begin{array}{c}0.042 \\
(0.740)\end{array}$ & $\begin{array}{c}0.072 \\
(0.366)\end{array}$ \\
\hline SD Public school & $\begin{array}{c}1.632^{* * *} * \\
(0.129)\end{array}$ & $\begin{array}{c}1.872^{* * * *} \\
(0.211)\end{array}$ & $\begin{array}{c}1.799 * * * \\
(0.239)\end{array}$ & $\begin{array}{c}1.079 * * * \\
(0.250)\end{array}$ \\
\hline SD Protestant school & $\begin{array}{c}0.520 \\
(0.474)\end{array}$ & $\begin{array}{l}1.023^{*} \\
(0.605)\end{array}$ & $\begin{array}{l}1.111^{* *} \\
(0.524)\end{array}$ & $\begin{array}{c}0.097 \\
(0.811)\end{array}$ \\
\hline SD Islamic school & $\begin{array}{c}13.236^{* * *} \\
(2.429)\end{array}$ & $\begin{array}{c}5.438^{* * * *} \\
(2.041)\end{array}$ & $\begin{array}{c}22.904 * * \\
(11.140)\end{array}$ & $\begin{array}{c}30.910^{* * *} \\
(8.601)\end{array}$ \\
\hline SD Alternative teaching philosophy & $\begin{array}{c}0.237 \\
(0.317)\end{array}$ & $\begin{array}{c}2.095^{* * *} \\
(0.342)\end{array}$ & $\begin{array}{c}0.129 \\
(0.399)\end{array}$ & $\begin{array}{c}0.426 \\
(0.327)\end{array}$ \\
\hline Observations & 349,945 & 136,460 & 124,750 & 88,735 \\
\hline Number of schools & 183 & 183 & 183 & 183 \\
\hline$\underline{\text { Number of students }}$ & 9451 & 3687 & 3365 & 2399 \\
\hline
\end{tabular}

Notes: The variable "std. CITO score" represents the three year CITO score average of from 2008, 2009 and 2010 at the school level. Standard errors in parentheses; Alternative teaching philosophy refers to Montessori schools, Jenaplan school and "vrije" schools; The omitted school type is "Catholic school". The group "higher educated" refers to families where the father holds degree from higher professional education (HBO) or university degree. The middle educated group refers to a degree from preparatory scientific education (VWO) as the highest obtained degree of the father and the "lower educated group" represents families where the father holds a lower $(\mathrm{HAVO} /(\mathrm{V}) \mathrm{MBO})$ or no educational degree. ${ }^{* * *} \mathrm{p}<0.01,{ }^{* *} \mathrm{p}<0.05,{ }^{*} \mathrm{p}<0.1$ 
An important caveat is that the inclusion of variables for different denomination types and an alternative teaching concept does not systematically alter the preference estimates for achievement test scores and the Inspectorate's assessment. This supports that parental preferences for these special school characteristics are not captured by the available traditional measures of school quality.

Schools with higher average student attainments and better quality assessments have a higher probability of being chosen, but parental preferences for certain denomination types and an alternative teaching concept are heterogeneous and particularly strong in some subgroups of the population. ${ }^{24}$

\footnotetext{
${ }^{24}$ For CITO scores there is substantial variation in the preference among the group of lower educated people. About 32 percent of the lower educated families prefer lower CITO score schools over higher CITO score schools.
} 


\section{6 | Conclusion}

This chapter investigates which school characteristics matter for parental primary school choice in the well-established system of free school choice in the Netherlands. We find that school quality (measured by average test scores) predicts school choice. Publicly available information on school assessments seems to influence choice behavior, particularly of higher educated families. However this "taste for quality" seems to be dominated by the strong preference for schools that are close to the homes of the parents. Our findings confirm evidence from the US, which shows that lower educated parents appear to have weaker preferences for school quality.

Moreover, our findings show that parents have strong preferences for a schools' religious affiliation and the educational philosophy that is being applied at a school. Specific subgroups of the population have orthogonal preferences for a given school attribute. Parental choice preferences regarding these specialized schools with particular educational concepts have previously not been investigated.

Our results have implications for the discussion about the long run effects of free school choice that currently takes place in the US, UK and many other countries. Some schools in the Netherlands seem to have specialized on particular socio-economic subgroups with particular norms and values. From a school perspective, specialization might be a rational response when being faced with more transparency about school quality and increased competition for students. Policies aiming to increase school competition may be the tide that lifts all boats, but they might also foster school specialization in the long run. The case of the Netherland shows that specialized schools are able to offer something valuable to parents, that is different to traditionally measured academic quality. 



\section{Chapter 4}

\section{School Quality and the Development of Cognitive Skills Between Age Four and Six}

\footnotetext{
* This chapter is based on joined work with Lex Borghans and Bart Golsteyn. The authors received valuable comments among others from Benedikt Vogt, Nicolas Salamanca and seminar participants at Leuven (2012), Maastricht University (2012), the ORD (2012) and the second Lisbon Research Workshop on Economics, Statistics and Econometrics of Education (2013). We thank Paul Jungbluth for generously sharing data and providing important background information.
} 



\section{1 | Introduction}

Abilities develop in a cumulative, dynamic process in which today's skills of a child determine tomorrow's development possibilities. Empirical evidence suggests that cognitive ability is formed relatively early in life and becomes less malleable as children age. While there is substantial evidence that preschool programs targeted at disadvantaged children have significant benefits, much less is known about the role of school quality for children's early cognitive development in a more general population of children.

This chapter investigates the effect of school quality on the development of cognitive skills using a new panel data set on a representative sample of Dutch school starters. We relate the gains in cognitive tests scores measured over the course of two years to the quality of the school environment. We use school average scores on an achievement test which children take at age 12 (grade 8) as an indicator for school quality.

In our analyses we control for many attributes which may drive the relationship between quality of schools and cognitive development. First and foremost, we control for initial cognitive ability in our regressions. This variable picks up selection into schools related to cognitive ability. Our estimates show a low correlation between the quality of schools and this initial ability, indicating that selection of this kind does not seem to be a large problem. Second, we control for parental education and household income. Parents with a higher socioeconomic background may have stronger preferences for school quality and therefore be more likely to send their children to higher-achieving schools. Third, we include a number of detailed neighborhood characteristics that pick up heterogeneity at the postal code level. This procedure ensures that we control for a potentially non-random geographical distribution of school and student quality over different neighborhoods.

Our results show that children in above-median schools develop their skills substantially faster than those in below-median schools. The difference in cognitive development is large and accumulates to .17 standard deviations by the end of grade two. We further find some evidence that the effect is heterogeneous: children with lower initial levels of cognitive ability benefit more from higher-achieving schools. 
Although we control for a large set of important attributes, our results may still partly be driven by unobserved characteristics. In a robustness analysis, we estimate the relationships applying an instrumental variable approach. We use geographical proximity to a high-achieving school as an instrument for attending a school with a higher quality. ${ }^{25}$ Proximity to schools plays a predominant role in the choice process of parents and is therefore highly related to the probability of choosing a school. 72 percent of the parents choose the primary school that is located closest to their residential location and 93 percent of the parents choose one of the four schools closest to their residential location. The results of this robustness analysis confirm our findings from the OLS estimation and provide point estimates very similar to our baseline estimates.

Our analysis shows that schools matter for the cognitive development of young children. This has important consequences since various other studies have indicated that stimulating cognitive development at a young age can have benefits throughout life. For instance, analyses of the Perry preschool program and the STAR experiment reveal that interventions at the school level affect early child development and later outcomes. Krueger (1999) and Chetty et al. (2011) who review the project STAR data show that the effect of the intervention on test scores and grades fades out after some time, but also that the kindergarten test scores strongly correlate with wages at age 27.26 Blomeyer et al. (2009) study evidence from Germany and show that the development level of cognitive abilities at age two, four and eight are important predictors of later educational attainment and grades.

Our analysis also relates to the literature evaluating the effects of increased parental school choice possibilities on student achievement tests. Hastings et al. (2008) investigate the effect of information provision on school choice and student achievement tests. The authors analyze the results of two experiments, where the provision of information on school test scores leads to an increase in math and reading test scores in secondary education. In contrast to that, Cullen

\footnotetext{
25 This approach is similar to Gibbons et al. (2008) and Hastings et al. (2008). The main threat to the identification is that distance to a good school is not random.

${ }^{26}$ Chetty et al. (2011) find that a one percent increase in end of kindergarten test scores translates into a $\$ 94$ increase in yearly earnings after controlling for parental background.
}

64 | School Quality and the Development of Cognitive Skills | Chapter 4 
et al. (2006) do not find an effect of attending the "better" school of choice on individual academic achievements when using the exogenous variation of high school admission lotteries in Chicago for their analysis.

The contribution of this chapter is twofold. Firstly, whereas many studies have explored the effects of early intervention programs on later outcomes, no study to the best of our knowledge has examined the effects of school quality on the early development process of children's cognitive skills. Our results reveal that the effect of school quality is already visible during the first year of preschool and continues into the second year. We further show that the choice of a higher-quality preschool matters most for children with low initial levels of cognitive ability.

Secondly, our findings add to the literature on the formation of cognitive skills by showing that school quality is an important environmental factor that influences the development of cognitive skills at ages 4-6. Our results suggest that some parts of the later observed heterogeneity in student outcomes may already be established at an early stage of life due to differences in school quality. These findings are consistent with results of Cunha et al. (2010) and Knudsen et al. (2006) who underline the importance of early investments for the formation of skills.

The remainder of this chapter is structured as follows. Section 2 provides background information on the Dutch education system. Section 3 discusses the data. Section 4 describes our identification strategy. Section 5 shows the results. Section 6 discusses robustness analyses. Section 7 concludes. 


\section{2 | The Dutch primary education system}

Elementary education in the Netherlands consists of eight grades and almost all children enter school at the age of four. ${ }^{27}$ Dutch parents enjoy the right to freely choose which elementary school their child will attend. Free school choice in the Netherlands has been introduced more than 100 years ago. ${ }^{28}$ Dutch parents do not have to apply for schools, nor face complex admission lotteries in the areas where our data was collected. There is also no default "home school" assignment or official choice constrains based on the residential location or school district. In addition, there are no school admission fees and all public and private schools receive government funding if they fulfill certain requirements. Parents can freely choose a school that fits their educational or religious values. ${ }^{29}$ At the same time the population density of the Netherlands is relatively high and a number of elementary schools is usually available within walking or cycling distance. In the dataset that we use, there are on average 6.2 primary schools to choose from within a radius of 2 kilometers. Capacity constrains do not play a major role for choice process in the area where our data were collected. The most obvious costs that parents face when choosing a more distant school are the opportunity costs of time to travel to school and to classmates of their children.

The first two years of primary education (age 4-6) are comparable to kindergarten in the US and children receive no formal schooling but engage in many preparatory activities. After completing the second preschool grade the class composition and the schooling location usually remain the same.

\footnotetext{
27 Primary education is compulsory from the age of five. Effectively $98.5 \%$ of all children enroll in primary education at the age of four. (CBS - Statistics Netherlands 2003)

${ }^{28}$ The results presented in this study can be interpreted as evidence from a school system that would be somewhat closer to a steady state of choice behavior than studies that investigate effects of recently introduced choice plans. If we identify that the school environment affects the cognitive development at an early stage it is unlikely that this effect is driven by recent changes in educational policy. This complements the evidence from other regions that evaluates recently introduced policy changes in school choice.

${ }^{29}$ Parents can choose from public primary schools without a religious affiliation and Catholic, Protestant or Islamic elementary schools. Other schools like the Montessori, Jenaplan, or the union of Vrije scholen are dedicated to alternative educational concepts and offer different teaching methods.
} 
In grade eight, the last year of primary education (around age 12), children take a nationwide standardized achievement test, the CITO test. The result of the CITO test, together with the teacher's recommendation determine which of three secondary school tracks a child will attend. Switching between the secondary school tracks becomes difficult as children age. Admission to scientific studies at university is only possible with a diploma from the highest secondary school track. This indicates that the CITO test is a high stakes achievement test. In the analysis we use the school's average of the CITO test as an indicator for school quality.

\section{3 | Data description}

The data used in this chapter was collected in the Mastricht University Moelejaan Project. This project collected student, parental, and school level data in 2007 and 2008 in the southern part of the Dutch province Limburg. 210 out of the 216 primary schools in South Limburg took part in the study by providing their administrative data and distributing questionnaires to parents. ${ }^{30}$ The essential feature of this dataset is that test scores from school sources can be matched to detailed survey information from parents.

\subsection{Data on preschool test scores}

The central variable we use in our analysis to measure cognitive skills is the score on a test called "ordering test for kindergarten children". ${ }^{31}$ In the first two years of the education, four of these tests are conducted. The tests are designed to measure students' progress during preschool and to identify possible problems in the cognitive development of children during the first two years of primary education. The test deals with matching and identification of shapes and objects as well as concepts like size, amount or length. Every test contains 42 questions. Examples of the test questions can be found in the appendix.

\footnotetext{
${ }^{30}$ Using the schools as the distribution and collection channel leads to an unusually high response rate of almost 70 percent for the sample of children where schools provided test score information.

31 In Dutch: "ordenen toets voor kleuters".
} 
All four tests are conducted by elementary school teachers, who receive very detailed instructions. The teachers read the questions out aloud and children mark the correct answer in their test booklet. Within a given school, most children take the test on one specific day. Figure 1 shows a timeline with the conducted tests during preschool. The first test in preschool grade one usually takes place in January and is repeated with the exact same questions in May or June (second test). The third test is usually conducted in January of the second preschool grade and is then repeated with the same content in May or June (fourth test). The exact date of testing is known and serves as an additional control in the later analysis where we account for pre- and postponed testing dates and the time that elapsed between two tests.

Figure 1: Timeline of the conducted tests in preschool

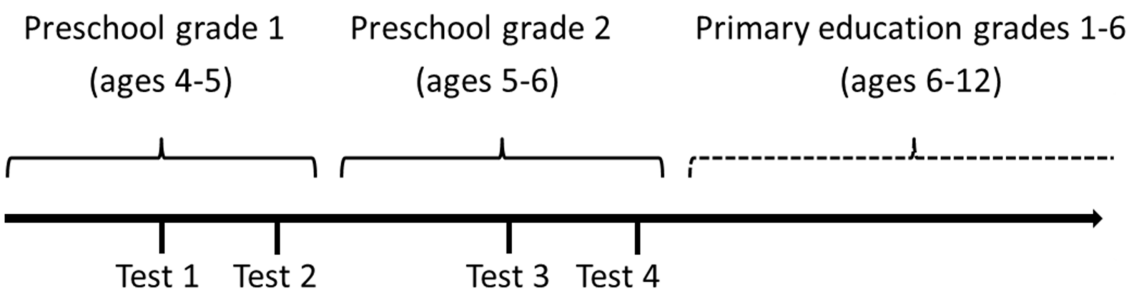

Note: Tests 1 is taken in January 2007. Test 2 is taken in May or June 2007. Test 3 is taken in January 2008 and Test 4 is taken in May or June 2008.

The participation at the school level was voluntary and there were no financial or other incentives related to the test performance of the children present. In total 162 schools out of the 210 participating schools decided to conduct the proposed test for cognitive development and submitted student data in 2007 and/or in 2008. Within the participating schools, $85 \%$ of the children in grade one and two took part in at least one of the tests. At the school level, higherperforming schools had about 2\% higher participation rates. During 2007 and 2008 in total 3,225 first graders participated in test 1 and test 2. Children had on 
average 6.0 months of school experience when they were tested first. The average age at the day of the first testing was 4.5 years. 2,665 second graders participated in the tests 3 and $4 .{ }^{32}$ Out of the 1463 first graders who took the tests in the 2007 wave, we can follow 1,112 students throughout all four consecutive tests. We do not find evidence for selective attrition on observables over time.

Figure 2 shows the distribution of outcomes for the four different tests. The individual scores range between 0 and 42 . For the repeated tests (tests two and four) the distributions are shifted to the right. The distribution of test 2 , which was taken at the end of preschool grade one, shows that the data is censored to some extent. $5 \%$ of all students reached the maximum number of 42 points. Children at better schools have a higher measured initial ability and therefore the potential gains in the measured cognitive development are somewhat smaller. Due to this ceiling effect we may underestimate the effect of school quality on cognitive development to some degree.

Observing the cognitive achievements of a child repeatedly over a time span of two years makes our data unique and allows us to relate the rate of cognitive development to the characteristics of the school that the child attends. The repeated measures also enable us to control for the previous state of development and to obtain better estimates of the added value of school quality.

32 In the 2007 wave we observe the test scores of 1463 first graders and 134 second graders. In the 2008 wave we observe the test scores of 1762 first graders and 2531 second graders. 
Figure 2: Cognitive development during preschool - Distribution of test scores
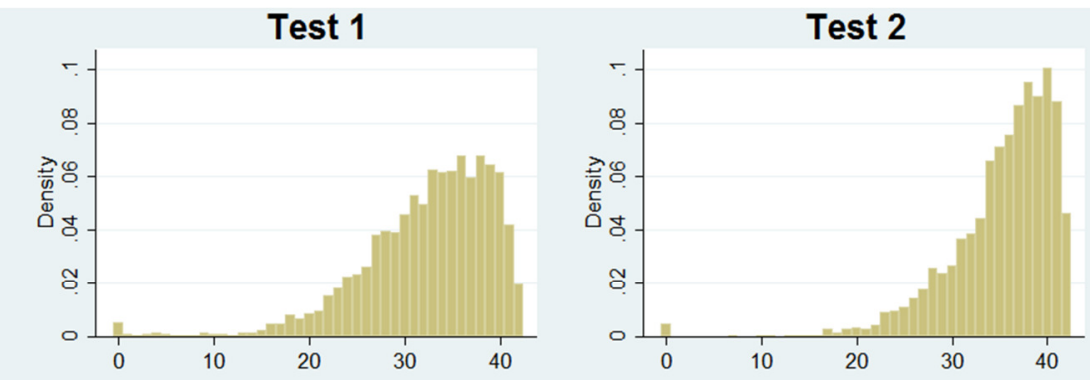

Test 3
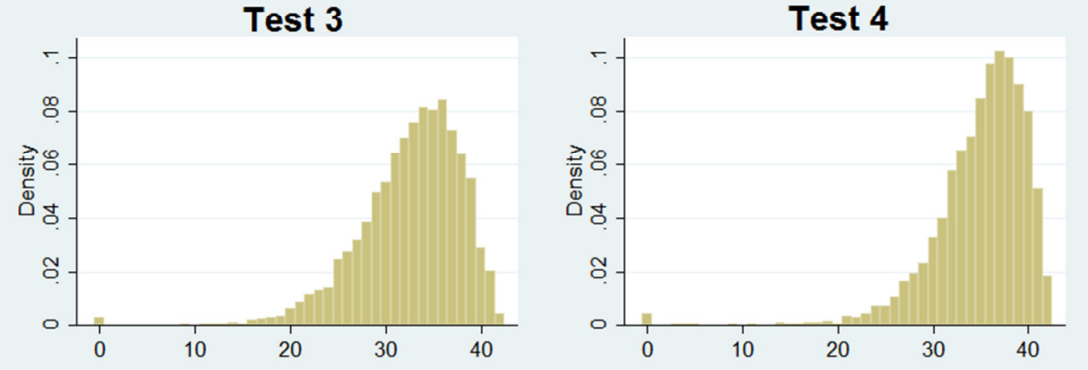

Notes: Test two is a repetition of the first test containing the same questions. Likewise, test four is the same as test three. Children had on average six months of schooling when taking the first test. The average time that elapsed between the first two tests in preschool grade one is 4.3 months and 3.9 month between test three and four in preschool grade two. The time that passed between test one and four is 16.3 months.

\subsection{School performance measure}

We use the school's average CITO score as a measure for the quality of the school. This is a standardized test, which is conducted nationwide at one specific day at the end of primary education. It is used for tracking students into secondary education. The score ranges between 500 and 550 at the individual level. Figure 3 shows the distribution of the three year school average CITO score of the schools that took part in the Moelejaan Project. 
Figure 3: Distribution of the school quality measure

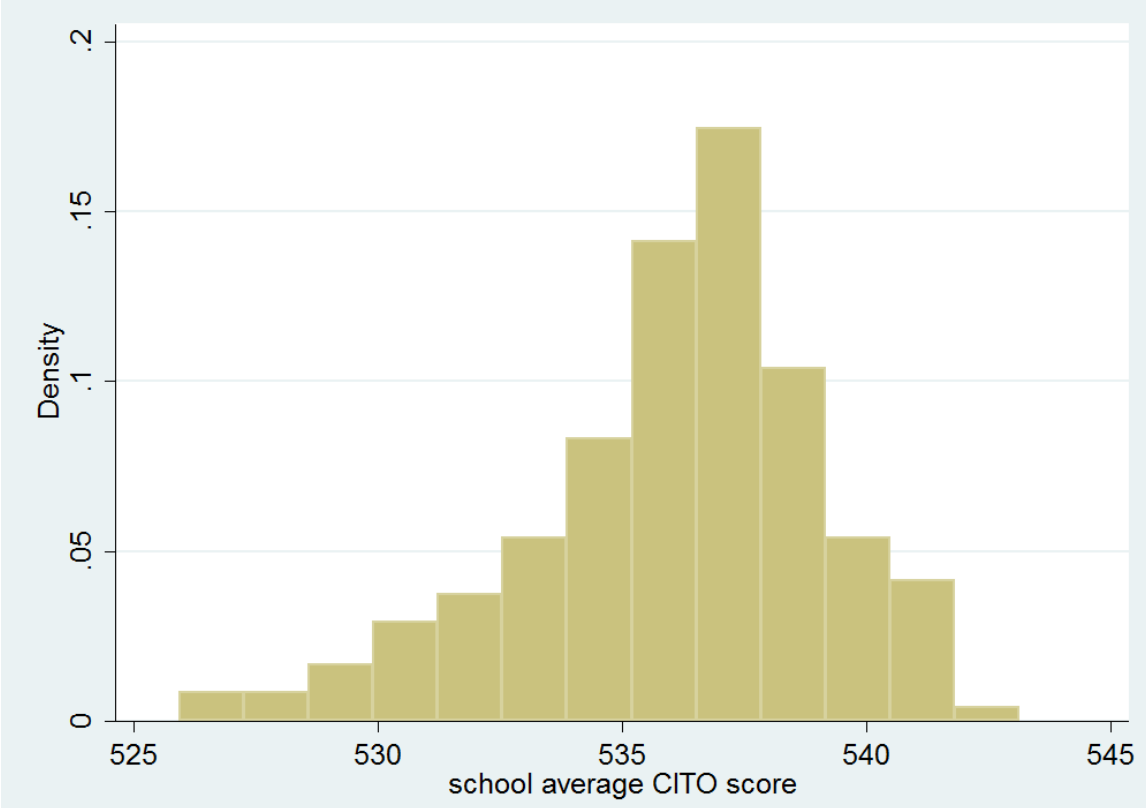

Notes: The figure shows the distribution of the school level three year average of the CITO scores from 2008, 2009 and 2010. The CITO test is designed to have a score ranging from 500 to 550 for each individual student.

The school's average CITO score is potentially influenced by many different school attributes: the quality of teachers, the educational concept of the school, the technical equipment, but also the composition, ability, motivation and parental background of the children who graduate from this school are potential components of this score. In this chapter, we are not primarily interested in what is causing a high or low CITO score. We aim to answer whether it is beneficial for the early cognitive development of a child to choose and attend a school that performs well on this indicator for the quality of school environment. 
Throughout the analysis we will use a binary indicator for the quality of the school environment. Based on the three year overall school's average CITO score we label all schools that have an above median score as "higherachieving" and schools below as "lower-achieving". This arbitrarily defined threshold simplifies the analysis and interpretation of the coefficients. The obtained results can be interpreted as the effect of attending an above-median (higher-achieving) school versus attending a below-median school on the cognitive development of a child. All the main results of this chapter remain qualitatively similar when using a continuous version of the CITO score in the estimations.

The summary statistics in Table 1 show how the schools in our dataset differ in a number of observable characteristics when split at the median into higherand lower-achieving schools. Children at higher-achieving schools have on average higher educated parents, come from a household with more income and perform better on all four cognitive ability test scores during preschool. This table can be interpreted as evidence for selection into schools on observable characteristics and raises valid concerns about potential differences in unobservable dimensions.

\subsection{Data from the parental questionnaire}

All parents with children in grades one, two or three in the participating schools received a questionnaire via the schools. Children took the questionnaires home and brought them back to school in a sealed envelope after their parents had filled them out.

The questionnaire contained 51 questions with in total more than 150 items. Important for the purpose of this paper are the education level of the parents, the household income and the geographical location of their home which allows us to determine which postal code attributes apply and to calculate the distance to schools. The questionnaire further assessed motives for school choice, school satisfaction and the parents' expectations about future child performance and outcomes. 
Table 1: Summary statistics

\begin{tabular}{|c|c|c|c|c|c|c|}
\hline \multirow[b]{2}{*}{ Test-scores for cog. development } & \multicolumn{2}{|c|}{$\begin{array}{c}\text { (1) } \\
\text { Higher- } \\
\text { achieving school } \\
\end{array}$} & \multicolumn{2}{|c|}{$\begin{array}{c}(2) \\
\text { Lower- } \\
\text { achieving school } \\
\end{array}$} & \multicolumn{2}{|c|}{$\begin{array}{c}\text { (3) } \\
\text { All schools } \\
\end{array}$} \\
\hline & & & & & & \\
\hline Test score 1 (grade 1$)$ & 33.03 & $(5.88)$ & 31.64 & $(6.47)$ & 32.38 & $(6.23)$ \\
\hline Test score 2 (grade 1$)$ & 35.72 & $(4.36)$ & 34.77 & $(5.22)$ & 35.30 & (4.83) \\
\hline Test score 3 (grade 2) & 33.35 & $(4.64)$ & 31.67 & $(5.26)$ & 32.62 & $(5.02)$ \\
\hline Test score 4 (grade 2) & 35.54 & $(3.82)$ & 34.3 & $(4.40)$ & 35.00 & $(4.16)$ \\
\hline Age at the time of school start & 3.96 & $(.30)$ & 3.97 & $(.32)$ & 3.96 & $(.31)$ \\
\hline Months at school at time of test 1 & 6.10 & & 5.9 & & 6.00 & \\
\hline Months between test 1 and 2 & 4.35 & $(.82)$ & 4.32 & $(1.29)$ & 4.34 & $(1.07)$ \\
\hline Months between test 2 and 3 & 8.10 & $(2.19)$ & 8.43 & $(2.97)$ & 8.24 & $(2.60)$ \\
\hline Months between test 3 and 4 & 3.87 & $(1.65)$ & 3.86 & $(1.89)$ & 3.87 & $(1.77)$ \\
\hline One if pupil female & 0.49 & $(.50)$ & 0.48 & $(0.50)$ & 0.48 & $(0.50)$ \\
\hline \multicolumn{7}{|l|}{ Distribution of $\mathrm{HH}$ income $(€)$} \\
\hline below 800 & $1.60 \%$ & & $4.30 \%$ & & $2.70 \%$ & \\
\hline $800-1250$ & $7.30 \%$ & & $13.40 \%$ & & $9.90 \%$ & \\
\hline $1250-1750$ & $6.80 \%$ & & $11.10 \%$ & & $8.60 \%$ & \\
\hline $1750-2250$ & $11.00 \%$ & & $14.90 \%$ & & $12.70 \%$ & \\
\hline $2250-2750$ & $18.10 \%$ & & $18.40 \%$ & & $18.20 \%$ & \\
\hline $2750-3250$ & $19.30 \%$ & & $15.00 \%$ & & $17.50 \%$ & \\
\hline $3250-3750$ & $13.20 \%$ & & $9.50 \%$ & & $11.60 \%$ & \\
\hline $3750-4250$ & $7.20 \%$ & & $4.70 \%$ & & $6.10 \%$ & \\
\hline $4250-4750$ & $4.10 \%$ & & $2.80 \%$ & & $3.60 \%$ & \\
\hline $4750-5250$ & $3.30 \%$ & & $1.90 \%$ & & $2.70 \%$ & \\
\hline above 5250 & $8.10 \%$ & & $4.10 \%$ & & $6.40 \%$ & \\
\hline \multicolumn{7}{|l|}{$\begin{array}{l}\text { Education level father (highest } \\
\text { obtained degree): }\end{array}$} \\
\hline No degree & $4.00 \%$ & & $7.50 \%$ & & $5.40 \%$ & \\
\hline $\begin{array}{l}\text { Lower vocational education } \\
\text { (Lbo) }\end{array}$ & $7.70 \%$ & & $12.30 \%$ & & $9.60 \%$ & \\
\hline $\begin{array}{l}\text { General continued education } \\
\text { (Mavo/Havo) }\end{array}$ & $8.40 \%$ & & $12.10 \%$ & & $10.00 \%$ & \\
\hline $\begin{array}{l}\text { Preparatory scientific education } \\
\text { (mbo/vwo) }\end{array}$ & $34.80 \%$ & & $37.30 \%$ & & $35.80 \%$ & \\
\hline $\begin{array}{l}\text { Higher professional education } \\
\text { (Hbo) }\end{array}$ & $30.50 \%$ & & $21.70 \%$ & & $26.80 \%$ & \\
\hline University degree & $14.70 \%$ & & $9.10 \%$ & & $12.40 \%$ & \\
\hline \multicolumn{7}{|l|}{ Education level mother (highest) } \\
\hline No degree & $3.00 \%$ & & $8.00 \%$ & & $5.10 \%$ & \\
\hline $\begin{array}{l}\text { Lower vocational education } \\
\text { (Lbo) }\end{array}$ & $5.70 \%$ & & $10.90 \%$ & & $7.90 \%$ & \\
\hline $\begin{array}{l}\text { General continued education } \\
\text { (Mavo/Havo) }\end{array}$ & $9.40 \%$ & & $14.00 \%$ & & $11.40 \%$ & \\
\hline $\begin{array}{l}\text { Preparatory scientific education } \\
\text { (mbo/vwo) }\end{array}$ & $42.80 \%$ & & $44.00 \%$ & & $43.40 \%$ & \\
\hline $\begin{array}{l}\text { Higher professional education } \\
\text { (Hbo) }\end{array}$ & $28.50 \%$ & & $17.60 \%$ & & $23.90 \%$ & \\
\hline University degree & $10.60 \%$ & & $5.60 \%$ & & $8.40 \%$ & \\
\hline
\end{tabular}


Table 1: ...continued

\begin{tabular}{lccc}
\hline 3 year school average CITO score & 538.4 & 533.5 & 536 \\
Number of schools & 80 & 76 & 156 \\
Number of students & 4246 & 3435 & 7681 \\
Average no. of students per school & 53 & 45 & 49 \\
\hline
\end{tabular}

Notes: Since we do not know the exact date of the first day at school from administrative sources we use the questionnaire answer to the question "In which month did your child go to school for the first time?" to calculate the variable "Months at school at time of test 1". Standard deviations in parentheses.

\section{4 | Strategy}

This chapter aims to identify how school quality, measured as end of primary education school average CITO test score, relates to the rate of cognitive development at the beginning of primary education. We run OLS regressions in which we control for important potential confounders which may drive the relationship between school quality and cognitive development.

Firstly, in all specifications, we control for scores on test 1 to correct for differences in the initial level of cognitive ability. This will pick up potential selection of high ability children into high quality schools. Regressing this baseline measure of cognitive ability on the quality of the chosen school reveals limited evidence of such selection. ${ }^{33}$

\footnotetext{
33 In order to investigate whether high ability students select into high-achieving schools, we perform an OLS regression where we regress baseline cognitive ability on the quality of the chosen school (see table A1 in the appendix). The dependent variable represents the standardized values of test 1 , which was taken after on average 6.0 months of schooling. Column (1) shows that children at higher-achieving schools perform on average .173 standard deviations higher than children at below-median school. When including the education level of both parents and the aggregate household income as controls in column (2) the coefficient decreases to .112 standard deviations but remains significant at the 5 percent level. In column (3), when taking into account differences in neighborhood characteristics, the coefficient drops further and becomes insignificant. This indicates that after controlling for these variables, we no longer find evidence for selection into schools based on initial ability.
} 
Secondly, parental preferences for schools may be heterogeneous across different socio-economic subgroups. ${ }^{34}$ For instance, parents with stronger preferences for school quality may have children with higher initial cognitive abilities and a steeper development curve. In order to take this into account we control for the education level of the mother, the father and the household income.

Thirdly, children from higher socioeconomic backgrounds may have better access to high-quality schools due to their residential location and the clustering of higher-achieving schools in advantaged neighborhoods. We address the issue of geographical clustering by including a number of neighborhood characteristics at the postal code level. These neighborhood controls are the percentage of households under the social minimum income, the percentage of households with low income (less than $€ 25,100$ per year), the percentage of households with high income (more than $€ 46,500$ per year) and the percentage of households with at least one child.

In a robustness analysis, we use distance to a high-achieving school as an instrument. This instrument has a substantial influence on the decision of choosing a higher- or lower-achieving school, and is plausibly unrelated to confounding factors that drive cognitive development.

${ }^{34}$ Hastings et al. (2010) show that preferences for school quality increase with the socioeconomic status of the parents. 


\section{5 | Results}

Table 2 shows the basic estimation results using an OLS regression. We regress scores on tests 2,3 , and 4 on a dummy variable which indicates whether the child attends a high-quality school. The estimates point at a positive relationship between attending a high-quality school and cognitive development.

Comparing columns 1, 2 and 3 shows that the effect size of the coefficient "Higher-achieving school" increases for every consecutive test taken. While the effect of school quality on test 2 is ambiguous, there is a clear increase for test 3 and test 4 . The effect increases over time both in size and significance. Children at higher-achieving schools develop cognitive abilities faster during school. On the last test, they perform .18 standard deviations higher compared to children at lower-achieving schools. Holding everything else constant this means that children attending above median schools answer on average 1.1 more questions correctly (out of the 42 question in test 4). Test 4 was conducted after on average 22.1 months of schooling and 16.1 months after taking test 1 . Given this time span, the quality of the schools seems to have a large influence on the cognitive skill development of the four to six year olds.

The effect size of attending a higher-achieving school is quantitatively comparable to the effect size of having a mother with a university degree compared to no degree.

In columns 4-6 of table 2, we add a set of neighborhood controls to the model. These include the percentage of households under the social minimum income, the percentage of households with low income (less than $€ 25,100$ per year), the percentage of households with high income (more than $€ 46,500$ per year) and the percentage of households with at least one child at the postal code level of the school. ${ }^{35}$ In column 6 , the estimated coefficient is .17 , which shows that there is hardly any change in the point estimates after controlling for the detailed set of neighborhood characteristics.

\footnotetext{
35 The population characteristics at the postal code level were provided by the Statistics Netherlands (CBS) 2010.
} 
Table 2: The effect of attending a higher-achieving school on cognitive development - OLS estimation

\begin{tabular}{lcccccc}
\hline & $(1)$ & $(2)$ & $(3)$ & $(4)$ & $(5)$ & $(6)$ \\
& Test 2 & Test 3 & Test 4 & $\begin{array}{c}\text { Test 2 } \\
\text { Test 3 }\end{array}$ & Test 4 \\
\hline Higher-achieving school & 0.040 & $0.163^{* * *}$ & $0.177^{* * *}$ & 0.056 & $0.153^{* * *}$ & $0.167^{* * *}$ \\
& $(0.036)$ & $(0.046)$ & $(0.040)$ & $(0.037)$ & $(0.048)$ & $(0.041)$ \\
Test 1 & $0.671^{* * *}$ & $0.599^{* * *}$ & $0.521^{* * *}$ & $0.673^{* * *}$ & $0.598^{* * *}$ & $0.519^{* * *}$ \\
& $(0.020)$ & $(0.027)$ & $(0.023)$ & $(0.020)$ & $(0.027)$ & $(0.023)$ \\
Time between test 1\&2 & 0.001 & & & -0.004 & & \\
$\quad$ in months) & $(0.024)$ & & & $(0.024)$ & & \\
$\begin{array}{l}\text { Time between test 1\&3 } \\
\text { (in months) }\end{array}$ & & $0.051^{*}$ & & & $0.050^{*}$ & \\
Time between test 1\&4 & & $(0.027)$ & & & $(0.027)$ & \\
$\quad$ (in months) & & & $0.035^{* *}$ & & & $0.038^{* *}$ \\
Constant & 0.078 & $-0.756^{* *}$ & $-0.645^{* *}$ & 0.236 & -0.406 & -0.086 \\
& $(0.100)$ & $(0.315)$ & $(0.270)$ & $(0.331)$ & $(0.481)$ & $(0.437)$ \\
& & & & & & \\
Observations & 1,112 & 1,112 & 1,112 & 1,112 & 1,112 & 1,112 \\
$\begin{array}{l}\text { Adj. R-squared } \\
\text { Parental background }\end{array}$ & 0.528 & 0.366 & 0.379 & 0.528 & 0.368 & 0.381 \\
$\quad$ controls & Yes & Yes & Yes & Yes & Yes & Yes \\
Neighborhood controls & No & No & No & Yes & Yes & Yes \\
\hline
\end{tabular}

Notes: The dependent variable, the test score of test 1 is standardized to mean zero and a standard deviation of one. The sample is restricted to the children who took all four consecutive tests and started school in 2007. A higher-achieving school is defined as having an above median three year school average CITO score. Parental background controls are the household income and the education level of the father and mother. Neighborhood controls include a set of variables measured at the four digit postal code area. The neighborhood controls are the percentage of households under the social minimum income, the percentage of households with low income (less than $€ 25,100$ per year), the percentage of households with high income (more than $€ 46,500$ per year) and the percentage of households with at least one child. The data on neighborhood characteristics was collected by CBS Statistics Netherlands. Standard errors in parentheses; ${ }^{* * *} \mathrm{p}<0.01,{ }^{* *} \mathrm{p}<0.05$, * $\mathrm{p}<0.1$. 
Figure 4: The effect of attending a higher-achieving school on cognitive test scores

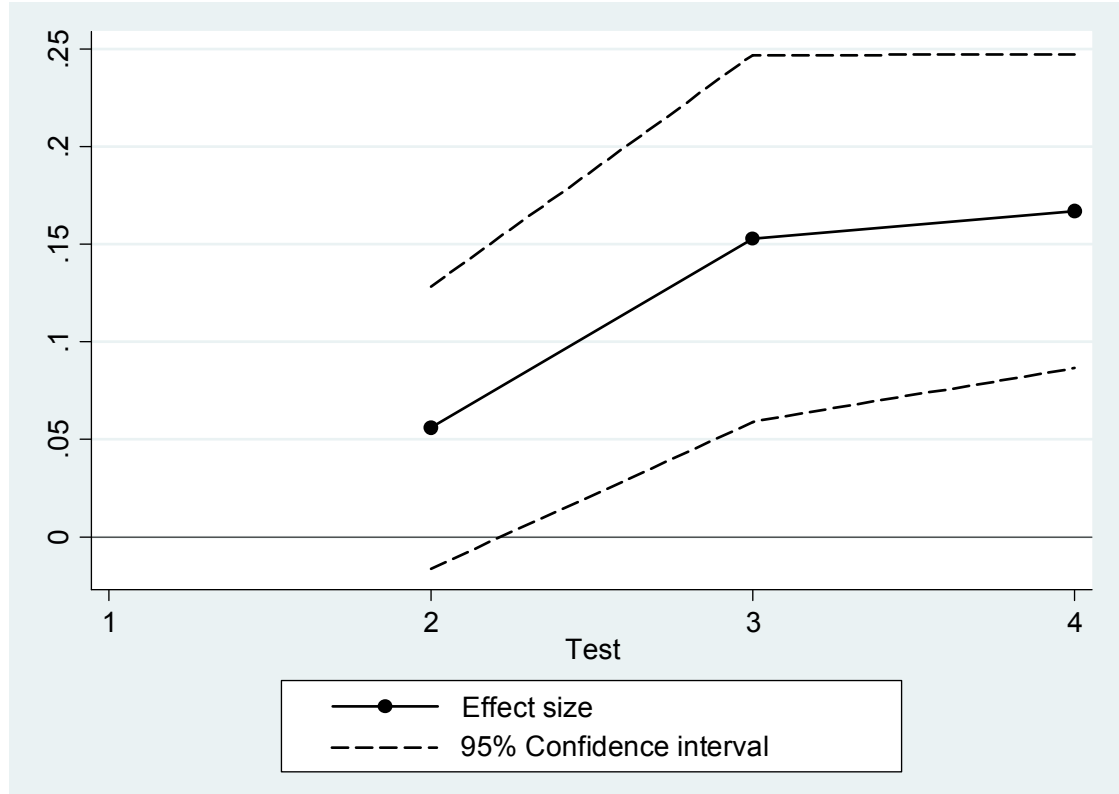

Notes: The figure shows the effect size obtained from the regressions in table 2 (columns $4,5,6$ ).

Figure 4 illustrates how the effect size exacerbates over time. On the horizontal axis we plot the average number of months that children have been at school when they were tested. The vertical axis shows the effect size of "attending a higher-achieving school". The increase in effect size suggests that the cognitive skills of children at lower- and higher-performing schools follow different growth patterns. Whether these differences at age six further increase, stabilize or decrease after the first two years is not clear from the time horizon of our data. Other authors find evidence that early differences sustain or even increase. Chetty et al. (2011) who review the Project STAR data show that kindergarten test scores highly correlate with later outcomes such as earnings, college attendance and the quality of the attended college at age 27 . The findings of Carneiro et al. (2007) show that individual differences in cognitive and non-cognitive skills at age 11 foster and have economically large consequences for future wages and other outcomes like participation in crime, truancy or teenage pregnancy. 
Table 3: Heterogeneous treatment effects - OLS estimation

\begin{tabular}{lcccccc}
\hline & $(1)$ & $(2)$ & $(3)$ & $(4)$ & $(5)$ & $(6)$ \\
& Test 2 & Test 3 & Test 4 & Test 2 & Test 3 & Test 4 \\
\hline & & & & & & \\
Higher achieving school & 0.044 & $0.165^{* * *}$ & $0.183^{* * *}$ & 0.060 & $0.155^{* * *}$ & $0.171^{* * *}$ \\
& $(0.036)$ & $(0.047)$ & $(0.040)$ & $(0.037)$ & $(0.048)$ & $(0.041)$ \\
Higher achieving school & -0.057 & -0.027 & -0.074 & -0.055 & -0.030 & -0.071 \\
* Test 1 & $(0.040)$ & $(0.052)$ & $(0.045)$ & $(0.040)$ & $(0.053)$ & $(0.045)$ \\
& & & & & & \\
Test 1 & $0.699^{* * *}$ & $0.613^{* * *}$ & $0.559^{* * *}$ & $0.701^{* * *}$ & $0.613^{* * *}$ & $0.555^{* * *}$ \\
& $(0.029)$ & $(0.037)$ & $(0.032)$ & $(0.029)$ & $(0.037)$ & $(0.032)$ \\
Time between test 1 \& 2 & -0.002 & & & -0.007 & & \\
(in months) & $(0.024)$ & & & $(0.024)$ & & \\
Time between test 1 \& 3 & & $0.050^{*}$ & & & $0.049 *$ & \\
$\quad$ (in months) & & $(0.027)$ & & & $(0.027)$ & \\
Time between test 1 \& 4 & & & $0.034^{* *}$ & & & $0.038^{* *}$ \\
(in months) & & & $(0.017)$ & & & $(0.017)$ \\
Constant & 0.089 & $-0.748^{* *}$ & $-0.634^{* *}$ & 0.223 & -0.410 & -0.106 \\
& $(0.100)$ & $(0.315)$ & $(0.270)$ & $(0.331)$ & $(0.482)$ & $(0.437)$ \\
& & & & & & \\
Observations & 1,112 & 1,112 & 1,112 & 1,112 & 1,112 & 1,112 \\
R-squared & 0.539 & 0.381 & 0.395 & 0.542 & 0.385 & 0.399 \\
Adj. R-squared & 0.528 & 0.366 & 0.380 & 0.529 & 0.368 & 0.382 \\
Parental background controls & Yes & Yes & Yes & Yes & Yes & Yes \\
Neighborhood controls & No & No & No & Yes & Yes & Yes \\
\hline
\end{tabular}

Notes: All test scores are standardized to mean zero and a standard deviation of one. A higher-achieving school is defined as having an above median three year school average CITO score. Parental background controls are the household income and the education level of the father and mother. Neighborhood controls include a set of variables measured at the four digit postal code area. The neighborhood controls are the percentage of households under the social minimum income, the percentage of households with low income (less than $€ 25,100$ per year), the percentage of households with high income (more than $€ 46,500$ per year) and the percentage of households with at least one child. The data on neighborhood characteristics was collected by CBS Statistics Netherlands. Standard errors in parentheses; ${ }^{* * *} \mathrm{p}<0.01,{ }^{* *} \mathrm{p}<0.05,{ }^{*} \mathrm{p}<0.1$. 
Table 4: Heterogeneous treatment effects (larger sample) - OLS estimation

\begin{tabular}{|c|c|c|c|c|c|c|}
\hline & $\begin{array}{c}(1) \\
\text { Test } 2 \\
\end{array}$ & $\begin{array}{c}(2) \\
\text { Test } 3 \\
\end{array}$ & $\begin{array}{c}(3) \\
\text { Test } 4\end{array}$ & $\begin{array}{c}(4) \\
\text { Test } 2\end{array}$ & $\begin{array}{c}(5) \\
\text { Test } 3 \\
\end{array}$ & $\begin{array}{c}(6) \\
\text { Test } 4\end{array}$ \\
\hline Higher achieving & $\begin{array}{c}0.073^{* * *} \\
(0.023)\end{array}$ & $\begin{array}{c}0.206^{* * *} \\
(0.033)\end{array}$ & $\begin{array}{l}0.050^{*} \\
(0.026)\end{array}$ & $\begin{array}{c}0.075^{* * *} \\
(0.025)\end{array}$ & $\begin{array}{c}0.183^{* * *} \\
(0.035)\end{array}$ & $\begin{array}{c}0.028 \\
(0.028)\end{array}$ \\
\hline $\begin{array}{l}\text { Higher achieving } \\
* \text { Test } 1\end{array}$ & $\begin{array}{c}-0.236 * * * \\
(0.024)\end{array}$ & & & $\begin{array}{c}-0.229 * * * \\
(0.025)\end{array}$ & & \\
\hline $\begin{array}{l}\text { Higher achieving } \\
{ }^{*} \text { Test } 2\end{array}$ & & $\begin{array}{c}-0.064 * \\
(0.037)\end{array}$ & & & $\begin{array}{c}-0.075^{* *} \\
(0.038)\end{array}$ & \\
\hline $\begin{array}{l}\text { Higher achieving } \\
{ }^{*} \text { Test } 3\end{array}$ & & & $\begin{array}{c}-0.184^{* * *} \\
(0.025)\end{array}$ & & & $\begin{array}{c}-0.188^{* * *} \\
(0.025)\end{array}$ \\
\hline Test 1 & $\begin{array}{c}0.859^{* * *} \\
(0.016)\end{array}$ & & & $\begin{array}{c}0.859^{* * *} \\
(0.016)\end{array}$ & & \\
\hline Test 2 & & $\begin{array}{c}0.594^{* * *} \\
(0.028)\end{array}$ & & & $\begin{array}{c}0.594^{* * * *} \\
(0.028)\end{array}$ & \\
\hline Test 3 & & & $\begin{array}{c}0.735^{* * *} \\
(0.016)\end{array}$ & & & $\begin{array}{c}0.734^{* * * *} \\
(0.017)\end{array}$ \\
\hline Constant & $\begin{array}{l}-0.002 \\
(0.022)\end{array}$ & $\begin{array}{c}-0.182^{* * *} \\
(0.033)\end{array}$ & $\begin{array}{c}0.002 \\
(0.025)\end{array}$ & $\begin{array}{l}0.298^{*} \\
(0.179)\end{array}$ & $\begin{array}{c}0.190 \\
(0.293)\end{array}$ & $\begin{array}{c}0.051 \\
(0.221)\end{array}$ \\
\hline Observations & 3,333 & 2,365 & 2,683 & 3,206 & 2,277 & 2,598 \\
\hline R-squared & 0.587 & 0.318 & 0.545 & 0.591 & 0.319 & 0.549 \\
\hline Parental background controls & Yes & Yes & Yes & Yes & Yes & Yes \\
\hline Neighborhood controls & No & No & No & Yes & Yes & Yes \\
\hline Adj. R-squared & 0.584 & 0.311 & 0.541 & 0.587 & 0.310 & 0.544 \\
\hline
\end{tabular}

Notes: The sample is restricted on the children who took at least two consecutive tests. All test scores are standardized to mean zero and a standard deviation of one. A higher-achieving school is defined as having an above median three year school average CITO score. Parental background controls are the household income and the education level of the father and mother. Neighborhood controls include a set of variables measured at the four digit postal code area. The neighborhood controls are the percentage of households under the social minimum income, the percentage of households with low income (less than $€ 25,100$ per year), the percentage of households with high income (more than $€ 46,500$ per year) and the percentage of households with at least one child. The data on neighborhood characteristics was collected by CBS Statistics Netherlands. Standard errors in parentheses; *** $\mathrm{p}<0.01,{ }^{* *} \mathrm{p}<0.05,{ }^{*} \mathrm{p}<0.1$ 
In table 3 we investigate whether the effect of attending a higher-achieving school is heterogeneous with respect to the baseline ability by including an interaction term between the first test and the variable "Higher-achieving school". We find no evidence for heterogeneous effects in this estimation. Children with lower initial levels of cognitive ability do not seem to benefit more from being in the environment of a higher-achieving school. ${ }^{36}$

Table 4 investigates whether heterogeneity can be identified when using a sample of all children who took at least two consecutive tests during the two years. This provides us with larger samples for the estimation, but makes it more difficult to compare estimates among columns since they are based on different subgroups. In table 4 we do not control for the initial baseline ability test 1, but for the previous test taken, given the dependent variable. For example, in column (2) we explain performance in test 3 and control for test 2. Throughout the table we observe a clear pattern of heterogeneous treatment effects. The interaction of the previous test and attending a higher-achieving school is significant in all specifications.

\section{6 | Robustness analyses}

Although we control for a large set of important attributes in our regressions, our results may still partly be driven by unobserved characteristics. Our proposed solution is to apply an instrumental variable approach using proximity to high-quality schools as an instrument. This instrument should have a substantial influence on the decision of choosing a higher- or lower-achieving school, but should be unrelated to confounding factors that drive cognitive development.

The first stage regressions in table 5 show how the choice of a high-quality school relates to various measures of distance from school to the residential location of the student. The dependent variable "Attending higher-achieving school" is an indicator variable that equals one if the child attends an above median school. Column (1) shows that parents are less likely to choose a high-

\footnotetext{
36 Tables A2 and A3 in the appendix show that results are very similar when using a continuous school quality indicator.
} 
quality school if it is located further away. People live at various distances from schools. Therefore, instead of using the distance in kilometers to a high-quality school, it is more precise to ask whether the closest school is a high-performing school. Therefore, we use as an instrument in our IV estimation the proximity dummy included in column (2) that equals one if the closest school, given the residential location of the student, belongs to the category "higher-achieving". The estimates show that this is a strong instrument for attending a higherachieving school. ${ }^{37}$ Column (3) shows that including family characteristics such as the education level of the mother, father and household income does not affect the coefficient of the instrument. These covariates are largely unrelated to the probability of attending a higher-achieving school.

Column (4), the full model which is the first stage in our later IV estimations, includes the initial ability test - our baseline measure for cognitive ability - and shows that children with a higher performance on test 1 are somewhat more likely to attend an above median school. The inclusion of the scores on test 1 does not add much to the explanatory power of the model. As expected, the proximity coefficient remains virtually changed.

The IV approach relies on the assumption that proximity to higher-achieving schools is a strong predictor of choice and that it is unrelated to the error term in the equation explaining the cognitive ability test score conditional on including parental background and neighborhood characteristics. Concerning the first condition, table 5 shows that the F-statistic of the instrument is very high which suggests that we have a strong instrument.

\footnotetext{
37 Our results hold also when we use distance in kilometers as an instrument. We use the proximity to a high-achieving school as an instrument because as the F-statistics in the table indicate, it is a much stronger instrument than distance in kilometers.
} 
Table 5: First stage regressions - Determinants of attending higher-achieving schools

\begin{tabular}{|c|c|c|c|c|}
\hline $\begin{array}{l}\text { Dependent variable: } \\
\text { Attending higher- achieving school }\end{array}$ & (1) & (2) & (3) & (4) \\
\hline $\begin{array}{l}\text { Distance to the next higher-achieving } \\
\text { school }(\mathrm{km})\end{array}$ & $\begin{array}{c}0.098^{* * *} \\
(0.021)\end{array}$ & & & \\
\hline One if closest school higher-achieving & & $\begin{array}{c}0.741 * * * \\
(0.020)\end{array}$ & $\begin{array}{c}0.731 * * * \\
(0.021)\end{array}$ & $\begin{array}{c}0.729 * * * \\
(0.021)\end{array}$ \\
\hline Education level mother middle & & & $\begin{array}{c}0.065 \\
(0.041)\end{array}$ & $\begin{array}{c}0.061 \\
(0.041)\end{array}$ \\
\hline Education level mother high & & & $\begin{array}{l}0.066 \\
(0.048)\end{array}$ & $\begin{array}{l}0.057 \\
(0.048)\end{array}$ \\
\hline Mother education level missing & & & $\begin{array}{c}0.159^{* *} \\
(0.074)\end{array}$ & $\begin{array}{c}0.160^{* *} \\
(0.073)\end{array}$ \\
\hline Education level father middle & & & $\begin{array}{c}0.034 \\
(0.039)\end{array}$ & $\begin{array}{c}0.033 \\
(0.039)\end{array}$ \\
\hline Education level father high & & & $\begin{array}{c}0.025 \\
(0.043)\end{array}$ & $\begin{array}{c}0.024 \\
(0.043)\end{array}$ \\
\hline Father education level missing & & & $\begin{array}{l}-0.070 \\
(0.068)\end{array}$ & $\begin{array}{l}-0.072 \\
(0.068)\end{array}$ \\
\hline Income $1501-2500 €$ & & & $\begin{array}{l}-0.004 \\
(0.050)\end{array}$ & $\begin{array}{l}-0.008 \\
(0.050)\end{array}$ \\
\hline Income $2501-3500 €$ & & & $\begin{array}{l}-0.008 \\
(0.049)\end{array}$ & $\begin{array}{l}-0.012 \\
(0.049)\end{array}$ \\
\hline Income $3501-4500 €$ & & & $\begin{array}{l}0.025 \\
(0.057)\end{array}$ & $\begin{array}{c}0.019 \\
(0.057)\end{array}$ \\
\hline Income above 4501 & & & $\begin{array}{c}0.023 \\
(0.059)\end{array}$ & $\begin{array}{c}0.020 \\
(0.059)\end{array}$ \\
\hline Income information missing & & & $\begin{array}{l}-0.037 \\
(0.049)\end{array}$ & $\begin{array}{l}-0.043 \\
(0.049)\end{array}$ \\
\hline Test 1 & & & & $\begin{array}{l}0.020^{*} \\
(0.012)\end{array}$ \\
\hline Constant & $\begin{array}{c}0.459 * * * \\
(0.020)\end{array}$ & $\begin{array}{c}0.119 * * * \\
(0.015)\end{array}$ & $\begin{array}{c}0.057 \\
(0.048)\end{array}$ & $\begin{array}{l}0.065 \\
(0.048)\end{array}$ \\
\hline Observations & 1,112 & 1,112 & 1,112 & 1,112 \\
\hline F statistic excluded instrument(s) & 21.16 & 1334.82 & 1213.09 & 1208.52 \\
\hline Adj. R-squared & 0.0178 & 0.546 & 0.546 & 0.547 \\
\hline
\end{tabular}

Notes: The dependent variable "Attending higher-achieving school" is defined as having an above median three year school average CITO score. The omitted education categories are "Education level mother low" and "Education level father low". The omitted monthly household income category is "Income below $€ 1500$ ". Standard errors in parentheses; ${ }^{* * *} \mathrm{p}<0.01,{ }^{* *} \mathrm{p}<0.05,{ }^{*} \mathrm{p}<0.1$. 
Proximity to an above median performing school in addition needs to be exogenous. Estimates may potentially be biased if school quality is not randomly distributed in a geographical sense. This may be the case if people choose their housing location based on similarity in neighborhood characteristics or families with a higher socioeconomic background simply prefer living closer to higherachieving schools. Reversing the causality, "good" schools may simply develop in neighborhoods with a higher socio-economic status. "Lower-achieving" schools might have this status, because they serve the population of a less advantaged neighborhood. In addition to that, children with higher cognitive ability might simply be born closer to better schools.

We cannot directly test for the instrument's exogeneity, but address this issue by (1) controlling for initial ability, and (2) controlling for a set of neighborhood characteristics at the postal code level of the school that may pick up the effects of non-random variation in the proximity to higher-quality schools. Any unobserved variable which would still confound the relationship, would have to be orthogonal to the included control variables that pick up the socio-economic background of the parents, the characteristics of the neighborhood and the child's baseline measure for cognitive ability. The existence of such a variable appears to be highly unlikely and provides confidence for the causal interpretation of our results.

Table 6 shows the estimation results we obtain from IV regressions in which the dependent variables are the outcomes of three cognitive ability tests taken during the first two years of school. In the full model in column 6 , the estimated coefficient is .22, which shows that if anything the results from our OLS estimations are somewhat underestimated. 38

\footnotetext{
38 Table A4 in the appendix shows that results are similar when using a continuous school quality indicator.
} 
Table 6: The effect of attending a higher-achieving school on cognitive development - IV estimation

\begin{tabular}{lcccccc}
\hline & & & & & & \\
& $(1)$ & $(2)$ & $(3)$ & $(4)$ & $(5)$ & $(6)$ \\
& Test 2 & Test 3 & Test 4 & Test 2 & Test 3 & Test 4 \\
\hline & & & & & & \\
Higher-achieving school & 0.063 & $0.225^{* * *}$ & $0.231^{* * *}$ & $0.093^{*}$ & $0.212^{* * *}$ & $0.218^{* * *}$ \\
& $(0.049)$ & $(0.064)$ & $(0.054)$ & $(0.052)$ & $(0.066)$ & $(0.057)$ \\
Test 1 & $0.670^{* * *}$ & $0.597^{* * *}$ & $0.519^{* * *}$ & $0.672^{* * *}$ & $0.597^{* * *}$ & $0.518^{* * *}$ \\
& $(0.020)$ & $(0.026)$ & $(0.023)$ & $(0.020)$ & $(0.026)$ & $(0.023)$ \\
Time between test 1\&2 & -0.002 & & & -0.009 & & \\
$\quad$ (in months) & $(0.024)$ & & & $(0.024)$ & & \\
Time between test 1\&3 & & $0.047^{*}$ & & & $0.048^{*}$ & \\
$\quad$ (in months) & & $(0.026)$ & & & $(0.027)$ & \\
Time between test 1\&4 & & & $0.034^{* *}$ & & & $0.037^{* *}$ \\
$\quad$ (in months) & & & $(0.017)$ & & & $(0.017)$ \\
Constant & 0.080 & $-0.745^{* *}$ & $-0.645^{* *}$ & 0.246 & -0.396 & -0.074 \\
& $(0.098)$ & $(0.311)$ & $(0.267)$ & $(0.326)$ & $(0.475)$ & $(0.431)$ \\
& & & & & & \\
Observations & 1,112 & 1,112 & 1,112 & 1,112 & 1,112 & 1,112 \\
Parental background controls & Yes & Yes & Yes & Yes & Yes & Yes \\
Neighborhood controls & No & No & No & Yes & Yes & Yes \\
\hline
\end{tabular}

Notes: The instrumented variable is "Higher-achieving school". The sample is restricted to the children who took all four consecutive tests and started school in 2007. All test scores are standardized to mean zero and a standard deviation of one. A higher-achieving school is defined as having an above median three year school average CITO score. Parental background controls are the household income and the education level of the father and mother. Neighborhood controls include a set of variables measured at the four digit postal code area. The neighborhood controls are the percentage of households under the social minimum income, the percentage of households with low income (less than $€ 25,100$ per year), the percentage of households with high income (more than $€ 46,500$ per year) and the percentage of households with at least one child. The data on neighborhood characteristics was collected by CBS Statistics Netherlands. Standard errors in parentheses; *** $\mathrm{p}<0.01,{ }^{*} * \mathrm{p}<0.05,{ }^{*} \mathrm{p}<0.1$. 


\section{7 | Conclusion}

In this chapter we show that children who attend schools with higher average achievement test scores in grade six benefit from the more stimulating environment during the first two years of school in terms of cognitive development. This observed difference in developed skills is substantial even when controlling for a baseline measure of cognitive skills. The identified effect is heterogeneous with respect to previous levels of cognitive skills. Children with lower initial levels of cognitive ability benefit more from higher-achieving schools.

Our results confirm previous evidence that underlines the importance of school choice and school quality for cognitive development and later outcomes (Hasting, 2008, Hastings, 2010 and Hoxby, 2002). We show that the school related development differences are substantial and already visible as early as ten months after the start of preschool. School related differences in measured cognitive abilities seem to accumulate during the first two years of primary education.

A clear identification of the early determinants of ability formation is crucial if the development of cognitive skills and personality traits indeed depends on the stock of previously acquired skills, as suggested by Cunha et al. (2010) and Heckman (1999). Improving the quality of the early childhood environment potentially decreases outcome inequality in earlier and later stages of the lifecycle at a lower cost when compared to interventions that target older age groups.

From a policy perspective, lower-achieving schools might require closer monitoring, since they seem to cause a slower development of cognitive abilities. The channel through which the observed effect operates is not yet clearly identified. Whether teachers, peers, the educational concept or other unobserved factors that relate to school quality drive the results remains subject to future research that will shed more light on the underlying channels.

Policy makers - especially in the US - have been experimenting with the introduction of different kinds of school choice programs. Parents are increasingly given the opportunity to choose schools with higher average student achievement scores. The introduction of these school choice policies is based on the implicit assumptions (1) that parents will choose better schools if they are given 
the opportunity and (2) that there is a causal link between school quality and the individual student performance. Our study provides evidence that the latter assumption seems to hold in the well-established education system of free school choice in the Netherlands. Our findings indicate that the effect of school quality is already visible during the first two years of preschool. 


\section{Appendix}

\section{A.1 Additional tables}

Table A1: Determinants of baseline ability

\begin{tabular}{|c|c|c|c|}
\hline & $\begin{array}{c}\text { (1) } \\
\text { Test } 1 \\
\text { OLS }\end{array}$ & $\begin{array}{c}(2) \\
\text { Test } 1 \\
\text { OLS }\end{array}$ & $\begin{array}{c}(3) \\
\text { Test } 1 \\
\text { OLS }\end{array}$ \\
\hline Higher-achieving school & $\begin{array}{c}0.173 * * * \\
(0.052)\end{array}$ & $\begin{array}{c}0.112 * * \\
(0.053)\end{array}$ & $\begin{array}{c}0.088 \\
(0.054)\end{array}$ \\
\hline \multicolumn{4}{|l|}{ Household characteristics } \\
\hline Education level mother middle & & $\begin{array}{c}0.212^{* *} \\
(0.104)\end{array}$ & $\begin{array}{l}0.204^{*} \\
(0.104)\end{array}$ \\
\hline Education level mother high & & $\begin{array}{c}0.465^{* * * *} \\
(0.121)\end{array}$ & $\begin{array}{c}0.447 * * * \\
(0.121)\end{array}$ \\
\hline Mother education level missing & & $\begin{array}{l}-0.062 \\
(0.186)\end{array}$ & $\begin{array}{l}-0.067 \\
(0.186)\end{array}$ \\
\hline Education level father middle & & $\begin{array}{c}0.009 \\
(0.098)\end{array}$ & $\begin{array}{c}0.006 \\
(0.099)\end{array}$ \\
\hline Education level father high & & $\begin{array}{c}0.043 \\
(0.110)\end{array}$ & $\begin{array}{c}0.034 \\
(0.110)\end{array}$ \\
\hline Father education level missing & & $\begin{array}{c}0.111 \\
(0.172)\end{array}$ & $\begin{array}{c}0.111 \\
(0.172)\end{array}$ \\
\hline Income $1501-2500 €$ & & $\begin{array}{c}0.174 \\
(0.126)\end{array}$ & $\begin{array}{c}0.162 \\
(0.126)\end{array}$ \\
\hline Income $2501-3500 €$ & & $\begin{array}{c}0.156 \\
(0.123)\end{array}$ & $\begin{array}{c}0.135 \\
(0.123)\end{array}$ \\
\hline Income $3501-4500 €$ & & $\begin{array}{l}0.275^{*} \\
(0.144)\end{array}$ & $\begin{array}{l}0.255^{*} \\
(0.144)\end{array}$ \\
\hline Income above 4501 & & $\begin{array}{c}0.162 \\
(0.150)\end{array}$ & $\begin{array}{c}0.148 \\
(0.150)\end{array}$ \\
\hline Income information missing & & $\begin{array}{c}0.289 * * \\
(0.123)\end{array}$ & $\begin{array}{c}0.270^{* *} \\
(0.124)\end{array}$ \\
\hline \multicolumn{4}{|l|}{ Neighborhood characteristics } \\
\hline$\% \mathrm{HH}$ under the social minimum & & & $\begin{array}{l}-0.007 \\
(0.015)\end{array}$ \\
\hline$\% \mathrm{HH}$ with low income & & & $\begin{array}{c}0.002 \\
(0.008)\end{array}$ \\
\hline$\% \mathrm{HH}$ with high income & & & $\begin{array}{c}0.009 \\
(0.008)\end{array}$ \\
\hline$\% \mathrm{HH}$ with one or more children & & & $\begin{array}{l}-0.002 \\
(0.006)\end{array}$ \\
\hline Constant & $\begin{array}{l}-0.023 \\
(0.037)\end{array}$ & $\begin{array}{c}-0.410^{* * *} \\
(0.122)\end{array}$ & $\begin{array}{l}-0.495 \\
(0.474)\end{array}$ \\
\hline Observations & 1,112 & 1,112 & 1,112 \\
\hline Adj. R-squared & 0.00907 & 0.0355 & 0.0357 \\
\hline
\end{tabular}


Notes table A1: The dependent variable, the score on test 1 is standardized to mean zero and a standard deviation of one. A higher-achieving school is defined as having an above median three year school average CITO score. Neighborhood characteristics were measured at the four digit postal code area by CBS Statistics Netherlands. The omitted education categories are "Education level mother low" and "Education level father low". The omitted monthly household income category is "Income below $€ 1500 "$ ". Standard errors in parentheses; *** $\mathrm{p}<0.01$, ** $\mathrm{p}<0.05, * \mathrm{p}<0.1$.

Table A2: Continuous CITO model - OLS estimation

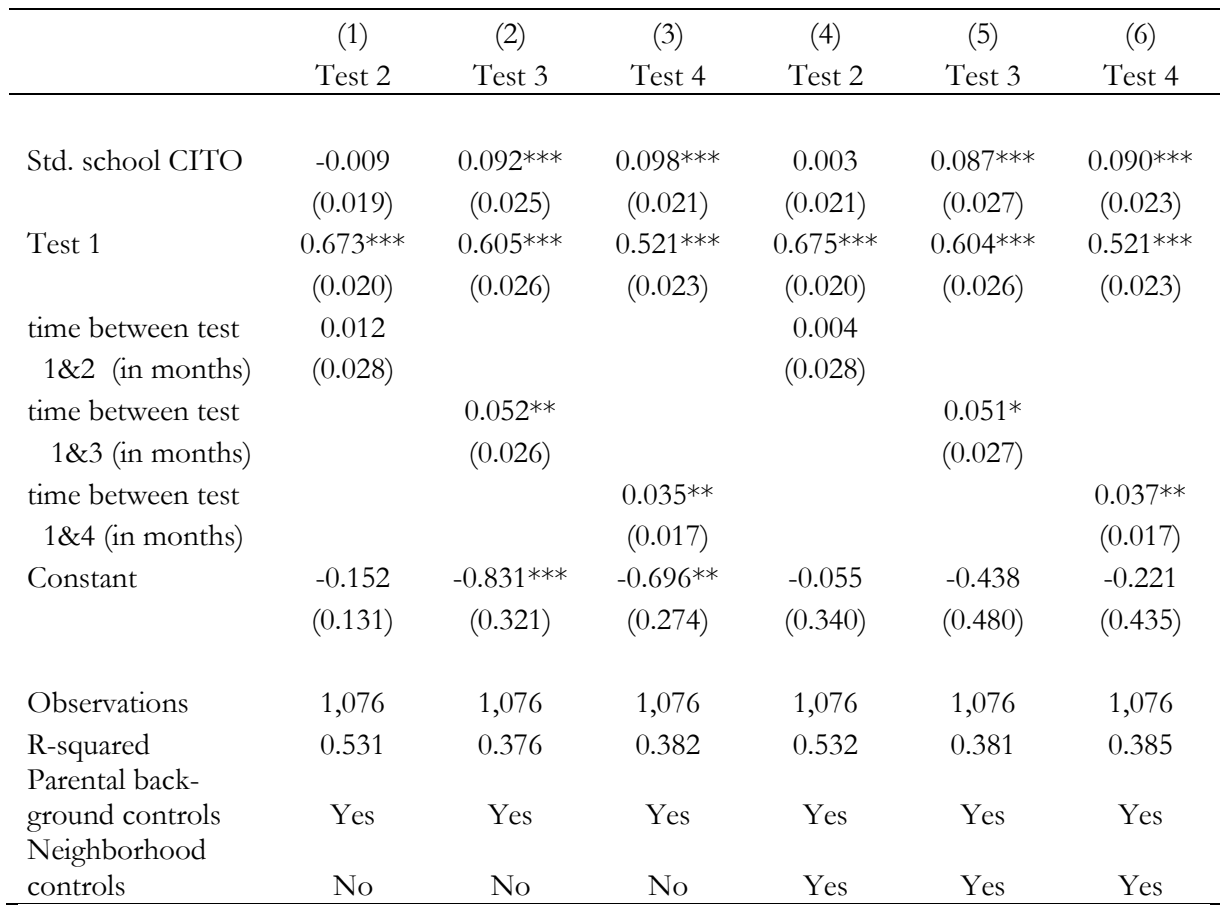

Note: Parental background controls are the household income and the education level of the father and mother. Neighborhood controls include a set of variables measured at the four digit postal code area. The neighborhood controls are the percentage of households under the social minimum income, the percentage of households with low income (less than $€ 25,100$ per year), the percentage of households with high income (more than $€ 46,500$ per year) and the percentage of households with at least one child. The data on neighborhood characteristics was collected by CBS Statistics Netherlands. Standard errors in parentheses; *** $\mathrm{p}<0.01$, ** $\mathrm{p}<0.05, * \mathrm{p}<0.1$ 
Table A3: Continuous CITO model with heterogeneous treatment effects - OLS estimation

\begin{tabular}{lcccccc}
\hline & $(1)$ & $(2)$ & $(3)$ & $(4)$ & $(5)$ & $(6)$ \\
& Test 2 & Test 3 & Test 4 & Test 2 & Test 3 & Test 4 \\
\hline Std. school CITO & -0.002 & -0.004 & $-0.045^{*}$ & -0.002 & -0.005 & $-0.043^{*}$ \\
* Test 1 & $(0.023)$ & $(0.029)$ & $(0.025)$ & $(0.023)$ & $(0.029)$ & $(0.025)$ \\
& & & & & & \\
Std. school CITO & -0.008 & $0.088^{* * *}$ & $0.098^{* * *}$ & 0.004 & $0.085^{* * *}$ & $0.090^{* * *}$ \\
& $(0.020)$ & $(0.025)$ & $(0.021)$ & $(0.021)$ & $(0.027)$ & $(0.023)$ \\
Test 1 & $0.674^{* * *}$ & $0.604^{* * *}$ & $0.519^{* * *}$ & $0.675^{* * *}$ & $0.603^{* * *}$ & $0.518^{* * *}$ \\
& $(0.021)$ & $(0.027)$ & $(0.023)$ & $(0.021)$ & $(0.027)$ & $(0.023)$ \\
time between test & 0.011 & & & 0.003 & & \\
1\&2 (in months) & $(0.028)$ & & & $(0.029)$ & & \\
Time between test & & $0.051^{*}$ & & & $0.050^{*}$ & \\
$\quad$ 1\&3 (in months) & & $(0.027)$ & & & $(0.027)$ & \\
Time between test & & & $0.033^{*}$ & & & $0.035^{* *}$ \\
$\quad$ 1\&4 (in months) & & & $(0.017)$ & & & $(0.017)$ \\
Constant & -0.167 & $-0.813^{* *}$ & $-0.594^{* *}$ & -0.063 & -0.406 & -0.177 \\
& $(0.142)$ & $(0.330)$ & $(0.280)$ & $(0.344)$ & $(0.485)$ & $(0.437)$ \\
& & & & & & \\
Observations & 1,076 & 1,076 & 1,076 & 1,076 & 1,076 & 1,076 \\
R-squared & 0.531 & 0.379 & 0.389 & 0.533 & 0.384 & 0.391 \\
$\begin{array}{l}\text { Parental background } \\
\text { controls }\end{array}$ & Yes & Yes & Yes & Yes & Yes & Yes \\
Neighborhood controls & No & No & No & Yes & Yes & Yes \\
\hline
\end{tabular}

Note: Parental background controls are the household income and the education level of the father and mother. Neighborhood controls include a set of variables measured at the four digit postal code area. The neighborhood controls are the percentage of households under the social minimum income, the percentage of households with low income (less than $€ 25,100$ per year), the percentage of households with high income (more than $€ 46,500$ per year) and the percentage of households with at least one child. The data on neighborhood characteristics was collected by CBS Statistics Netherlands. Standard errors in parentheses; *** $\mathrm{p}<0.01$, ** $\mathrm{p}<0.05, * \mathrm{p}<0.1$ 
Table A4: Continuous CITO model - IV estimation

\begin{tabular}{lcccccc}
\hline & $(1)$ & $(2)$ & $(3)$ & $(4)$ & $(5)$ & $(6)$ \\
& Test 2 & Test 3 & Test 4 & Test 2 & Test 3 & Test 4 \\
\hline \multirow{3}{*}{ Std. school CITO } & & & & & & \\
& 0.010 & $0.117^{* * *}$ & $0.106^{* * *}$ & 0.031 & $0.115^{* * *}$ & $0.096^{* * *}$ \\
Test 1 & $(0.023)$ & $(0.030)$ & $(0.026)$ & $(0.027)$ & $(0.033)$ & $(0.029)$ \\
& $0.672^{* * *}$ & $0.604^{* * *}$ & $0.521^{* * *}$ & $0.674^{* * *}$ & $0.604^{* * *}$ & $0.520^{* * *}$ \\
Time between test & $(0.020)$ & $(0.027)$ & $(0.023)$ & $(0.020)$ & $(0.027)$ & $(0.023)$ \\
$1 \& 2$ (in months) & 0.006 & & & -0.005 & & \\
Time between test & $(0.028)$ & & & $(0.029)$ & & \\
$1 \& 3$ (in months) & & $0.050^{*}$ & & & $0.048^{*}$ & \\
Time between test & & $(0.026)$ & & & $(0.027)$ & \\
$1 \& 4$ (in months) & & & $0.034^{* *}$ & & & $0.037 * *$ \\
Constant & -0.123 & $-0.801^{* *}$ & $-0.689^{* *}$ & -0.000 & -0.399 & -0.212 \\
& $(0.132)$ & $(0.321)$ & $(0.275)$ & $(0.342)$ & $(0.481)$ & $(0.436)$ \\
Observations & & & & & & \\
Parental background controls & Yes & Yes & Yes & Yes & Yes & Yes \\
Neighborhood controls & No & No & No & Yes & Yes & Yes \\
\hline
\end{tabular}

Note: Parental background controls are the household income and the education level of the father and mother. Neighborhood controls include a set of variables measured at the four digit postal code area. The neighborhood controls are the percentage of households under the social minimum income, the percentage of households with low income (less than $€ 25,100$ per year), the percentage of households with high income (more than $€ 46,500$ per year) and the percentage of households with at least one child. The data on neighborhood characteristics was collected by CBS Statistics Netherlands. Standard errors in parentheses; *** $\mathrm{p}<0.01$, ** $\mathrm{p}<0.05, * \mathrm{p}<0.1$ 


\section{A.2 Cognitive achievement tests}

Ordering test for kindergarten children ("Ordenen voor jongste kleuters")

The text was read out aloud to the children and the child had to mark the respective box in their booklet. Teachers were instructed to repeat the item only once if necessary. Not answering a question was counted as a wrong answer. Every test had 42 items. The following questions are translated from Dutch.

Examples from the test:

"Draw a line under the picture with the square:"
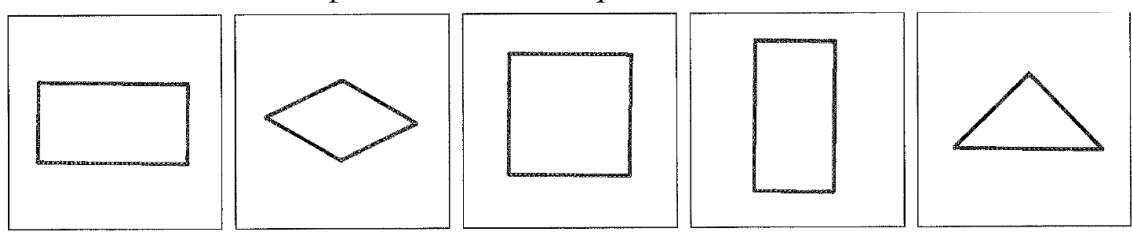

"Draw a line under the picture that is the same as the first one:"
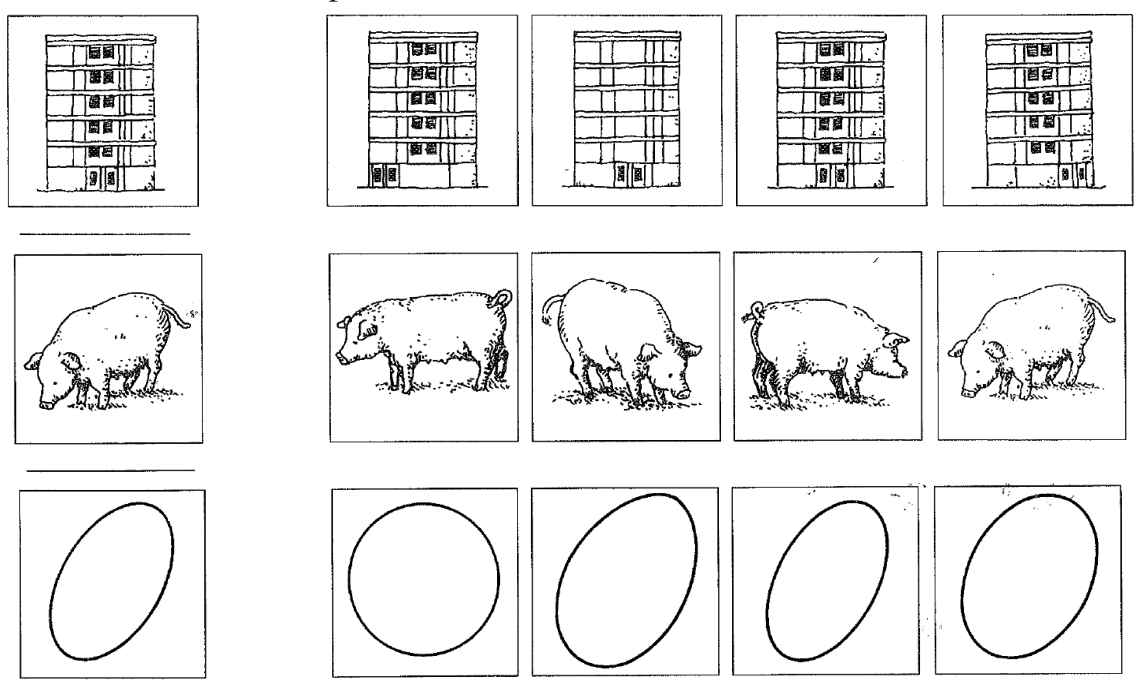

92 | School Quality and the Development of Cognitive Skills | Chapter 4 

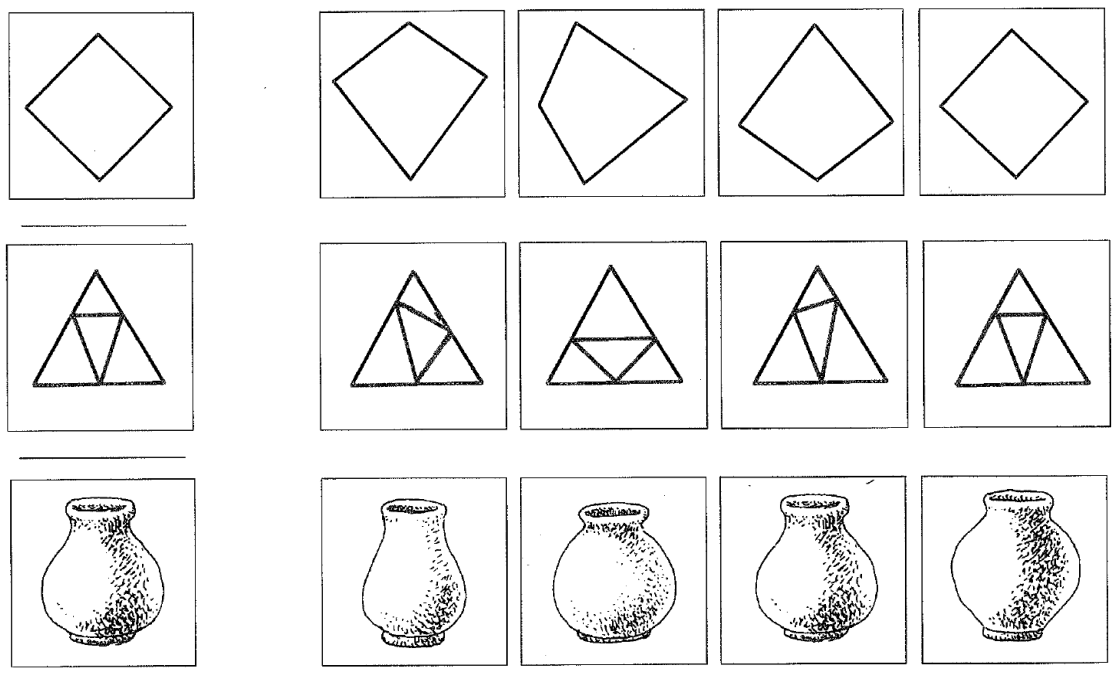

"Which one of these five does not fit in?"
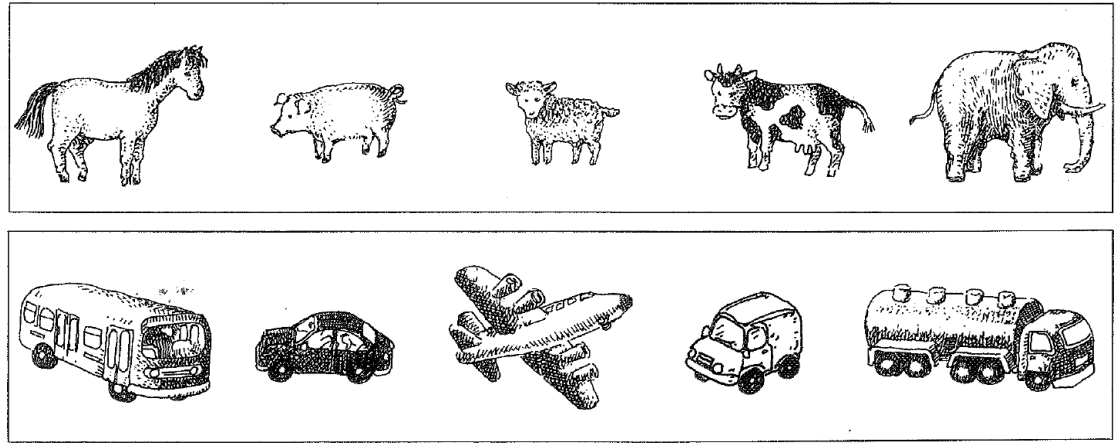

"Which rooster is smaller than the first one?"
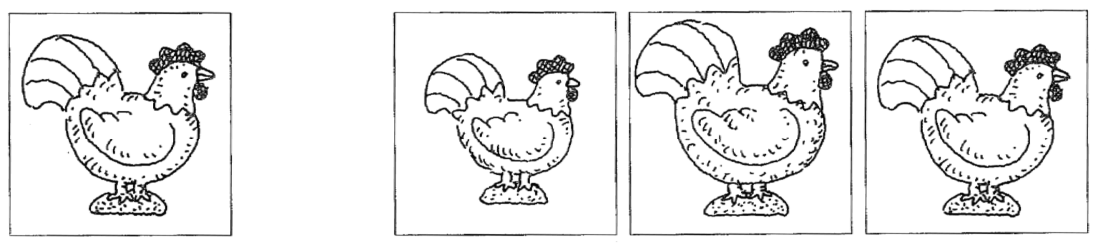
"Which tower is the highest?"
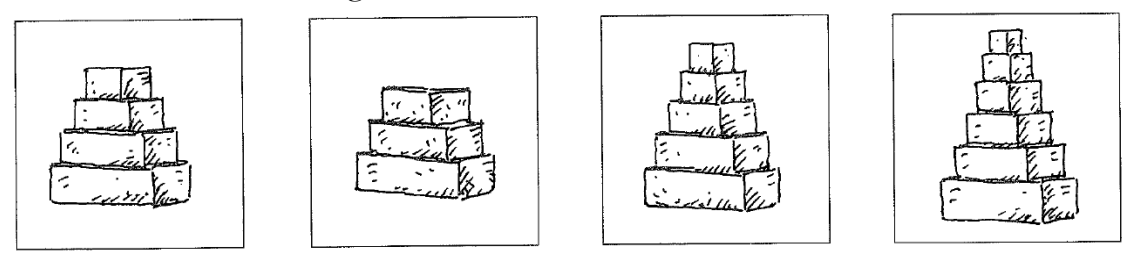

"Which wheelbarrow contains the least sand?"
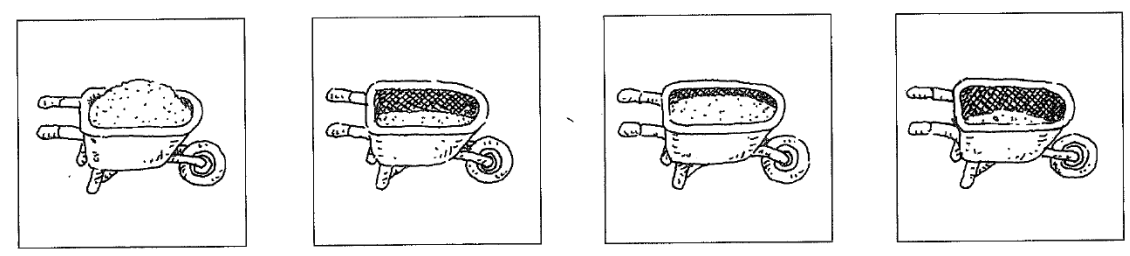

"In which of the boxes are the dolls sorted from fat to thin?"
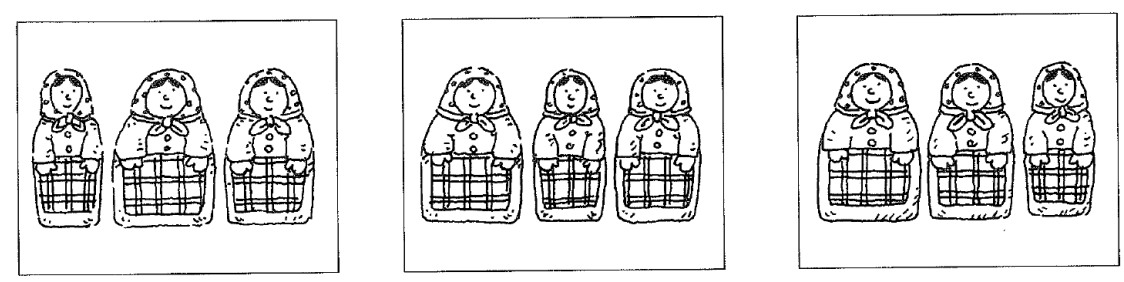

"In which of the boxes are the sticks sorted from long to short?"
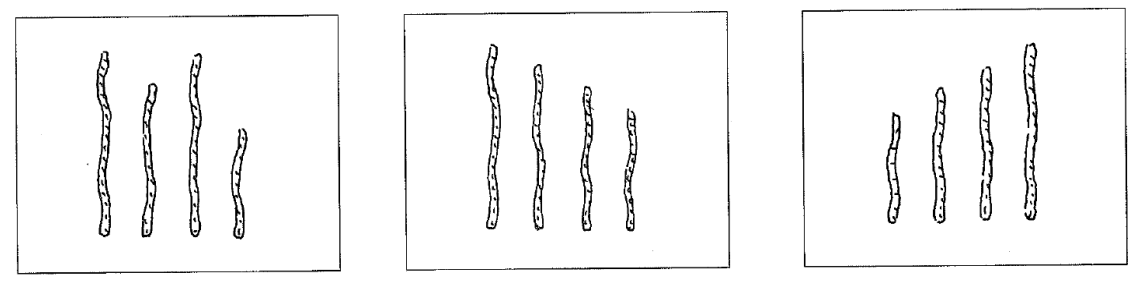
"Which clown has the least hair?"
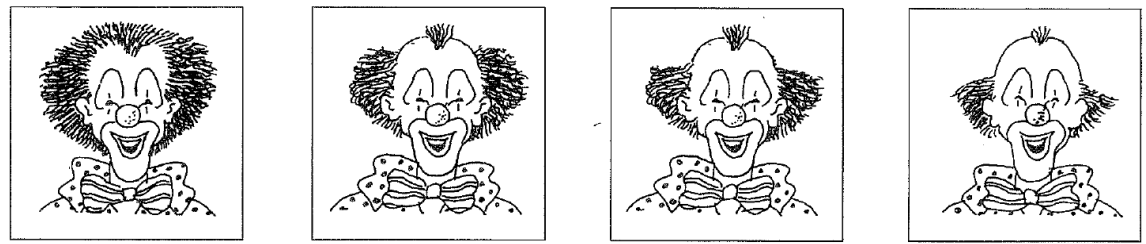

"Which box contains the most mushrooms?"

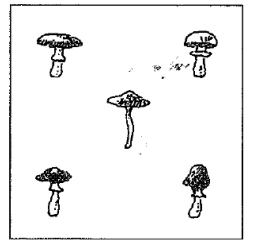

\begin{tabular}{|c|c|}
\hline कृतs & 9 \\
\hline 罩 & 9 \\
\hline di & 烈 \\
\hline
\end{tabular}
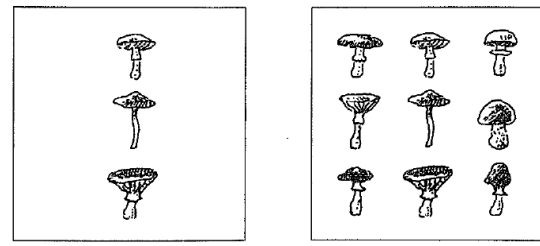

"Which box contains 5 things?"
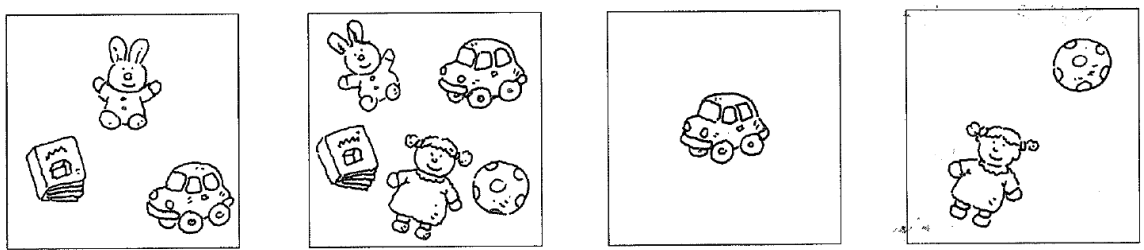

Chapter 5

\section{Does Information Provision Affect Primary School Choice? \\ - The Design of a Field Experiment*}





\section{1 | Introduction}

Chapter three of this thesis shows that parental preferences for school characteristics are heterogeneous. Different socio-economic groups of parents value particular school attributes differently. Preferences for school quality, measured as school average test scores (CITO toets), are relatively weak in comparison to preferences for school proximity. We further show that preferences for school quality increase with the education level of the parents. In chapter four we provide evidence that attending a school that performs better in terms of average CITO scores benefits the early cognitive development of children. We also show that low ability children, who are more likely to have lower educated parents, benefit more from attending a higher quality school. Children with a lower socio-economic background benefit more from a "good" school but their parents seem to care less about school quality. Another explanation is that low educated parents lack information on schools. Therefore one obvious policy recommendation would be to inform parents about the different school options that they face. Children could benefit from the provision of information if parents know and consider quality differences of schools during the choice process. Well-informed choices potentially lead to better educational outcomes either directly through a better school-child match or indirectly through increased school competition in the domain of educational quality offered.

In this chapter we describe a field experiment that we conduct in the city of Rotterdam. We conduct this experiment to investigate how the provision of multidimensional information to parents of children who are about to go to primary school will affect school choice behavior. We will (1) discuss the design of the experiment with a focus on how to measure potential information spillover effects, (2) conduct a simulation of the experiment that provides us with estimates of the expected changes in student numbers at the school level and (3) provide a power analysis that reveals how many participants we need under different effect size scenarios.

In this experiment a randomly selected sample of the families from the city of Rotterdam receives multidimensional information about schools in their neighborhood. This sample is selected from the cohort of primary school starters in Rotterdam. We will provide the treatment group with information on school 
options in their neighborhood. The other half of the cohort will serve as the control group which receives no information about school characteristics. The information that the parents in the treatment group receive is a school comparison table that contains multidimensional, easy to understand information designed to reach all parts of the population. The information sheet is individualized at the household level and contains simplified statistics on student achievements, the assessment outcome of the Dutch Inspectorate of Education, the distance to school, its educational philosophy, religious affiliation and parental satisfaction with different aspects of the 10 closest schools in the neighborhood. Using administrative application and enrollment data, we later will be able to identify which school characteristics affect choice strongest and whether the response of different socio-economics subgroups to the information is heterogeneous. Due to the ex-ante randomization of the assignment to treatment and control group causal effects can be identified.

Since this experiment will be conducted in the field, information spillovers have to be taken in consideration. It is likely that parents in the treatment and control group will talk about the school information provided. We can expect that the control group will face contamination from the treatment group that spreads the provided information in the neighborhood. Since it is not possible to completely avoid information spillover effects in a field experiment like this, our experimental design entails some particular features that allow measuring the size of information spillover. We aim to measure spillovers by varying the amount of information that is available over time and by city district. When more people in a district are provided with information, information spillover effects between treatment and control group become more likely. Differences in spillover effects will translate into differences in the treatment effect and therefore become measurable.

In order to quantify what changes in student numbers we can expect from the provision of information we simulate the experiment using actual residential and school level data from Rotterdam. As mentioned, the information we plan to provide is multidimensional. However, for the simulation we use only distance and school average CITO scores as predictors of choice, since parental sensitivity with respect to test scores has been estimated both in chapter three 
of this thesis and the experiment of Hastings et al. (2008) where test-score information was provided in an experimental way. We therefore model the provision of information as an increase in the sensitivity to school average (CITO) test scores.

We use the predictions of a conditional choice model to provide a distribution of expected changes in student numbers per school. Due to the high sensitivity of parents with respect to school distance the expected average changes in school level student numbers are on average between 0.6 and 1.2 percent. The percentage change for the schools most affected by the information provision is around 6 percent.

In order to quantify how many children need to participate for observing statistically significant results we conduct a power analysis for three different effect size scenarios. The results show that if 500 children take part in the experiment every month, we can expect to observe an impact after 12-24 months depending on the actual effect size.

The experimental character of this study, in particular the randomized provision of information offers research opportunities beyond investigating the short run effect on school choice behavior. If the provided school information indeed affects choice it would be of particular interest to follow the treatment and control group over time and to investigate whether the different school choices made, also have an effect on later outcomes. An informed choice may potentially affect switching rates, parental involvement, scores on achievement tests, student motivation, school satisfaction, truancy rates or crime participation.

This chapter proceeds as follows: Section two provides a short literature overview, section three describes the experimental design and institutional background in detail. Section four contains the simulation with actual choice data from Rotterdam and shows the results of the power analysis. Section five concludes. 


\section{2 | Related literature}

Recently, some experimental and quasi-experimental evidence like Deming et al. (2011), Hastings, Kane and Staiger (2010), and also Hastings, van Weelden and Weinstein (2008) has given insights into how school choice affects student outcomes. The results from the US indicate that children appear to benefit in terms of school achievements when their parents made better informed choices and they therefore received access to higher-achieving schools. ${ }^{39}$ In the following we discuss two studies in more detail since they are of particular importance for the design of our experiment.

The experiment we describe in this chapter is closely related to a recent study by Hastings, van Weelden and Weinstein (2008), who conduct an in some aspects similar experiment in Charlotte, North Carolina (US). The chapter investigates how parental primary and secondary school choice behavior is affected by the provision of information. In this study the randomization is done at the school and choice district level. Parents in the same school or choice district were always either part of the treatment or the control group. The information sheet provided to the treatment group contained a transformation of school average student test scores and the percentage of students admitted in the last year. The control group did not receive any school information. The results show that the provision of information on school test scores has a significant impact on choice behavior. Parents who receive the information sheet are more likely to choose a school with higher average student attainments. The estimated treatment effect was strongest for parents who had higher scoring school alternatives relatively nearby. The authors argue that parents weight the benefits of choosing a higher performing school against the costs of increased traveling distance. The second part of the chapter investigates whether the experiment lead to increased student performance in the treatment group that received the information. Students attending a higher-achieving school benefit in terms of their math and reading test scores from being assigned to the treatment group. They score between 0.37-0.41 student-level standard deviations higher. The results further reveal that children from lower income families benefited less

\footnotetext{
${ }^{39}$ Few other studies e.g. Cullen, Jacob, Levit (2005) do not find an effect of attending a higher-achieving school on student outcomes.
} 
from attending a higher performing school. The authors argue that parents with a lower socio-economic status put lower expressed weights on academic achievements when choosing a school. The authors argue that lower educated parents have weaker preferences for school quality since their children's returns from attending a quality school are low. An alternative explanation for these findings could be that lower SES parents have the same preferences for student attainments, but in addition to that, also have preferences for other school characteristics that were not included in the provided information.

For the Dutch context in which our experiment takes place, there is no experimental evidence so far. Related to primary school choice, Koning and van der Wiel (2013) investigate how parents in the Netherlands react to (changes in) published information about secondary school quality. They show that the "Trouw" school ranking, which is published in local newspapers, is significantly related to next year's student enrolment: negative school quality scores decrease the number of enrolments and positive scores increase the number of students choosing that school. The largest effect is found in the response to scores about academic secondary schools ("VWO"). This suggests that parents of children who are eligible for this track either have stronger preferences for educational quality or are more likely to read the newspaper in which the results are published. The size of the estimates suggests that the impact of the "Trouw" publication is generally small compared to the impact of the overall reputation of a secondary school track or to the impact of the schools' distance from home. The implied willingness to travel for attending a well-performing school rather than an average secondary school is only about 220 meters. Even if parents are well informed, distance to different school options seems to remain the strongest choice driving factor.

Our experiment focusses on primary school choice. In this context parents are the main choosers and choice should be less affected by peer interactions of the student. Our experimental design differs from previous studies in a number of ways. In contrast to Hastings, van Weelden and Weinstein (2008) we conduct the experiment in a setting where choice is virtually unrestricted. Further, we do not provide a one-dimensional quality indicator based on student achievements, but aim to provide a more elaborate picture on schools. Since school quality is difficult to define universally and likely to be subject to individual subjective 
evaluation, as we have shown in chapter 3 , we provide a set of school characteristics from which parents can decide themselves what school attribute represents an important indicator of school quality. What further distinguishes our study from others is that the information we provide is specific for almost every household, it contains information on the characteristics of the 10 closest schools in the neighborhood. In the following section we will describe our experimental design in more detail.

\section{3 | Experimental Design}

In the following section 3.1 we will provide some institutional background information on school choice in Rotterdam. In section 3.2 we will explain how the information that we provide to parents is selected. In section 3.3 we will discuss the experimental procedure and explain how we aim to measure information spillover effects.

\subsection{School choice in Rotterdam}

The experiment that we describe in this chapter is planned for the city of Rotterdam, which is the second largest city in the Netherlands. Traditionally multicultural, about 60 percent of the children in primary education have foreign born parents or grandparents. ${ }^{40}$ Every year around 6500 children start primary education in Rotterdam. Rotterdam has a very high population density and for most families various primary schools are usually available within walking distance.

In the Netherlands, people are generally free to choose primary schools. While in practice some Dutch cities use lottery assignment in order to deal with oversubscriptions, this is not the case in Rotterdam. According to municipality officials, oversubscription or long waiting lists are not a major problem in the city of Rotterdam. This is important in order to treat parental choices as revealed preferences over school characteristics. If the odds of admission had an influence on the decision making, this would have to be incorporated in the information sheet provided and would give the choice process a strategic element.

\footnotetext{
${ }^{40}$ For more details on the composition of primary schools see table A1 in the appendix.
} 
Our experiment focuses exclusively on information provision about primary schools. Primary school in the Netherlands usually begins when children are four years old. During the first two years at school children are mainly busy with preparatory activities and receive no formal schooling. Given the young age of the children it can be assumed that the decision about which school to attend is primarily made by the parents of a child. In Rotterdam, school choice and enrollment is a continuous process throughout the year with a peak in August.

Figure 1 shows histograms for the time of enrollment. In general, there is not one fixed date in the year at which all children start school. The figure shows an enrollment peak at the end of summer holidays in August.

Figure 1: Primary school enrolment in Rotterdam

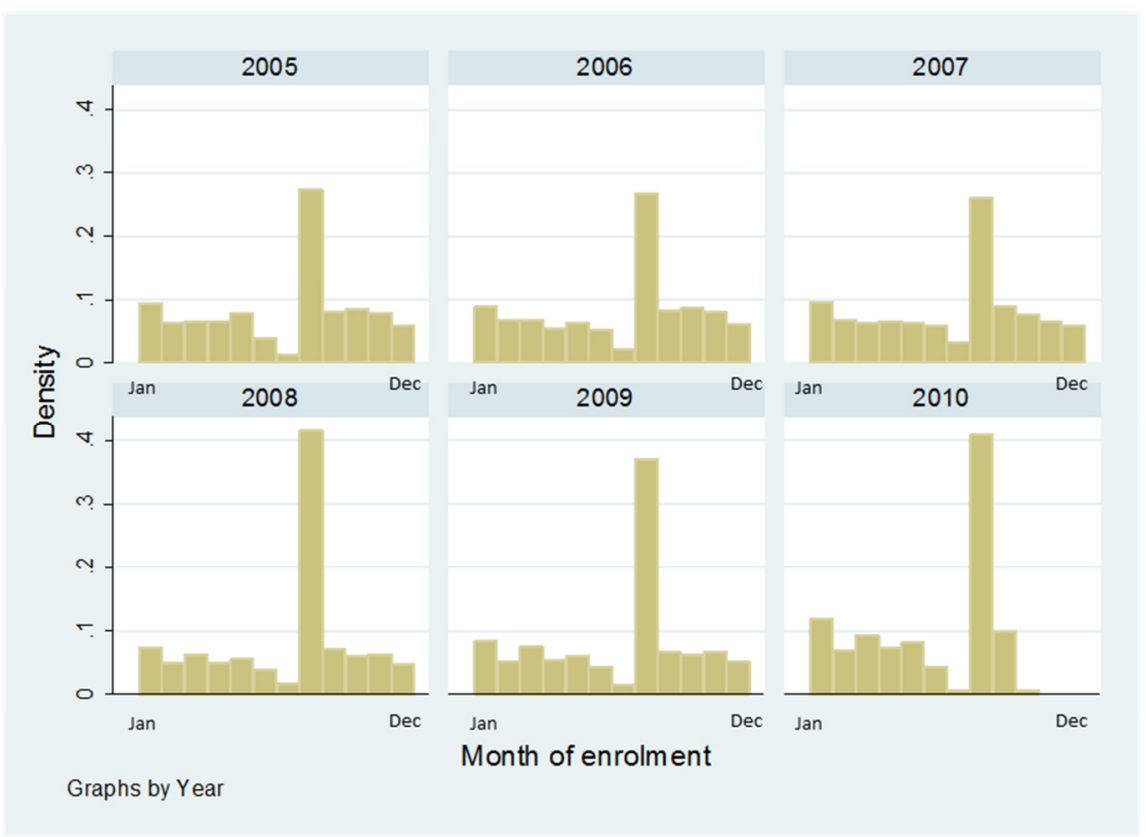


Most children start school around their fourth birthday and we therefore chose to provide the information exactly six months before children turn four. All families in Rotterdam with children at that age receive a letter that informs parents that it is time to choose a school. Attached to this letter is a school enrollment card that can be submitted to the school of choice. For the treatment group of our experiment an information sheet about school options in the neighborhood will be added to this letter. This information sheet will be sent out to parents on a monthly basis. Around six months later, we will observe the outcome of the choice process in administrative enrollment data. In the following we will explain what kind of information will be provided and how the data that we use to design the information card was collected. Section A.5 in the appendix proves an overview on the exact time schedule of the experiment.

\subsection{Information provision}

We will provide the treatment group with a multidimensional picture that displays different facets of school quality. In contrast to the experiment of Hastings, van Weelden and Weinstein (2008) that provides only information about student achievement, we have chosen to provide information on school characteristics from three different perspectives. First, how the school principle describes the school, second how parents evaluate the school based on their experience and third how the Inspectorate of Education assesses the school. Using only school average student achievements appeared unattractive since they are likely to be strongly affected by the composition of the student population. Over the course of designing this field experiment, different versions of the information sheet were tested in three panel discussions with primary school parents in Rotterdam and Maastricht. Based on the insights generated in these discussions with parents, the content and presentation style of information was simplified and adjusted. Reports on these panel discussions and how they affected the design process can be found in section A.5 of the appendix. Figure 2 shows an example of the provided map. Table 1 shows the information sheet that we plan to provide. ${ }^{41}$

\footnotetext{
41 This information sheet serves only as an example. The displayed information does not match existing schools and all cell entries on this sheet were generated from simulated data.
} 
Figure 2: Example map showing non-existing schools
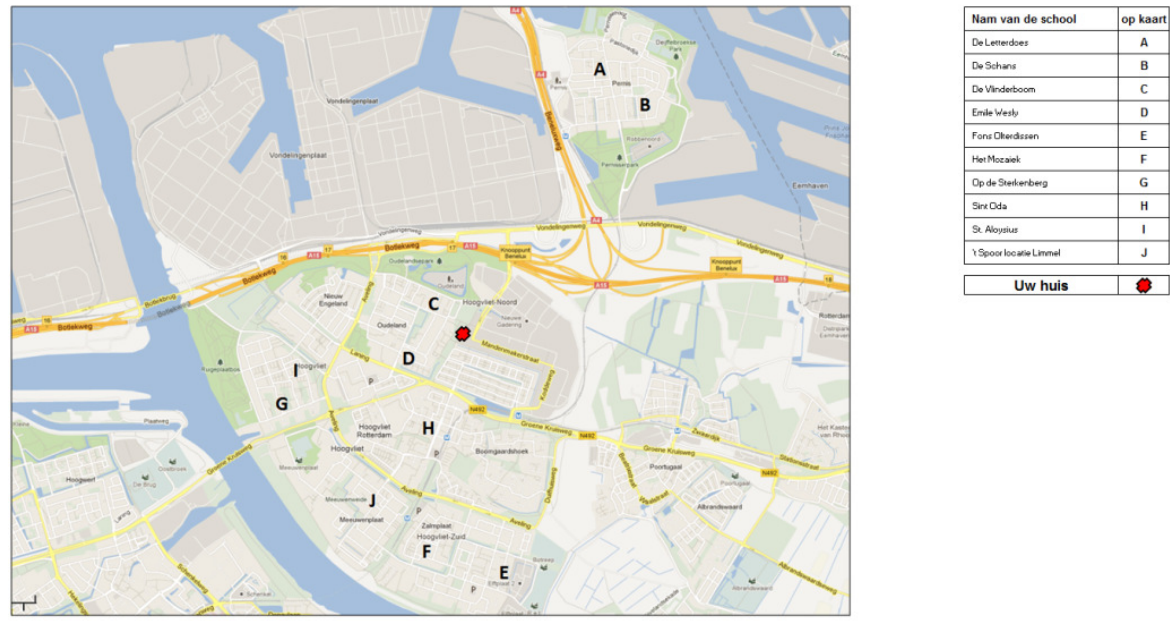

Note: This is an example map. There are no schools existing at the spots marked in the map.

The information sheets are individualized for every household. Conditional on the house address of the family, the ten closest schools are selected and placed on the information sheet. In addition to that, the air distance to these ten surrounding schools is calculated and placed on the sheet together with a local map that indicates the location of the school options in the neighborhood.42 From an analysis of current enrollment data in Rotterdam we know that more than 80 percent of the parents choose one of the ten closest schools. ${ }^{43}$

\footnotetext{
${ }^{42}$ See columns 11 and 12 on table 1 . See also Figure 2 for an example of the map.

43 For more information on how many parents choose the closest schools, the second closest school and so forth see table A2 in the appendix.
} 


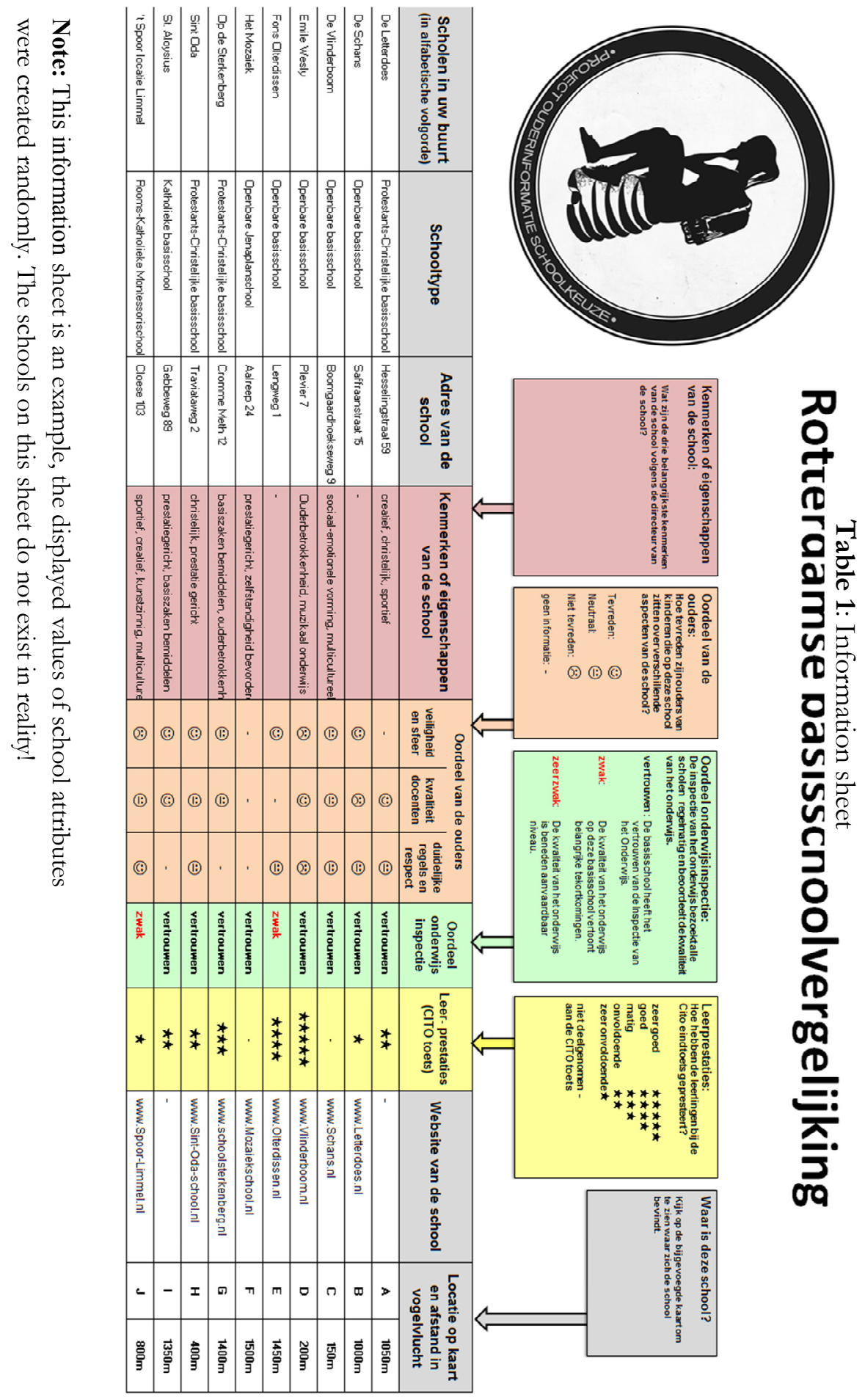

108 | The Design of a Field Experiment | Chapter 5 
The first three columns of the information sheet displayed in table 1 show the name, address and type of a school. Information on the type of the school informs the parents about whether it is a public or private school, the denomination of a school and whether a particular teaching concept is practiced at a particular school. Column four (red) shows how the school describes itself. The collection of these characteristics was done by the Inspectorate of Education via an online questionnaire addressed directly to the primary school director. The column displays up to three attributes or characteristics that are typical for the school according to the director of that particular primary school. More details on the assessment procedure can be found in sections A1 and A2 of the appendix.

The following three orange columns (column five, six and seven) display the satisfaction of parents who currently have children attending that school with three different aspects of the school. These satisfaction domains are "security and atmosphere", "teacher quality" and "clear rules and respect". This assessment of parental school satisfaction will be done using short "postcardquestionnaires", which are sent out to all families that currently have children enrolled in primary education in Rotterdam. The four questions on the card ask about satisfaction with different domains of the daily school life. The original card can be found in the supplementary material in part A.3 of the appendix. The questions have an ordinal answering scale that ranges from 1 "very unsatisfied" to 10 "very satisfied". For the information sheet, the questionnaire answers were averaged at the school level and transformed into three categories of smiley symbols. For this transformation, the distribution of the school average satisfaction was divided into tertiles. The tertile of schools with the most satisfied parents received a laughing smiley, the tertile in the middle a neutral smiley and the tertile of school with the least satisfied parents received an unhappy smiley symbol. The existing data was simplified into these easy to understand symbols in order to reach all parts of the population in Rotterdam. This simplification bears the cost of losing the precision that is present in the original data. The benefit of this simplification is that in particular lower educated families and families with an immigration background may have a more intuitive understanding of smileys than of conditional means and standard deviations. 
Column eight (green) displays the assessment outcome of the Dutch inspectorate of education. The assessment outcome for the primary schools in Rotterdam can either be "trusted" or "weak". In general, there is a third category "very weak", which currently does not apply to any primary school in Rotterdam.

The Dutch Inspectorate of Education monitors school quality with regular visitations at schools and by evaluating schools' student achievements. Parts of the Inspectorate's assessment process are class observations, meetings with pupils, parents, teachers and the school management. The Inspectorate also assesses whether the school is able to perform a reliable self-evaluation and complies with statutory rules and regulations. One additional factor in the process of school evaluation is the schools' average student achievement test scores. For more than 90 percent of the schools in Rotterdam this is the outcome of the CITO test. ${ }^{44}$

The student achievement test that underlies the information in column nine the CITO test - is a student achievement test that is taken by children at the end of primary education. At that time, children have been in primary education for eight year and are on average around 12 years old. The CITO test is a nationwide standardized test that is used to determine which secondary school track a child will attend. Column nine (yellow) displays the transformed school average CITO score. Based on the original distribution of the school average CITO scores in Rotterdam we created five quantiles that correspond to a one to five star ranking system. Schools in the highest of the five quantiles receive five stars; schools in the second largest quintile receive four stars and so forth.

Column ten displays the website of the respective school, where parents can find more information about the schools. Column eleven shows the air distance to every school.

\footnotetext{
44 This number is based on data provided by the municipality of Rotterdam. Some schools perform other end of primary school achievement tests.
} 


\subsection{Randomization procedure and measurement of information spillovers}

We randomly assign children to either the control or treatment group. The assignment is conditionally random on living location and the ethic affiliation of the family. We decided to condition the randomization in order to make sure that the treatment and control group are balanced on these two observables.

One central feature in our experimental design is that we aim to measure information spillover effects. The problem of information spillover effects arises since parents originally assigned to the control group may receive the information that was provided to the treatment group by talking to friends, neighbors or colleges. When spillovers are present, the treatment effect of receiving information will be underestimated. With strong information spillover effects it may become practically impossible to identify a treatment effect. Since it is not possible to completely avoid this type of spillovers in a field experiment of this scale we aim to quantify the size of information spillovers.

It can be assumed that the degree of information spillovers - the control group contagion - will increase relative to the size of the treatment group in the city district and therefore become measurable. Figure 3 shows a simplified map of Rotterdam with 22 different regions. Each of these regions was randomly assigned to one of three types of information regimes. The different shades of grey represent these different regimes. For example in region R1, 20 percent of the population will receive the information and 80 percent will not receive any information. In contrast to that, in region R3, 80 percent of the parents will receive the information sheet and 20 percent will not. In the region R6, 50 percent of the population will receive the information and the remaining 50 percent will not receive any information. If we find that the treatment effect in the 80 percent treated regions is bigger than in the 50 or 20 percent treated regions we can interpret this as strong evidence for the presence of information spillover effects. The difference in effect sizes will represent a lower bound for the size of the spillover. It is important to keep in mind that the difference in treatment effect size can only be attributed to information spillovers if the districts are comparable in terms of population and school characteristics. If this is not the case, it may be necessary to control for these differences in observables. 
Figure 3: Abstract map of Rotterdam with different treatment regions

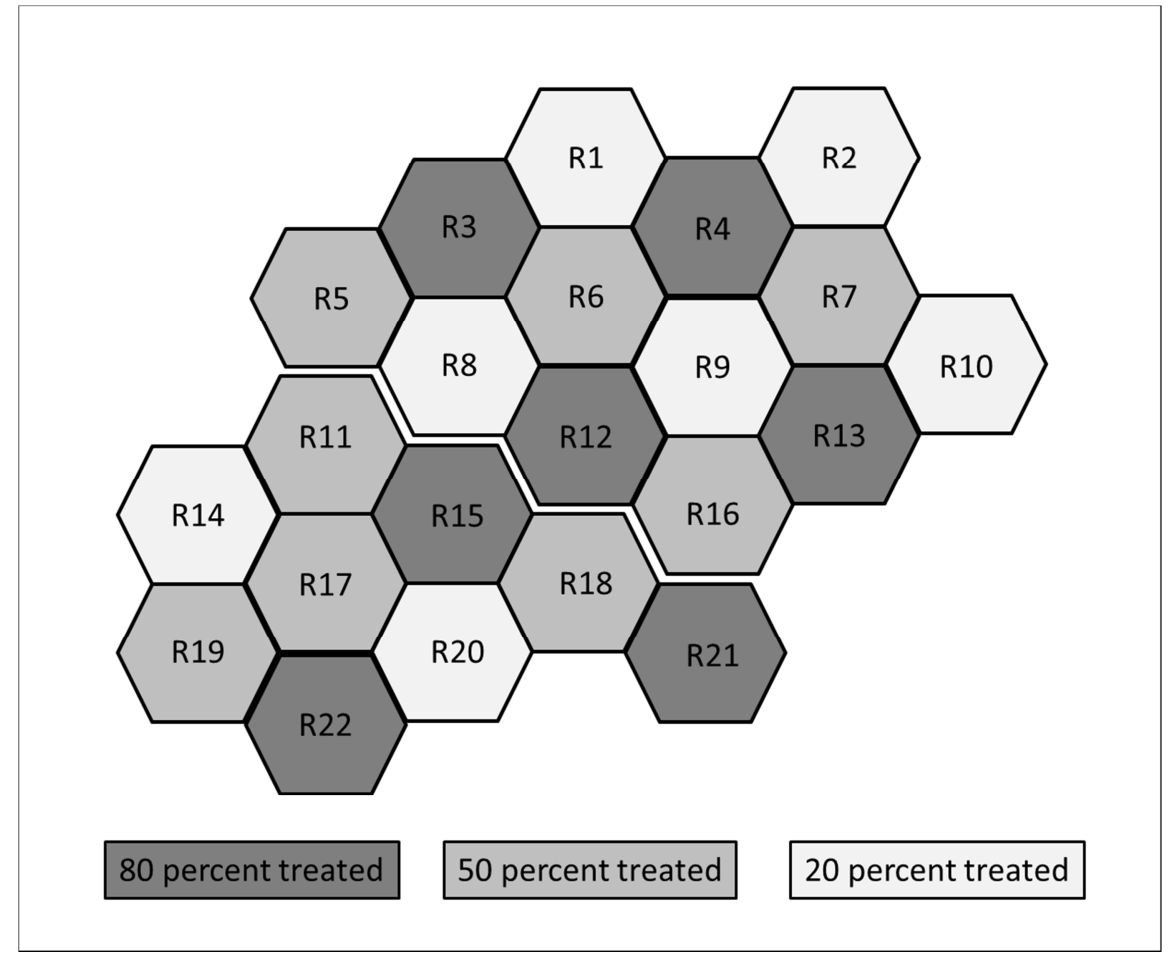

The fact that we provide the information sheets on a monthly basis generates additional variation in the amount of information available in the market over time. Every month that the experiment runs, the number of information sheets that are present in the city increases. As the number of information sheets sent out increases, the probability of control group contagion increases as well. Observing that the treatment effects at the beginning are bigger than those towards the end of the experiment would provide us with additional information about the size of the information spillover effect. In order to identify information spillover effects in this way it is required that no other time-variant unobserved factors affect the school choice behavior of the parents in the control group during the time of the experiment.

In addition to the described approaches we also aim to measure information spillover effects in one additional and more direct way. The information sheet in table 2, that will only be provided to parents in the treatment group, includes a picture of a school girl sitting on a beehive (top left corner). We use the re- 
recognition of this picture as a measure for spillovers. After parents have made their school choice both parents in the treatment and control group will receive a "post-choice postcard". This postcard displayed in section A.3 in the appendix contains a few questions on school satisfaction, alternative choices and asks parents whether they have seen the displayed picture of the "beehive-girl" before. Parents in the treatment group have seen this picture before on the information sheet. Parents in the control group however should not have seen this picture if there was no information spillover. If parents in the control group received access to the information table through colleagues, neighbors or other channels they will be more likely to report that they have seen this picture before. Differences in the picture re-recognition rates between control and treatment group will provide us with an estimate of the actual fraction that was unintentionally treated. This approach will inform us whether spillovers were a severe issue in the experiment and it has the potential to provide us with an estimate of the true treatment effect excluding information spillover effects.

\subsection{Evaluation of the experiment}

In order to evaluate whether the provision of information has an actual effect on school choice behavior we will use administrative school enrollment data provided by the municipality of Rotterdam. Comparing the average characteristics of the chosen schools in the treatment group with those in the control group will directly reveal which of the school attributes on the information sheet affects choice. We further aim to investigate whether the treatment is heterogeneous across the population of the treatment group. For example, parents from a higher socio-economic background may respond stronger to high average student achievements, because they have stronger preferences for school quality. On the other hand these parents may already have a good knowledge about the quality of the surrounding schools and might therefore be less affected by the information provision.

We further aim to evaluate whether the experiment has mid and long run effects beyond the direct effects on parental school choice behavior. If school choice is affected by the information provision we can also assess whether choosing a different school translates into higher student achievements in the future. 


\section{4 | Simulation and power analysis of the experiment}

The simulation in this chapter aims to answer what changes in student numbers schools can expect from the provision of quality information. In experiment of Hastings et al. (2008) conducted in Charlotte, Mecklenburg County, the provision of a one-page information on school tests caused parents to choose schools that had on average 0.05 to 0.10 standard deviations higher test scores. We use this range as a basis for three different effect size scenarios.

The power analysis in this section aims to answer how many observations we need to identify the effect. Since we send out school information on a monthly basis it is possible to stop the experiment any month if outcomes should be undesirable.

We simulate what changes in the local education market we can expect from the provision of test scores given the geographical characteristics of school and housing locations in Rotterdam. Using only distance and school average CITO test scores as predictors of choice is a simplification of the experiment, since the actual information sheet we provide also contains information on other potentially choice relevant school attributes. Taking into account also other school attributes might affect the predicted changes in student numbers depending on the structure of the covariance-matrix of the different school attributes we provide information on.

In order to make the simulation and the power analysis as realistic as possible we apply our simulation to the context and geographical characteristics of Rotterdam. We use administrative data from the municipality on about 44,000 children currently enrolled in primary education in Rotterdam. Based on the actual school locations in Rotterdam and the parental housing locations of the children we then first calculate the distance to surrounding school options and then estimate a conditional logit model of school demand. This approach allows us to estimate a model similar to the models shown in chapter three of this thesis which use data from South Limburg. Table 2 shows a conditional logit estimation for the full sample of primary school children in Rotterdam in column (1). 
Table 2: Preferences for distance and test scores:

Rotterdam vs. South Limburg

\begin{tabular}{lcc}
\hline & $(1)$ & $(2)$ \\
& $\begin{array}{c}\text { School choice in } \\
\text { Rotterdam }\end{array}$ & $\begin{array}{c}\text { School choice in } \\
\text { South Limburg }\end{array}$ \\
\hline Air distance $(100 \mathrm{~m})$ & $-1811^{* * *}$ & $-.2110^{* * *}$ \\
Std. school CITO & $(0.001)$ & $(0.002)$ \\
& $.2783^{* * *}$ & $.1440^{* * *}$ \\
Observations & $(0.008)$ & $(0.011)$ \\
Number of students & $5,170,000$ & 567,703 \\
\hline
\end{tabular}

Note: Standard errors in parentheses; ${ }^{* * *} \mathrm{p}<0.01,{ }^{* *} \mathrm{p}<0.05,{ }^{*} \mathrm{p}<0.1$

Column (2) shows the estimation results for South Limburg. The point estimates for distance are qualitatively similar. Parents in Rotterdam seem to be substantially more sensitive to the school average CITO score. The point estimate is about twice as large compared to the estimation using data from South Limburg. One reason for this could be the more competitive environment or the higher local density of schools in Rotterdam.

For the simulation, we repeatedly draw a sample of 6,000 children from the sample of 44,119 children shown in table 2.45 Each child out of this sample is then assigned to either the treatment or control group with a probability of 50 percent each. For the treatment group the effect of receiving information is modeled as an increase in the sensitivity to school average CITO test scores keeping parental sensitivity to distance constant. This means that they are generally more aware of quality differences. Parents in the treatment group do not only prefer high CITO score schools more, they also dislike schools with a low CITO score more than parents in the control group. Put differently this can be interpreted as parents knowing more about the school quality on both sides of the test score distribution.

45 About 6,000 children start school every year in Rotterdam. 
We perform this procedure for three different scenarios in which we assume that the sensitivity increases by $.10, .15$ and .20 school level standard deviations in test scores. This range appears plausible since it leads to a treatment effect size of similar magnitude as identified by Hastings et al. (2008). ${ }^{46}$

Using the predictions of the conditional choice model for the three different scenarios we obtain a distribution of expected changes in student numbers. Figure 4 shows histograms of the expected changes in student enrollment in percentage points for one full year based on 100 simulations.

Figure 4: Results of the simulation - Percentage changes in student numbers
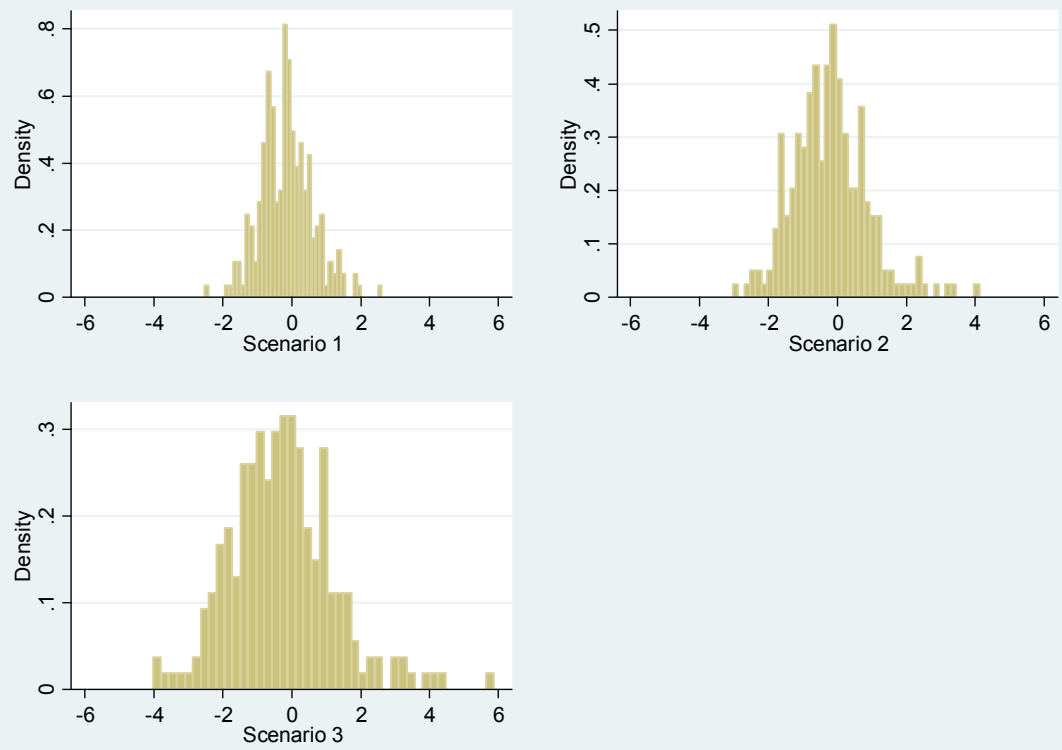

Note: Changes in the percentage of student numbers at the school level for three different scenarios. Scenario 1: 10 percent increased parental CITO sensitivity; Scenario 2: 15 percent increased parental CITO sensitivity; Scenario 1: 20 percent increased parental CITO sensitivity. Based on 100 independent draws.

\footnotetext{
46 This can be seen in the point estimates presented in table 5 where estimates of the treatment effect for 100 simulated draws are provided for the three different scenarios.
} 
Due to the high sensitivity of parents with respect to school distance the expected average percentage point changes in school level enrollments are only 6 for scenario 1, .9 for scenario 2 and 1.2 for scenario 3. The maximum enrollment percentage point change is around 6 percent. These changes are relatively small, since proximity to surrounding schooling options is a predominant driver of parental school choice behavior.

\subsection{Results of the power analysis}

For the power analysis we proceed in a similar way, but gradually increased the sample size in order to compute how many students we need or, put differently, after how many months we can expect significant results. Figure 5 displays the outcome of the power analysis. It shows how likely it is to find significant effects for a given sample size and effect size scenario. The $\mathrm{x}$-axis shows the sample size. The $y$-axis represents the fraction of regressions that identified treatment effects significantly different from zero at the 5 percent level. Every point on the graph is based on 100 underlying regressions. ${ }^{47}$

The graph shows when we can expect to find significant results. Every month about 500 children take part in the study, either in the treatment or control group. In scenario 1 we reach the power threshold of 80 already after 6 months (3,000 students). In scenario 2 we can expect to find significant results after 12 months (6,000 students). For scenario 3, the scenario with the weakest assumed effect size the power reaches 79 after 24 months (12,000 students).

47 These are conditional logit regressions with school choice as the dependent variable. Explanatory variables are distance, CITO and Treatment*CITO. 
Figure 5: Results of the power analysis

- Percentage significant effects identified

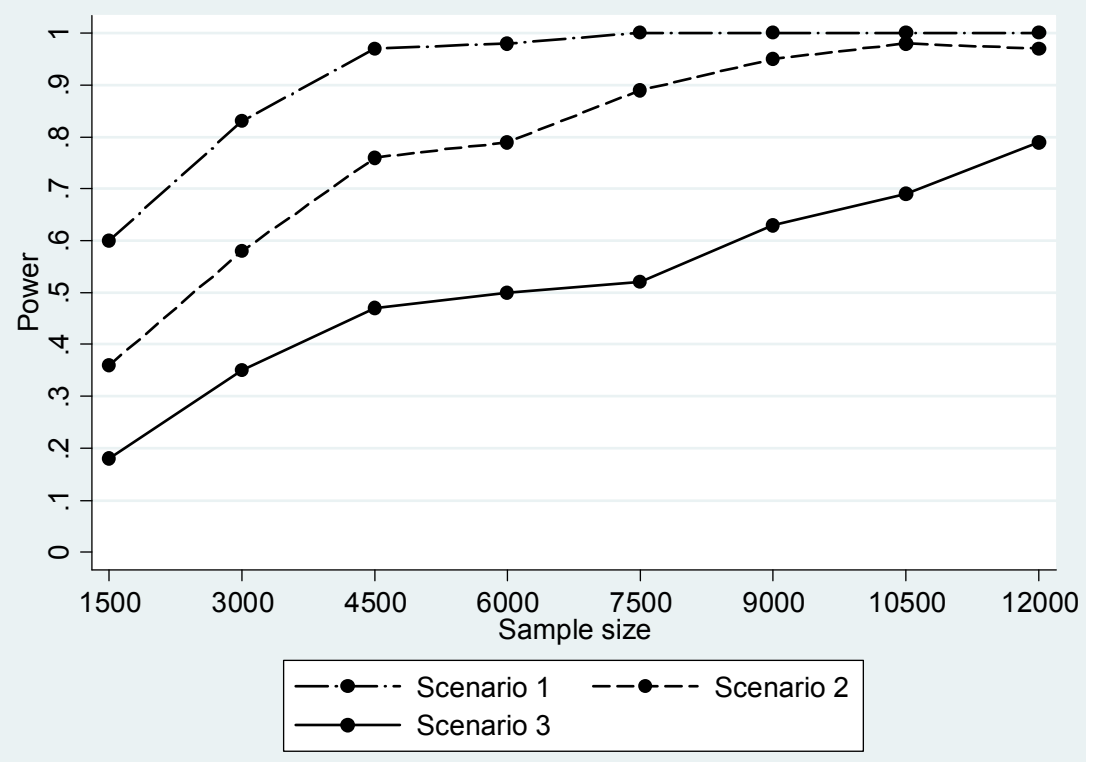




\section{5 | Summary}

The experiment described in this chapter builds upon the findings of chapter two, three and four of this thesis. We propose an experiment that measures to what extend providing information about school characteristics affects choices. Parents in the treatment group receive information on the school profile, test scores, parental satisfaction, the assessment outcome of the Inspectorate of Education and the distance to surrounding schools. The control group receives no information.

Using actual residential and school level data from Rotterdam, we simulate what changes in the local education market we can expect from the provision of test scores. We model the provision of information as an increase in the sensitivity to school average CITO test scores. Using the predictions of the conditional choice model we provide a distribution of expected changes in student numbers. Due to the high sensitivity of parents with respect to school distance the expected average changes in school level student numbers are around $.6-1.2$ percent. The maximum is around 6 percent. Since the information we actually provide is multidimensional, changes in student numbers might be somewhat larger or smaller depending on the covariance of the different school attributes we provide information on. Besides the described and simulated direct effects there may also be indirect effects of receiving information. Sending out information might trigger a thinking process in parents and further investigations that possibly lead to a different school choice.

The experimental design allows identifying the local demand for schools with particular attributes. This experiment will also be able to answer how much weight parents put on different characteristics when choosing a school. We can provide evidence whether the provision of information makes parents choose schools that the Inspectorate of Education considers to be good schools or whether the satisfaction of other parents is a stronger predictor of choice. In the long run it can be investigated whether receiving school information and choosing a different type of school also translates into higher student achievements. 


\section{Appendix}

\section{Additional supplementary material}

\section{A.0 Additional tables}

Table A1: Ethnic affiliations of primary school students in Rotterdam

\begin{tabular}{lc}
\hline Ethnic affiliation & Percentage \\
\hline Dutch & 38.28 \\
Moroccan & 13.91 \\
Turkish & 12.23 \\
Other non-western countries & 10.91 \\
Surinamese & 9.56 \\
Antilles & 4.82 \\
Northern Mediterranean & 3.31 \\
Cape Verdes & 2.70 \\
Other western countries & 2.53 \\
Central and eastern European (CEE) countries & 1.27 \\
Unknown ethnic affiliation & 0.46 \\
\hline
\end{tabular}

Note: Based on administrative date from the municipality of Rotterdam ( $\mathrm{n}=47,941)$

Table A2: Preferences for school proximity

\begin{tabular}{ccc}
\hline Proximity rank of the chosen school & Percent & Cumulative Percentage \\
\hline 1 & 28.56 & 28.56 \\
2 & 15.88 & 44.43 \\
3 & 11.34 & 55.77 \\
4 & 7.54 & 63.32 \\
5 & 5.64 & 68.96 \\
6 & 3.54 & 72.50 \\
7 & 2.70 & 75.20 \\
8 & 2.08 & 77.29 \\
9 & 1.57 & 78.86 \\
10 & 1.50 & 80.36 \\
\hline
\end{tabular}




\section{A.1 Email to the school principal}

Geachte Directie,

Voor ouders kan het lastig zijn om een passende school te kiezen voor hun kinderen. Informatie over scholen in de buurt is niet altijd eenvoudig te vinden. Daarnaast is het de vraag of de beschikbare informatie voor ouders voldoende relevante informatie bevat. Omdat scholen sterk kunnen verschillen, is het voor ouders van belang inzicht te krijgen in de verschillen tussen scholen. Alleen dan kunnen ze de school kiezen die het beste bij hun kinderen past. Een goede match tussen kind en school is vooral belangrijk omdat het de ontwikkeling van het kind ten goede komt. Daarnaast kan een goede schoolkeuze de betrokkenheid van de ouders bij de school versterken en leiden tot meer ouderparticipatie.

Vanaf september 2013 begint het pilot project 'Ouderinformatie Rotterdam', een initiatief van de inspectie van het onderwijs, de gemeente Rotterdam en de Universiteit Maastricht. Een deel van de Rotterdamse ouders krijgt een tabel met informatie over de scholen in de buurt. Om ouders een beeld van uw school te geven, vragen wij $\mathrm{u}$ als directeur het educatieve profiel van uw school weer te geven. Dit kunt u doen door de vragenlijst in uw internet school dossier in te vullen.

U kunt de vragenlijst invullen via http://schooldossier.owinsp.nl. De vragenlijst bestaat uit 5 vragen en het invullen duurt ongeveer 5 minuten. Zou u de vragenlijst willen versturen voor .... zodat wij de informatie op kunnen nemen in de informatie tabel die aan de ouders wordt verzonden.

Vragen

Bij problemen met of vragen over het inloggen op schooldossier.owinsp.nl kan contact worden opgenomen met de Helpdesk van Kennisnet (entree@kennisnet.nl).

Voor vragen over deze brief of de vragenlijst kunt u contact opnemen met het Loket Onderwijsinspectie (www.onderwijsinspectie.nl/site/contactformulier).

Wilt u hierbij uw brinnummer vermelden?

Met vriendelijke groet,

Inspectie van het Onderwijs 


\section{A.2 School online questionnaire}

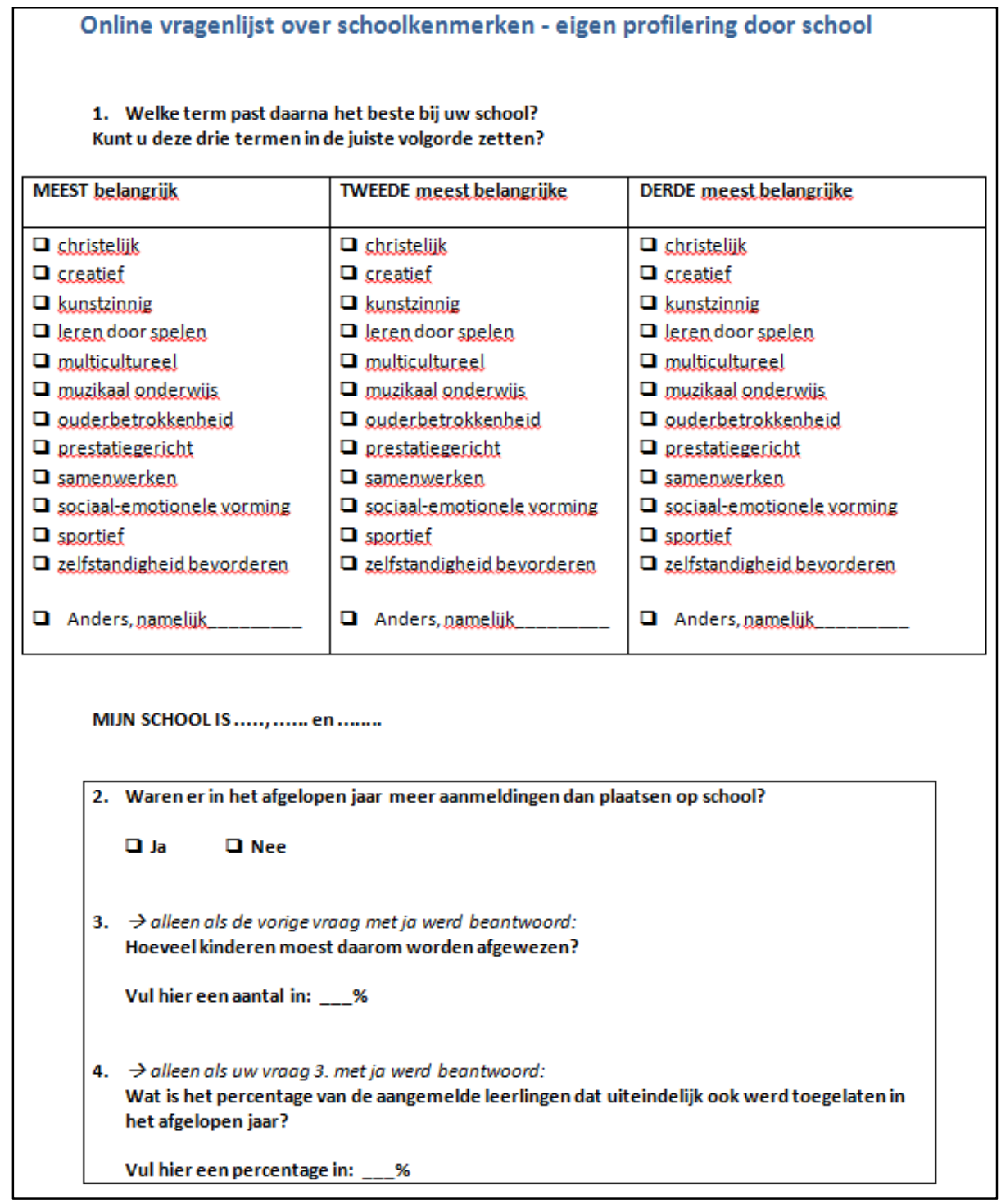




\section{A.3 Parental questionnaire (postcard survey)}

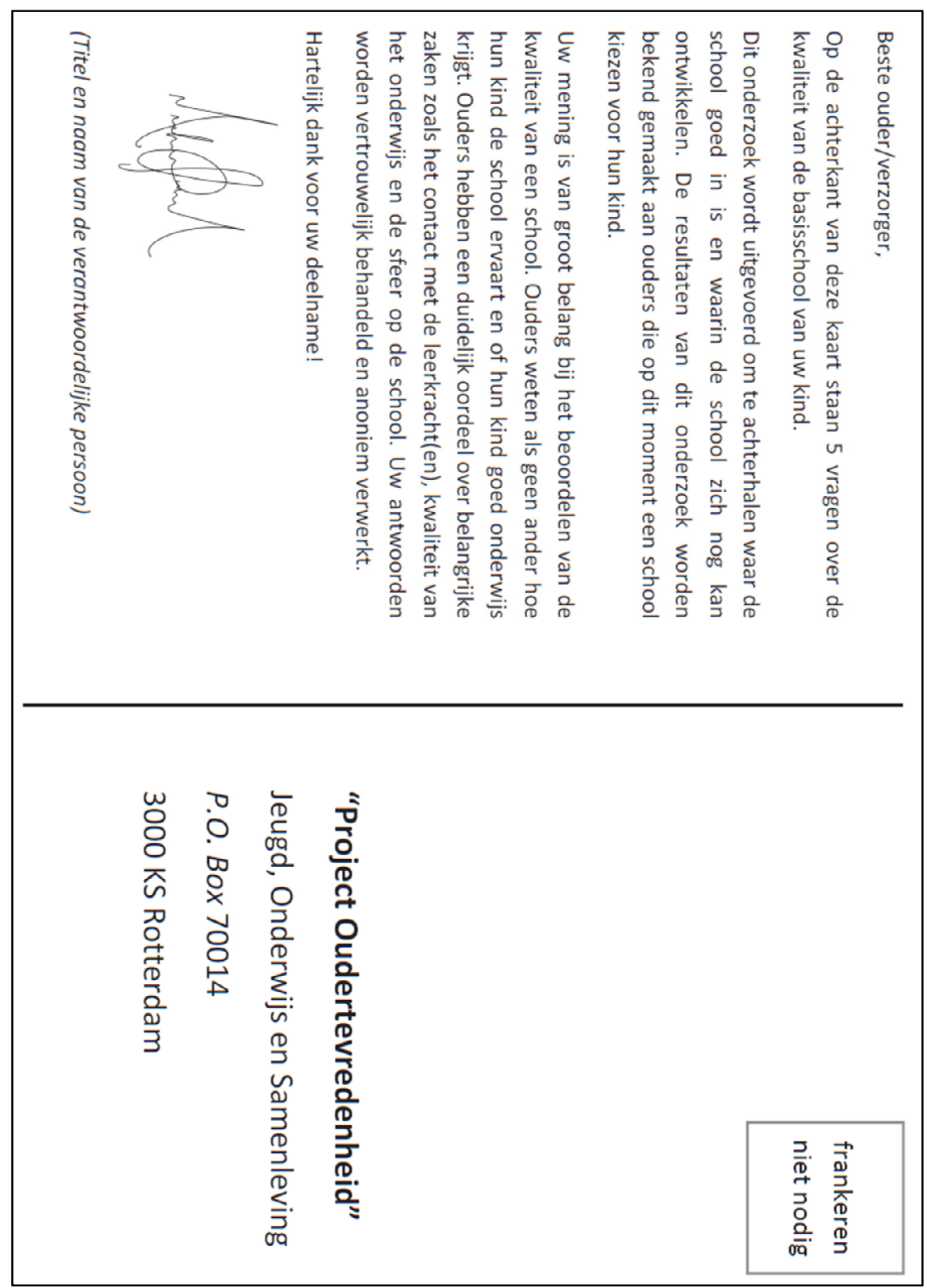




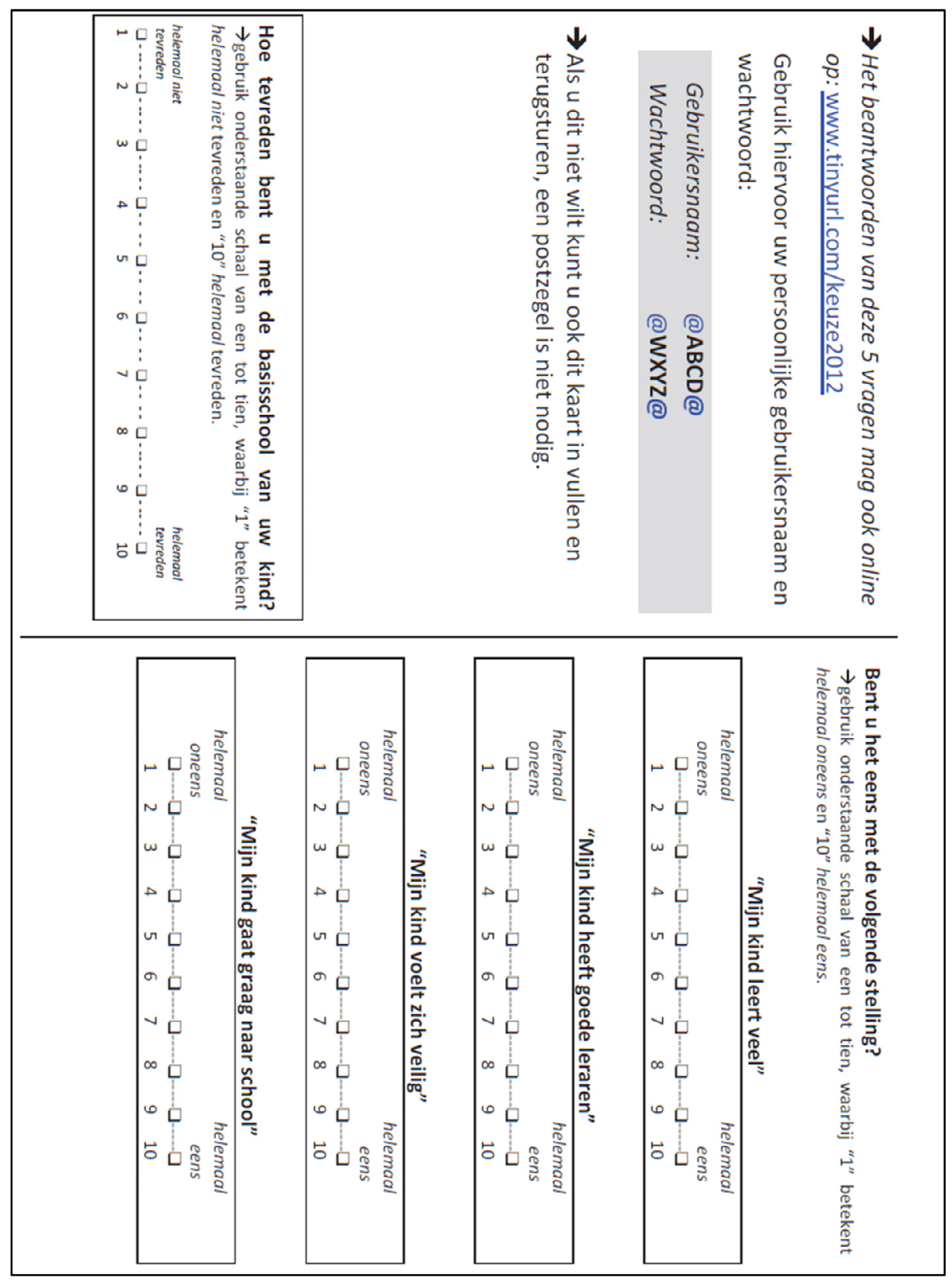


A.4 Parental post-choice questionnaire
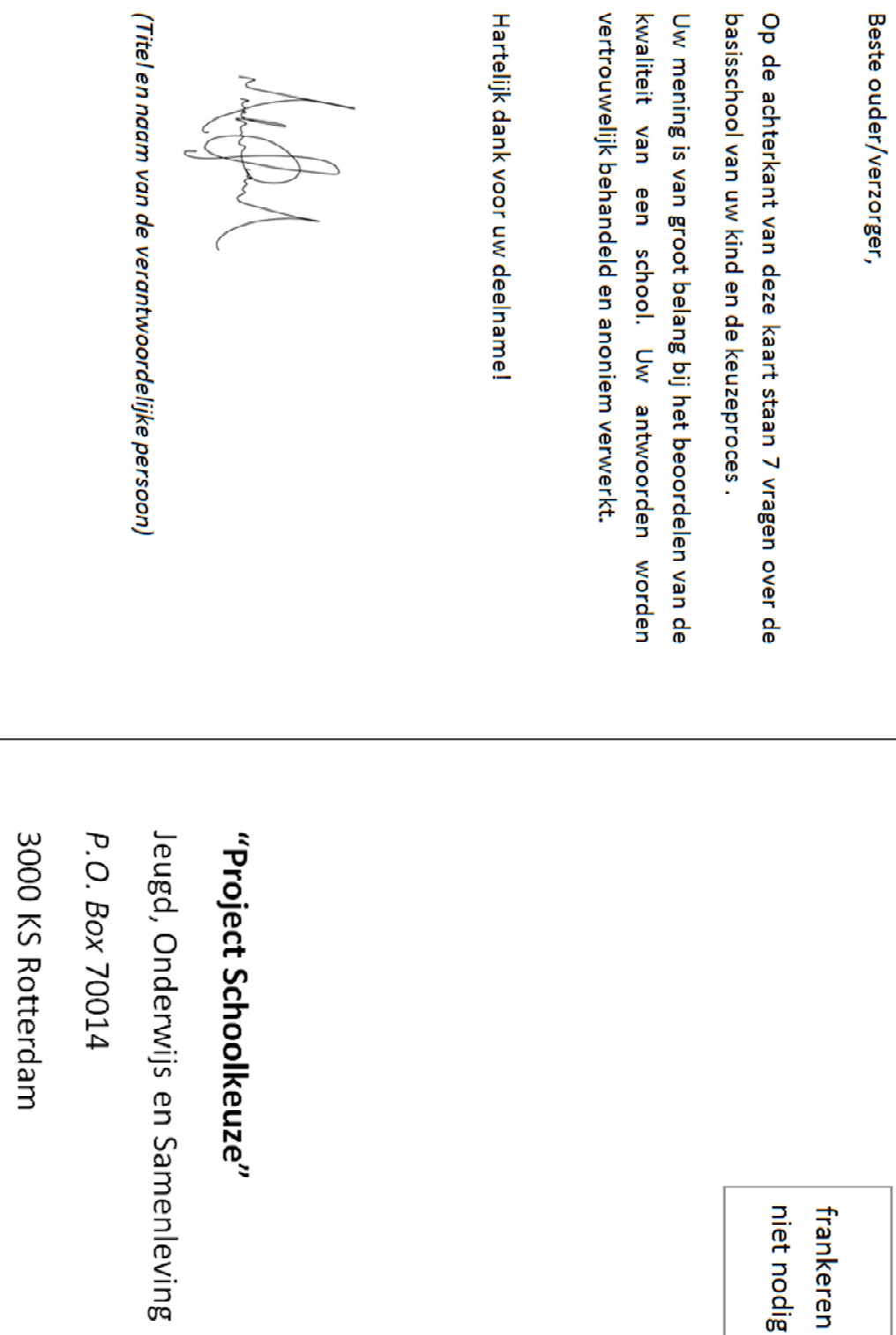

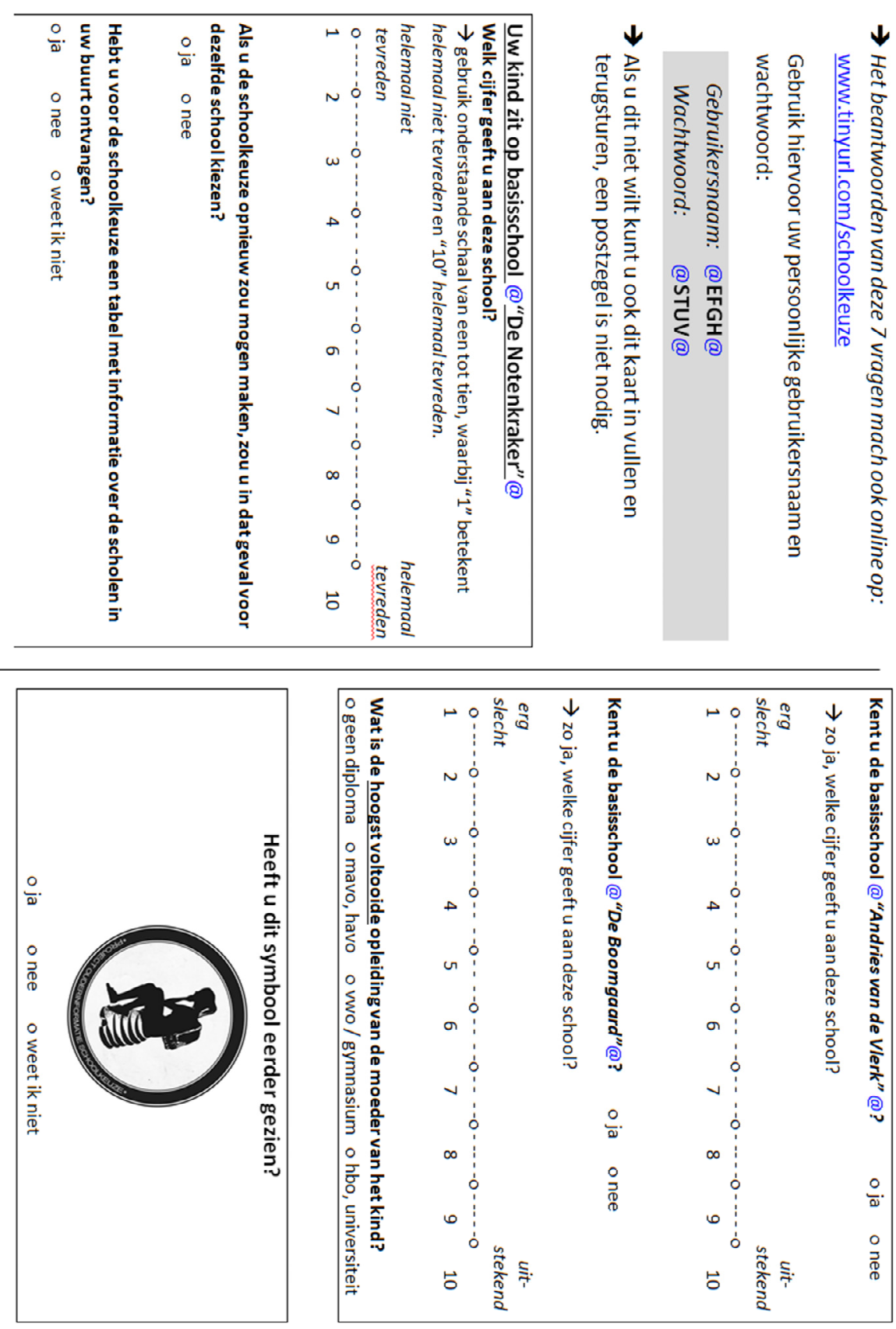


\section{A.5 Test report on the information sheet for parents in Rotterdam}

In order to gain more insights in how parents perceive and understand the information that we put on the information sheet for the project "Ouderinformatie Rotterdam" we organized a qualitative group discussion with "allochtone vrouwen" in Maastricht.

The group discussion took place at the $27^{\text {th }}$ of June at the home of a Moroccan family in Maastricht. We decided to organize the discussion here since we feared that the women might not be willing to come to the university and would participate less in the discussion in the clinical and less familiar environment of Maastricht University. Every participant received a VVV voucher of 10 euros. The meeting took about an hour and eleven women from Morocco (7), Turkey (2), Afghanistan (1) and the Netherlands (1) participated. All women had children and therefore at least some experience with primary education and school choice. One of the participants was not able to read and at least two more had major difficulties with reading in general.

The women recognized the purpose of the information sheet but had major difficulties with understanding the meaning of the different school characteristics. Although none of them knew the inspection of education, the women recognized that a red "zwak" has a negative meaning. The meaning of the CITO score was clear to most of them, but some expressed that they would dislike a school with a too high CITO score, because they feared their children would have a hard time to a school that could be too difficult them.

When asked which school they would choose if they had to choose a school for their child most of them did not trade off different characteristics, but chose the one with the most smileys. It was not fully clear to them that the displayed smileys were the results of parental questionnaires. This should be made clearer in the improved information table. Most of the participants placed a very high importance on the school characteristic "veiligheid". One mothers explicitly mentioned that the finds the police patrols on the school grounds of her sons school very important. 
It was also interesting to hear how they define a good school and what their experiences were with primary education. A repeatedly mentioned definition was: "A good school should have high level of security and teach children respect".

The results of this group discussions are important for the project "ouderinformatie Rotterdam" since more than $60 \%$ of the children in Rotterdam that attend primary education come from an immigration background (CPS 2011).

Taking into account the results of this first group discussion we will adjust the language that is used in the headlines of the table and try to make some school characteristics easier understandable for both families from a lower and higher socioeconomic background. 


\section{A.6 Time schedule of the experiment}

Figure F1 provides an overview of the for the experiment planned activities. In September 2013 we will send out surveys to all schools of the city in which we conduct the experiment. We will ask the head of the school to report features of the school and a questionnaire will include items that should measure the involvement of parents and the experienced degree of competition in the local "'education market"'.

The main information provision will start in January 2014 when we send out letters to the parents of prospective pupils. All future first graders of one year will be randomly assigned into one of the two treatment groups or the control group. The parents in the two treatment groups will receive information about the schools in their neighborhood. Parents in the control group will not receive any information from us. The random assignment of the three groups with different information sets is crucial to attribute observed differences in school choice to the received Treatment.

Using administrative data the actual school choice will be observable in June/July 2014. Directly after the choice is made we will survey the "'new"' parents about their reasons for choosing one school. The questionnaire should not only investigate the motives for school choice, but also which importance parents give to school choice. We will also ask them what their second and third choice would have been. If the effect of the provided information was not strong enough to influence the actual decision we might still observe changes in the perception of local schools.

A repeated survey to schools will be sent out in September 2014. Again we will ask questions about the experienced degree of competition and the involvement of parents. If the field experiment increases local competition, the head of the school might report more competition than in the year before. 
Figure F1: Timetable of the experiment

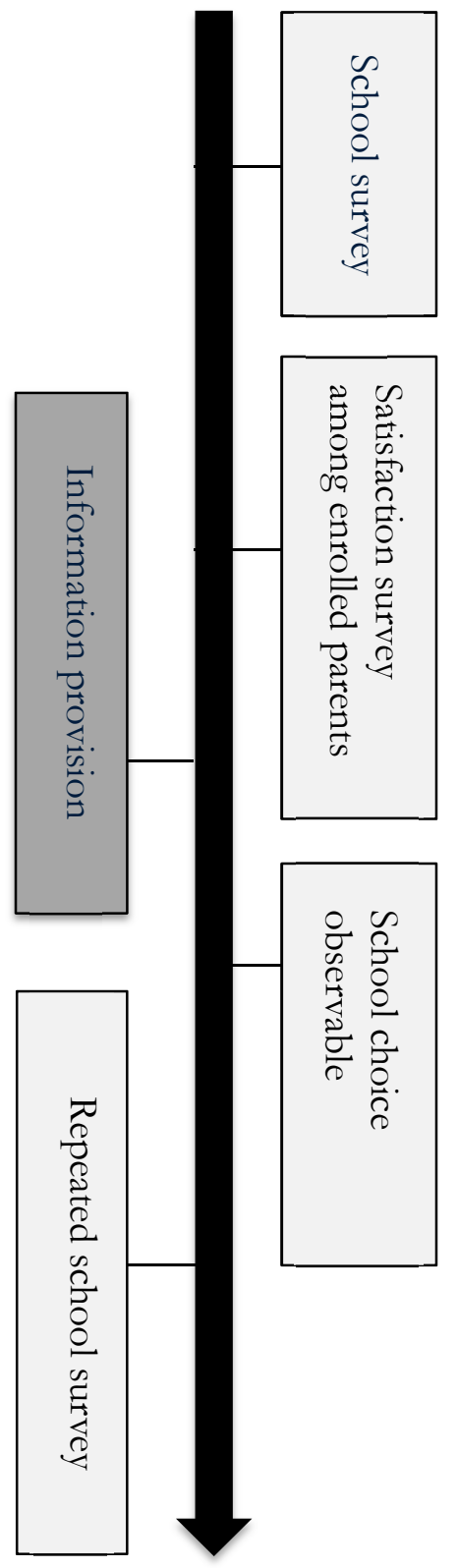






\section{Chapter 6}

\section{Bad Apples and Blinding Lights - On the Nature of Peer Effects in Academic Achievement ${ }^{*}$}

*This chapter is based on joined work with Jan Feld. We thank Joël Castermans, Sanne Klasen and Kim Schippers from the SBE Scheduling department and Sylvie Kersten from the SBE Exams office for providing data and valuable background information. We further like to thank Lex Borghans, Armin Falk, David Figlio, Bart Golsteyn, Nicolás Salamanca, Benedikt Vogt and participants at the Maastricht University DUHR-AIO seminar for helpful discussions and comments. 



\section{1 | Introduction}

Peer effects in education appear if students' achievements in education are affected by interacting with each other. The size and sign of these peer effects might not only depend on the average abilities of the classroom peers, but also on the degree of heterogeneity and the ability of particular individuals in the classroom. "Bad apples" might impose negative learning externalities on their peers, for example through disruptive behavior. "Shining lights" might have a positive effect on the learning of others. If the size of peer effects is substantial, optimized student grouping could increase the amount of accumulated human capital at a relatively low cost.

In this chapter we study the nature of university class peer effects on student grades. The aim of this chapter is to identify which moments of the peer quality distribution affect student achievement. We provide evidence on the role of class homogeneity and to which degree peer effects are heterogeneous with respect to student ability. In particular we test whether "one bad apple" and "one shining light" could have a particularly negative (positive) effect on student outcomes.

The dataset we use consists of all students enrolled at the School of Business and Economics (SBE) at Maastricht University over a period of three years, which amounts to 7,831 students and 42,170 student grades. Our identification exploits (conditionally) random assignment of students to classes within courses. Following the standard approach in the literature, we use a pre-treatment indicator of peer quality: the average GPA of the peers, to avoid the reflection problem as described by Manski (1993).

In the linear-in-means specification, we find that being assigned to a class with on average higher performing peers increases the student's grade in that course by a statistically significant, but small amount. One standard deviation increase in the average peer GPA causes a .0085 standard deviation increase in the individual student grade. As expected under random assignment, the size of our estimate is unaffected by the inclusion of large sets of teacher fixed effects and fixed effects for other courses taken at the same time, and is robust to several alternative model specifications. The peer effects we identify are heterogeneous: Low ability students benefit more from being assigned to peers with a high 
average GPA. Our results are in line with the "one bad apple" model. We find that students perform better when the worst student of the class has a higher GPA. Surprisingly, we do not find support for the "one shining light" model. We present evidence for the contrary: Students seem to be held back by the presence of a very good peer. The size of these effects is small in absolute terms, but relatively big when compared to the linear-in-means specification.

Studies that use random class assignment for identification of peer effects are rare and in particular evidence from western settings is lacking. ${ }^{48}$ This work is to the best of our knowledge the first that uses random assignment to estimate peer effects at the university classroom level. ${ }^{49} \mathrm{We}$ believe we are also the first to provide clear evidence on the negative effect of "bad apples" and "shining lights". At the post-secondary level, other studies have exploited (conditionally) random assignment to dorm room and living communities to estimate peer effects. The roommate literature generally finds small positive or no significant peer effects (Brunello et al., 2010; Sacerdote, 2001; Zimmerman, 2003). Carrell et al. (2009) investigate peer effects at the squadron level at the United States Air Force Academy (USAFA)..$^{50}$ They find peer effects which are larger in magnitude than estimates from the roommate studies. In a similar setting at the West Point military college, Lyle (2007) does not find significant peer effects but this might be due to limited variation in peer quality. De Paola and Scoppa (2010) investigate a sample of 212 Italian university students and use random first year assignment of students as an instrument for current university peers. They find that a one standard deviation increase in peer quality measured as first year GPA increases exam performance by .11 standard deviations (OLS

\footnotetext{
48 See Duflo et al. (2011) for evidence from peer effects in non-western settings.

${ }^{49}$ Peer effects at the university level, as compared to pre-university education, might not only be different in size but also follow different dynamics. On the one hand, university students, as opposed to students in pre-university education, are more homogeneous, spend less time in the classroom and invest a greater share of their time in self-study. This would suggest that peer effects are generally less important at the university level. On the other hand, students learn arguably more from each other in classroom discussions and study groups and comparably less from the classroom instructor 50 The squadron is the living community at the campus of the USAFA where students have much of their social and academic interactions. Classes, however, are composed of members of different squadrons.
} 
estimation) and .19 (IV estimation). ${ }^{51}$ Martins and Walker (2006) use the fact that the allocation of students to classes is conducted alphabetically by last names. In their sample of 441 students they do not find significant effects of classroom peers.

The remainder of the chapter is structured as follows: Section 2 provides information about the institutional environment and the assignment procedure of students to classes. Section 3 discusses the dataset and the sample restrictions. Section 4 provides evidence that the assignment to classes is random, controlling for scheduling constraints. Section 5 describes our empirical strategy. Section 6 shows the estimation results. Section 7 concludes.

\section{2| Background}

\subsection{Institutional environment}

The School of Business and Economics (SBE) of Maastricht University is located in the south of the Netherlands and has currently about 4,200 students enrolled in Bachelor and Master programs. Because of its proximity to Germany it has a large German student population (53 percent) mixed with Dutch (33 percent) and other nationalities. About 37 percent of the students are female. The academic year at the SBE is divided into four regular teaching periods of two months and two skills periods of two weeks. Students usually take two courses at the same time in the regular periods and one course in the skills period. We exclude courses in skills periods from our analysis because these are often not graded and we could not always identify the relevant peer group. ${ }^{52}$

The courses are organized by course coordinators, mostly senior staff, and most of the teachers are $\mathrm{PhD}$ students and teaching assistants. The classes usually have two weekly sessions of two hours each. Each course is divided into classes of maximum 16 students which are the focus of our analysis. The course

\footnotetext{
51 This effect is observed over a time periods of one to two years.

${ }^{52}$ In some skills courses, for example, students are scheduled in different classes which end up siting together in the same room.
} 
size ranges from 1 to 638 students and there are 1 to 43 classes per course. Most courses also have lectures which are followed by all students of the course and are usually given by the senior staff.

The SBE differs from other universities in its focus on Problem Based Learning (PBL). The general PBL setup is that students generate questions about a topic at the end of one session and then try to answer these questions through self-study outside the class. In the next session the findings are discussed in class. In the basic form of PBL the teacher takes only a guiding role and most of the learning is done by the students independently. Courses, however, differ in the extent to which they give guidance and structure to the students. This depends on the nature of the subject covered, with more difficult subjects usually requiring more guidance, and the preference of the course coordinator and teacher.

The PBL system is arguably more group focused because most of the teaching happens in small classes and the sessions are more interactive than lectures. Much of the students' peer interaction happens with members of their class, either in the meetings, during work for common projects or in learning groups.

\subsection{Assignment of students to classes}

The Scheduling Department of the SBE assigns students to classes, teachers to classes, and classes to time slots. Before each period, there is a time frame in which students can register online for the courses they want to take. After the registration deadline, the scheduler gets a list of registered students and allocates the students to classes with a computer program leaving about ten percent of the spots per class empty for late registrations. ${ }^{53}$ This procedure balances the amount of late registration students over classes. Before the start of the academic year 2010/11, the class assignment for Master courses and for Bachelor courses was done with the program Syllabus Plus Enterprise Timetable using the allocation option "allocate randomly" (see figure F1 in the Appendix). Since

\footnotetext{
53 The number of empty spots the scheduler leaves open depends on the number of late registrations from previous years and differs by course. 5.6 percent of the students register late.
} 
the academic year 2010/11 all Bachelor classes are stratified by nationality with the computer program SPASSAT. ${ }^{44}$ Some Bachelor courses are also stratified by exchange student status. After the assignment of students to classes, the classes are assigned to time slots and the program Syllabus Plus Enterprise Timetable indicates scheduling conflicts. ${ }^{5}$ This happens for about 5 percent of the initial assignment. If the computer program indicates a scheduling conflict the scheduler manually switches students from different classes trying to resolve all scheduling conflicts. After all classes have been allocated to time slots, the scheduler assigns teachers to the classes. ${ }^{56}$ The next step in the scheduling procedure is that the class and teacher assignment is published. After this, the scheduler receives information on late registering students and allocates them to the empty spots. Throughout the scheduling process, the scheduler, who does not know the students, does not observe the previous grades of the students.

We use the class that a student is being assigned to define the peer group. Only 20-25 students (less than one percent) officially switch class per period. Class switching is only possible through a student advisor and is only allowed for medical reasons or due to conflict with sports practice for students who are on

\footnotetext{
54 The stratification goes as follows: the scheduler first selects all the German students (which are not ordered by any observable characteristic) and then uses the option "Allocate Students set SPREAD" which assigns an equal number of German students to all classes. Then the scheduler repeats this with the Dutch students and lastly distributes the students of all other nationalities to the remaining spots.

55 There are four reasons for scheduling conflicts: (1) The student takes another regular course at the same time. (2) The student takes a language course at the same time. (3) The student is also teaching assistant and needs to teach at the same time. (4) The student indicated non-availability for evening education. By default all students are recorded as available for evening sessions. Students can opt out of this by indicating this in an online form. Evening sessions scheduled from 6 p.m. to 8 p.m. and about three percent of all sessions in our sample are scheduled for this time slot.

56 About ten percent of teachers indicate time slots when they are not available for teaching. This happens before they are scheduled and requires the signature from the department chair.
} 
a list of top athletes. ${ }^{57}$ There is some unofficial class switching that takes place for a single session when students have extra appointments, but permanent unofficial switching of classes rarely takes place. ${ }^{58}$ There are a few exceptions to this general procedure which we discuss in section 3. After removing these exceptions, in our estimation sample neither students nor teachers, and not even course coordinators, influence the class composition.

\section{3 | Data}

We obtained data for all students taking courses at the SBE during the academic years 2009/2010, 2010/2011 and 2011/2012. Scheduling data was provided by the Scheduling Department of the SBE. The scheduling data include information on class assignment, the allocated teaching staff, information on which day and time the sessions took place as well as a list of late registrations for our sample period. In total we have 7,831 students, 452 courses, 7,939 classes and 42,170 grades in our estimation sample. Panel A of table 1 provides an overview of courses, classes and students in the different years. ${ }^{59}$

The data on student grades and student background, such as gender, age and nationality were provided by the Examinations Office of the SBE.

The Dutch grading scale ranges from 0 to 10 , with 5.5 being the lowest passing grade. Figure 1 shows the distribution of final grades in our estimation sample.

\footnotetext{
${ }^{57}$ We do not have a record for these students and can therefore not exclude them. However, class switching in these rare cases is mostly due to conflicts with medical and sports schedules and therefore unrelated to class peers.

58 It is difficult to obtain reliable numbers on unofficial switching. From our own experience and consultation with teaching staff we estimate that session switching happens in less than 1 percent of the sessions and permanent unofficial class switching happens in less than 1 percent of students.

${ }^{59}$ We refer to each course-year combination as separate course. That means that we count a course with the same course code that takes place in three years as three separate courses.
} 
Table 1: Descriptive statistics

Panel A

\begin{tabular}{cccccc}
\hline $\begin{array}{c}\text { Academic } \\
\text { year }\end{array}$ & $\begin{array}{c}\text { Number of } \\
\text { courses }\end{array}$ & $\begin{array}{c}\text { Number of unique } \\
\text { students }\end{array}$ & $\begin{array}{c}\text { Number of } \\
\text { classes }\end{array}$ & $\begin{array}{c}\text { Average number of } \\
\text { students per class }\end{array}$ & $\begin{array}{c}\text { Number of } \\
\text { grades }\end{array}$ \\
\hline $2009 / 10$ & 121 & 3,909 & 1,155 & 13.31 & 12,257 \\
$2010 / 11$ & 163 & 4,113 & 1,457 & 13.11 & 14,855 \\
$2011 / 12$ & 168 & 4,242 & 1,327 & 14.20 & 15,058 \\
All years & 452 & 7,831 & 3,939 & 13.78 & 42,170 \\
\hline
\end{tabular}

Panel B

Obs. Mean S.D. Min 25p Median 75p Max

Student level information

Course dropout

Grade first attempt

Final grade

GPA

$\begin{array}{cccccccc}45949 & 0.08 & 0.27 & 0 & 0 & 0 & 0 & 1 \\ 42170 & 6.54 & 1.93 & 0 & 6 & 7 & 8 & 10 \\ 43004 & 6.74 & 1.73 & 0 & 6 & 7 & 8 & 10 \\ 45949 & 6.76 & 1.25 & 0 & 6.08 & 6.96 & 7.57 & 10\end{array}$

Class level information

$\begin{array}{lllllllll}\text { Number of students registered for class } & 45949 & 13.55 & 1.31 & 5 & 13 & 14 & 14 & 16\end{array}$

$\begin{array}{lllllllll}\text { Number of students that dropped class } & 45949 & 1.22 & 1.41 & 0 & 0 & 1 & 2 & 10\end{array}$

$\begin{array}{lllllllll}\text { Peer GPA (based on final grades) } & 45949 & 6.72 & 0.48 & 3.04 & 6.4 & 6.74 & 7.06 & 8.75\end{array}$

$\begin{array}{llllllllll}\text { Peer GPA (based on first sit grades) } & 45917 & 6.49 & 0.52 & 1.9 & 6.15 & 6.5 & 6.84 & 8.75\end{array}$

Within class standard deviation of peer GPA

$\begin{array}{llllllll}45949 & 0.91 & 0.33 & 0 & 0.68 & 0.89 & 1.12 & 4.58\end{array}$

Student Background information

\begin{tabular}{lccccccccc} 
Age & 42537 & 20.82 & 2.26 & 16.19 & 19.21 & 20.49 & 22.07 & 43.25 \\
Female & 42537 & 0.37 & 0.48 & 0 & 0 & 0 & 1 & 1 \\
Dutch & 45949 & 0.31 & 0.46 & 0 & 0 & 0 & 1 & 1 \\
German & 45949 & 0.49 & 0.5 & 0 & 0 & 0 & 1 & 1 \\
Bachelor student & 45949 & 0.78 & 0.41 & 0 & 1 & 1 & 1 & 1 \\
BA International & & & & & & & & \\
$\quad$ business & 45949 & 0.39 & 0.49 & 0 & 0 & 0 & 1 & 1 \\
BA Economics & 45949 & 0.28 & 0.45 & 0 & 0 & 0 & 1 & 1 \\
Exchange student & 45949 & 0.07 & 0.25 & 0 & 0 & 0 & 0 & 1 \\
\hline
\end{tabular}

Note: This table shows the descriptive statistics of the estimation sample. 
The final course grade is often calculated as the weighted average of multiple graded components such as the final exam grade, class participation grade, class presentation grade or midterm paper grade. The graded components and their respective weights differ by course, with most courses giving most of the weight to the final exam grade. For some courses part of the final grade consists of group graded components such as a group paper or a group presentation, for which all members of the group receive the same grade. The influence of these group grades on the final course grade might be one of the channels through which peers affect grades. Unfortunately, we only observe the final grade and not its individual components. If the final course grade of a student after taking the final exam is lower than 5.5, the student fails the course and has the possibility to take a second attempt at the exam. Grades below 5.5 are unreliable because course coordinators have different policies regarding failing students. ${ }^{60}$ We observe final grades after the first and second attempt separately.

Figure 1: Distribution of grades after the first examination

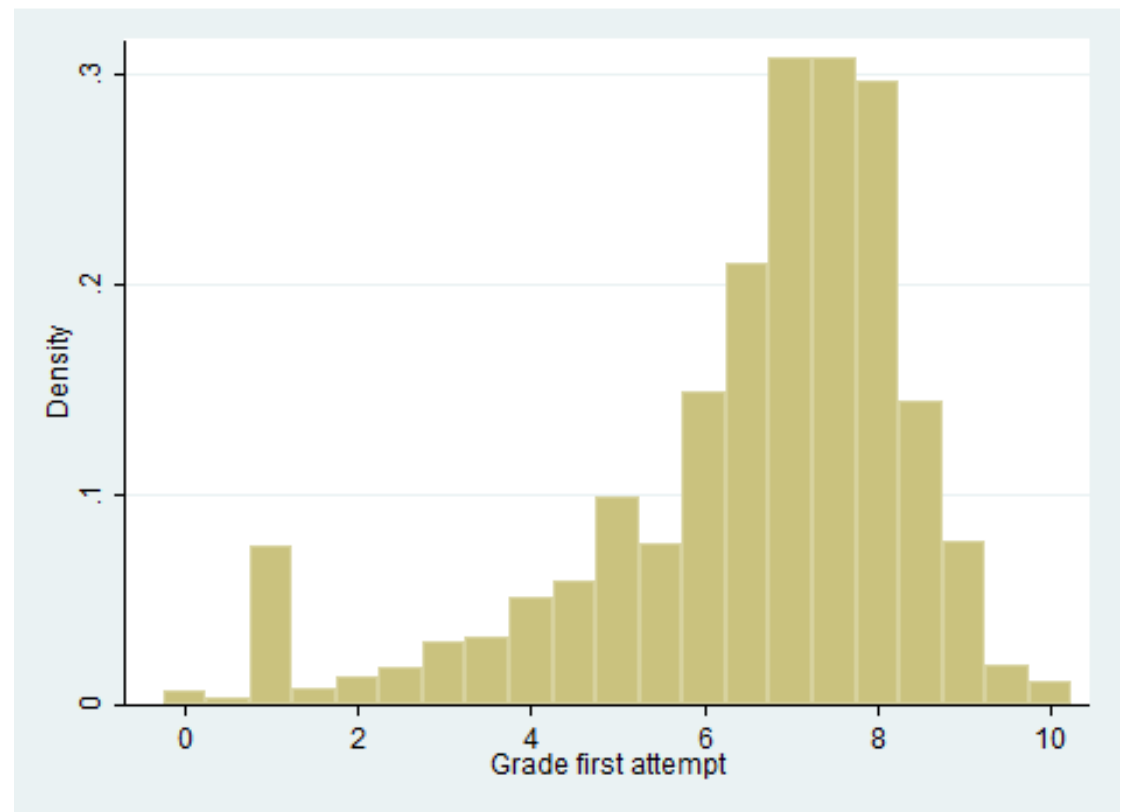

Note: Student grades after the first exam attempt. $\mathrm{N}=42,170$

\footnotetext{
${ }^{60}$ A systematic policy of giving all failing students a grade of 1 can easily explain the spike at grade 1 in figure 1.
} 
For our analysis we only use the final grade after the first exam attempt as an outcome measure, since first and second attempt grades are not comparable. ${ }^{61}$ For the construction of the student GPA we use the final grades after the last attempt. ${ }^{62}$

We excluded a number of special courses and classes where the class assignment was not random. When the number of late registering student exceeds the number of empty spots, the scheduler makes new classes which mainly consist of late registering students. We excluded eight late registration classes from the analysis. ${ }^{63}$ For some Bachelor courses there are special classes consisting mainly of repeating students. Whether a repeater class is created depends on the preference of the course coordinator and the number of repeating students. We excluded 34 repeater classes from the analysis. In some Bachelor courses students who are part of the Maastricht Research Based Learning (MARBLE) program are assigned to separate classes and these classes often get a more experienced teacher. Students of this program are typically the highest performing students of their cohort. We excluded 15 classes that consist of MARBLE students from the analysis. ${ }^{64}$ In six courses the course coordinator or other education staff influenced the class composition. We excluded these courses from our analysis. Some Master tracks have part time students. Part time students are scheduled mostly in evening classes and there are special classes with only part time students. We excluded 95 part time students from the analysis. Each teaching period 20-25 students (less than one percent) officially switch classes. We excluded first year first period courses of the two largest Bachelor

61 The second attempt exam usually takes place two months after the first exam.

${ }^{62}$ We decided to use the GPA calculated from final grades because this is closer to the popular understanding of GPA. However, using the GPA constructed from only on first attempt grades does not qualitatively affect our main results.

${ }^{63}$ Students who register late, for example, generally have a lower GPA and might be particularly busy/stressed in the period which the register late which also might affect their performance in this course. This might create a spurious relationship between GPA and grade which is due to factors like stress.

${ }^{64}$ We excluded pure late registration classes, repeater classes and MARBLE classes from the data. The scheduler confirmed the classes which we identified as repeater classes. The algorithm by which we identified late registration classes and MARBLE classes is available upon request. 
programs (International Business and Economics) because in these courses only particular students, such as repeating student, have previous grades. Moreover, we exclude classes for which less than five students had a past GPA. For these courses the peer GPA does not reliably capture the peer quality of the students in the class. We excluded classes with more than 16 students (two percent) because the official class size limit according to scheduling guidelines is 15 and in special cases 16. Classes we observe with more than 16 students are a result of room availability constraints or special requests from course coordinators.

Panel B of table 1 shows some descriptive statistics for our estimation sample. Our sample contains 45,949 student course registrations. Out of these 3779 (8 percent) dropped out of the course throughout the course period. We therefore observe 42,170 course grades after the first sit. Dropping out of a course means that a student was registered for a course but did not receive a grade. The average course grade after the first attempt is 6.54 . About one fifth of the graded students obtain a course grade lower than 5.5 after the first attempt and therefore fail the course. The average final course grade (including grades from second and third time attempts) is 6.74 , and the average GPA is 6.76 .

The peer GPA is the class average GPA excluding the grades of the student of interest. ${ }^{65}$ The mean of the class level standard deviation of the GPA is 1.17. For 93 percent of our sample we know the age, gender and nationality of the students. ${ }^{66}$ Figure 2 shows the distribution of peer quality measured as the average past GPA of all other students in class.

\footnotetext{
${ }^{65}$ For a more detailed explanation, see section 4 where we describe our empirical strategy.
}

${ }^{66}$ We do not know age, gender and nationality for most of the exchange students. 
Figure 2: Distribution peer GPA

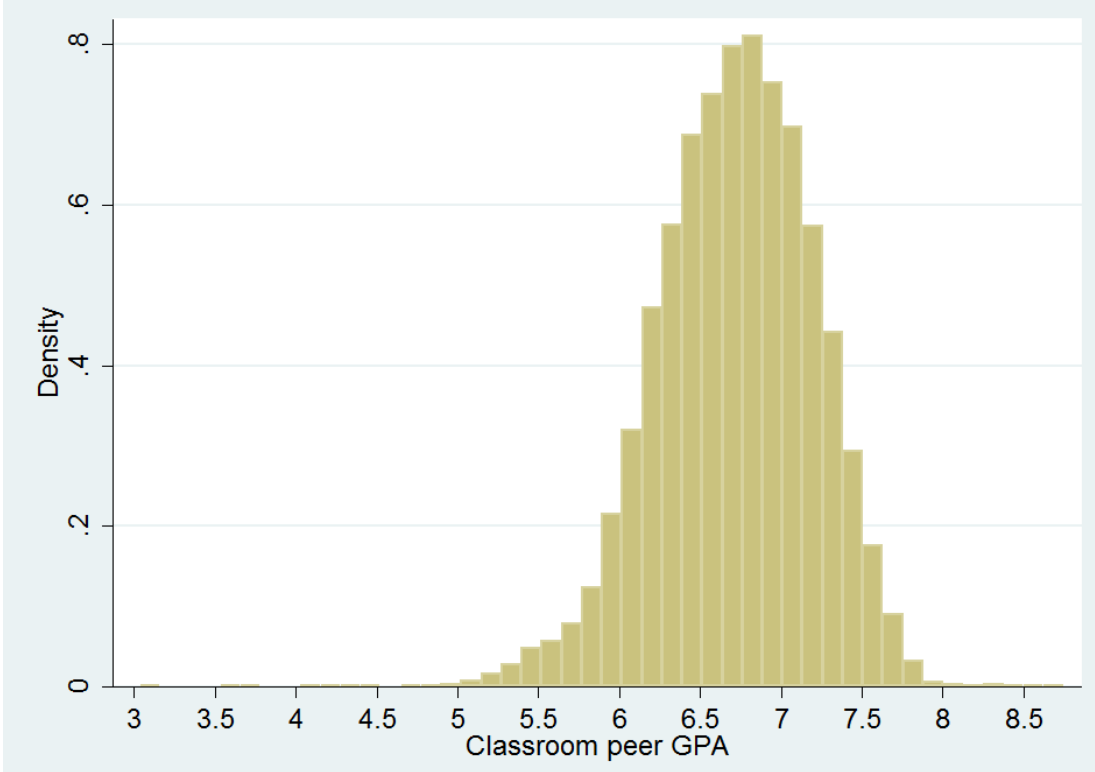

Note: Distribution class peer GPA. $\mathrm{N}=45,949$

\section{4 | Test for random assignment of students to classes}

The description of the scheduling procedure in section 2.2, and especially the fact that the scheduler does not know the students, suggests that allocation is random. Nevertheless, we want to test whether class assignment has the properties which one would expect under random assignment. In the spirit of standard randomization checks in experiments, we test whether class dummies jointly predict student pre-treatment characteristics when controlling for scheduling constraints. More specifically, for each course in our sample we perform an Ftest of joint significance of the class dummies in a regression of student pretreatment characteristic on class dummies and scheduling controls. Under conditional random assignment the p-values of these F-tests should be uniformly distributed with mean 0.5 (Murdoch et al. 2008). Furthermore, if the students are randomly assigned to classes within each course, the F-test should reject the null hypothesis of no relation between class assignment and students' pretreatment characteristics at the 5 percent, 1 percent and 0.1 percent significance level in close to 5 percent, 1 percent and 0.1 percent of the cases, respectively. 
Section A2 in the appendix provides a more detailed description on our randomization check. All together, we present strong evidence that the class assignment in our estimation sample is random, conditional on the observable scheduling and stratification indicators.

\section{5 | Empirical Strategy}

When trying to estimate peer effects there are three main empirical challenges. The first challenge is the so-called reflection problem, as defined by Manski (1993), which states that student and peer outcomes are both determined simultaneously and one cannot disentangle the effect from the peers on the student from the effect of the student on the peers. In order to avoid the reflection problem we follow the standard approach in the recent peer literature and use pre-treatment measures for student and peer ability (e.g. Carrell et al., 2009; Lyle, 2007). The second challenge is selection into peer groups. The estimation of peer effects is biased when peer group assignment is related to unobservable characteristics correlated with student outcomes. However, we do not face this selection problem because the assignment of classes is random conditionally on scheduling constraints, as we have shown in section $4 .{ }^{67}$ The third challenge, which has so far received little attention in the peer-effects literature, is that peers might also influence the probability of observing an outcome. In our case this means that measures of peer quality could affect course dropout rates. Good peers might enhance student learning and therefore increase the students' probability to take the exam. On the other hand, observing higher performing peers in class might lower the students' confidence in passing the exam. Ignoring the effect of peers on dropout behavior could bias the peer effects on grades in an unpredictable way.

\footnotetext{
${ }^{67}$ Note also that non-random assignment would only bias our estimates if the reasons for non-random assignment are related to unobserved characteristics that are correlated with the student outcome.
} 
We use the following model to estimate the effect of peers on dropout behavior and grades:

$$
Y_{i c t}=\alpha+\beta_{1} \overline{G P A}_{c-i, t-1}+\beta_{2} G P A_{i, t-1}+\gamma^{\prime} Z_{i c t}+\varepsilon_{i c t}
$$

The dependent variable $Y_{i c t}$ is the outcome (dropout/grade) of student $i$, in a course-specific class $c$, at time $t . \alpha$ is a constant; $\overline{G P}_{C-i, t-1}$ is the average past GPA of all the students in the class excluding student $i, G P A_{i, t-1}$ is the past GPA of student $i ; Z_{i c t}$ is a matrix of additional controls and $\varepsilon_{i c t}$ is an error term with the usual properties. Note that both $\overline{G P A}_{c-i, t-1}$ and $G P A_{i t-1}$ are constructed excluding period $t$ in order to avoid the reflection problem. We standardized $G P A_{i t-1}$ and $\overline{G P A}_{c-i, t-1}$ over the estimation sample to simplify the interpretation of the coefficients and to facilitate comparison with other studies. In all specifications, $Z_{i c t}$ consist of dummies for day and time of the sessions, German, Dutch, exchange student status and late registration status, and year-course-period fixed effects. The year-course-period fixed effects control for mean differences in outcomes across courses and time. This takes into account different grade levels in different years and courses with differing degrees of difficulty. In other specifications we also include other-course fixed effects - i.e. fixed effects for the other course taken at the same time - and teacher fixed effects. Conceptually, including scheduling controls and othercourse fixed effects should pick up all non-random variation in class assignment that is due to conflicting schedules. Including stratification controls should increase the precision but not affect the size of the estimates. Teacher fixed effects should control for potential non-random assignment of teachers to classes. To allow for correlations in the outcomes of students within each class, we cluster the standard errors at the class level.

\section{The effect of peers on dropout behavior}

Table 2 reports marginal effects from probit regressions with course dropout as the dependent variable. The four columns show models with different fixed effects specifications. Column (1) and all other specifications include dummies for day and time of the sessions, German, Dutch, exchange student status and 
late registration status, and year-course-period fixed effects. ${ }^{68}$ Column (2) additionally includes teacher fixed effects, column (3) additionally includes othercourse fixed effects, and column (4) includes both teacher fixed effects and other-course fixed effects. ${ }^{69}$

As it turns out, class peer quality, measured as standardized peer GPA, does not significantly predict course dropouts in any of the specifications. This finding assures us that our estimates of peer effects on grades do not suffer from selection bias. The issue of peer caused drop out behavior is neglected in most research on peer effects (e.g. Burke \& Sass, 2013; Carrell et al., 2009; Lyle, 2007).

Table 2: Course dropping and class peer quality (probit regression)

\begin{tabular}{lcccc}
\hline & $(1)$ & $(2)$ & $(3)$ & $(4)$ \\
& Dropout & Dropout & Dropout & Dropout \\
\hline \multirow{3}{*}{ Standardized peer GPA } & & & & \\
& -0.0015 & -0.0012 & -0.0011 & -0.0005 \\
Standardized GPA & $(0.002)$ & $(0.002)$ & $(0.002)$ & $(0.002)$ \\
& $-0.0575^{* * *}$ & $-0.0575^{* * *}$ & $-0.0565^{* * *}$ & -0.0565 \\
& $(0.001)$ & $(0.016)$ & $(0.005)$ & $(0.041)$ \\
Observations & & & & \\
Course FE & 45,723 & 45,723 & 45,723 & 45,723 \\
Staff FE & YES & YES & YES & YES \\
Other course FE & NO & YES & NO & YES \\
\hline
\end{tabular}

Note: Robust standard errors clustered at the class level are in parentheses; ${ }^{* * *} \mathrm{p}<0.01,{ }^{* *} \mathrm{p}<0.05,{ }^{*} \mathrm{p}<0.1$. This table reports marginal effects at the mean of probit regressions with course dropout (1 if dropout) as dependent variable. All specifications include dummies for day and time of the sessions, German, Dutch, exchange student status and late registration status. Other course FE means that we control for other courses taken at the same time period.

${ }^{68}$ For some classes the time and day of the sessions were missing. We include separate dummies for these missing values.

${ }^{69}$ Other-course fixed effects are dummies for the other course taken in the same period. These are only defined for students that take up to two courses per period. In only $1.5 \%$ of the cases students were scheduled for more than two courses. Teacher fixed effects are fixed effects of the first teacher assigned to a session. For less than 0.4 percent students have different teachers in one class. 
In many cases dropout behavior is unobserved, but reported estimates on peer effects are conditional on observing outcomes (e.g. grades). However, if peers affect both dropout probabilities and outcomes, the estimated peer effects on observable outcomes may be biased.

\section{6 | Results}

Table 3 shows marginal effects of tobit regressions with the standardized grade as the dependent variable. ${ }^{70}$ We use tobit instead of OLS estimation and censor our data at the standardized grade equivalent of 5.0 because grades below 5.5 might be affected by different course grading policies. Estimations of uncensored OLS regressions show similar result with somewhat larger point estimates and are available in table A1 in the Appendix.

Table 3 shows that being assigned to class peers with a higher GPA causes higher course grades. The coefficient of standardized peer GPA is very small but statistically significant in all models. The inclusion of teacher fixed effects and other-course fixed effects does not change the effect size or its standard errors. The marginal effect reported in the most conservative specification in column (4) shows that being assigned to peers with one standard deviation higher GPA increases the student's grade by 0.0085 standard deviations. This means that, for example, an increase of peer GPA from 6.5 to 7.0 is associated with a grade increase from 6.50 to 6.516 , a very small and economically insignificant effect.

\footnotetext{
${ }^{70}$ We apply tobit regressions since due to different grading policies at the course level grades below 5.5 might be unreliable. Based on the decision of the course coordinator students might be graded differently when failing an exam. Since this effect is non-linear and applies only for grades lower than 5.5 , it is not captured by the course fixed effects.
} 
Table 3: Student grades and class peer quality (tobit regression)

Std. Grade

Std. Grade

Std. Grade

Std. Grade

\begin{tabular}{lcccc} 
Standardized peer GPA & $0.0078^{* *}$ & $0.0072^{* * *}$ & $0.0091^{* * *}$ & $0.0085^{* * *}$ \\
Standardized GPA & $(0.004)$ & $(0.001)$ & $(0.001)$ & $(0.001)$ \\
& $0.4075^{* * *}$ & $0.4069^{* * *}$ & $0.4100^{* * *}$ & $0.4095^{* * *}$ \\
& $(0.005)$ & $(0.001)$ & $(0.002)$ & $(0.001)$ \\
Observations & & & & \\
Course FE & 41,962 & 41,962 & 41,962 & 41,962 \\
Staff FE & YES & YES & YES & YES \\
Other course FE & NO & YES & NO & YES \\
\hline
\end{tabular}

Note: Robust standard errors clustered at the class level are in parentheses; ${ }^{* * *} \mathrm{p}<0.01,{ }^{* *} \mathrm{p}<0.05,{ }^{*} \mathrm{p}<0.1$. This table reports marginal effects at the mean of tobit regressions with standardized grade as dependent variable. The lower censoring limit is at the standardized grade equivalent of 5 , the highest failing grade. All specifications include dummies for day and time of the sessions, German, Dutch, exchange student status and late registration status.

These estimates are largely in line with class peer effects in other Western settings. Burke and Sass (2013) find similarly small point estimates in the linear-inmeans specifications at the class level. With a rich set of student and teacher fixed effects they find that for high school students a one standard deviation increase in class peer quality is associated with a 0.0088 standard deviations increase on a standardized mathematics test and a 0.0124 standard deviations increase on a standardized reading test. Martins and Walker (2006) find no significant peer effects at the university class level, although this might be due to their limited sample size. Duflo et al. (2011) find a substantially larger point estimate of 0.445 in the setting of randomly assigned class peers for primary schools in Kenya.

So far we have only reported average effects from linear-in-means specifications. Peer effects, however, might be heterogeneous. We are going to look at potential heterogeneity from two angles. First, we will test which students benefit more from having higher peer quality. We do this by adding the interaction 
between student GPA and peer GPA to the basic model as specified in equation (2). Second we test whether other moments of the peer quality distribution matter. Students might, for example, benefit from a more homogeneous class because the teacher can more easily tailor the instructions to all students. On the other hand, students might benefit from heterogeneity in peer ability if students learn can learn more from each other if the differences in quality are larger. We test whether homogeneity or heterogeneity matters beyond average peer quality by adding the standard deviation of the peer GPA to the basic model. Further, it might be that students are particularly affected by some individuals in their class. According to the "one bad apple spoils the barrel" theory, one particular student can have a disproportionate negative effect on the group functioning and learning. According to the "shining light" model, one outstanding student can affect the student achievements in a disproportionately positive way. We test for "bad apple" and "shining light" by adding the peer with the GPA of the best other student and the GPA of the worst other student in a class separately in the baseline model and excluding them from the average peer quality measure.

Table 4 shows marginal effects of tobit regressions with the standardized grade as the dependent variable. In column (1) of table 4 we show evidence that peer quality matters more for low ability students. The coefficient of the interaction between the student GPA and the peer GPA is negative and significantly different from zero. This means that low ability peers benefit more from being assigned to higher quality peers. These findings are consistent with the majority of peer literature that finds non-linear effects (Burke \& Sass, 2013; Carrell et al., 2009; Sacerdote, 2001). Column (2) includes the standard deviation of classroom peer GPA as an explanatory variable. The point estimate of the peer GPA standard deviation is .0030 which would suggests that students benefit from heterogeneity in peer quality. However the effect is only marginally significant. In column (3) we test the "shining light" model by including the GPA of the best peer. The point estimate is negative and significant. This means that if the GPA of the best student in class is high, holding constant the GPA of the other peers, average grades are lower. This finding contradicts the "shining light" model and suggests that having an outstanding student in class actually reduces student learning. 
Table 4: Heterogeneous peer effects and the effect of heterogeneity in class (tobit regression)

\begin{tabular}{|c|c|c|c|c|c|}
\hline & $\begin{array}{c}(1) \\
\text { Std. Grade } \\
\end{array}$ & $\begin{array}{c}(2) \\
\text { Std. Grade } \\
\end{array}$ & $\begin{array}{c}\text { (3) } \\
\text { Std. Grade } \\
\end{array}$ & $\begin{array}{c}\text { (4) } \\
\text { Std. Grade } \\
\end{array}$ & $\begin{array}{c}(5) \\
\text { Std. Grade }\end{array}$ \\
\hline $\begin{array}{l}\text { Standardized GPA * } \\
\quad \text { Standardized peer GPA }\end{array}$ & $\begin{array}{c}-0.0010^{* * *} \\
(0.000)\end{array}$ & & & & \\
\hline Standardized peer GPA & $\begin{array}{c}0.0086^{* * *} \\
(0.001)\end{array}$ & $\begin{array}{c}0.0090^{* * *} \\
(0.001)\end{array}$ & & & \\
\hline GPA of best peer & & & $\begin{array}{c}-0.0038^{* * *} \\
(0.000)\end{array}$ & & $\begin{array}{c}-0.0025^{* * *} \\
(0.000)\end{array}$ \\
\hline GPA of worst peer & & & & $\begin{array}{c}0.0041^{* * *} \\
(0.000)\end{array}$ & $\begin{array}{c}0.0038^{* * *} \\
(0.000)\end{array}$ \\
\hline GPA of remaining peers & & & $\begin{array}{c}0.0190^{* * *} \\
(0.000)\end{array}$ & $\begin{array}{c}0.0107^{* * *} \\
(0.000)\end{array}$ & $\begin{array}{c}0.0121^{* * *} \\
(0.000)\end{array}$ \\
\hline $\begin{array}{l}\text { Standard Deviation of } \\
\text { peer GPA }\end{array}$ & & $\begin{array}{c}0.0030^{*} \\
(0.002)\end{array}$ & & & \\
\hline Standardized GPA & $\begin{array}{c}0.4092^{* * *} \\
(0.001)\end{array}$ & $\begin{array}{c}0.4092^{* * *} \\
(0.002)\end{array}$ & $\begin{array}{c}0.4095^{* * *} \\
(0.002)\end{array}$ & $\begin{array}{c}0.4094 * * * \\
(0.002)\end{array}$ & $\begin{array}{c}0.4094 * * * \\
(0.002)\end{array}$ \\
\hline Observations & 41,962 & 41,962 & 41,962 & 41,962 & 41,962 \\
\hline Course FE & YES & YES & YES & YES & YES \\
\hline Staff FE & YES & YES & YES & YES & YES \\
\hline Other course FE & YES & YES & YES & YES & YES \\
\hline
\end{tabular}

Note: Robust standard errors clustered at the class level are in parentheses; ${ }^{* * *} \mathrm{p}<0.01,{ }^{* *} \mathrm{p}<0.05,{ }^{*} \mathrm{p}<0.1$. This table reports marginal effects at the mean of tobit regressions with standardized grade as dependent variable. The lower censoring limit is at the standardized grade equivalent of 5, the highest failing grade. All specifications include dummies for day and time of the sessions, German, Dutch, exchange student status and late registration status.

Column (4) looks at how the GPA of the worst peer (the "bad apple") in class influences student grades. The point estimate is positive and significant. This suggests that the students benefit if the weakest student has a higher GPA. When including both the GPA of the best and worst other peer in column (5) both point estimates remain significant. While the absolute size of these 
estimates is small it is interesting to point out the large magnitude relative to the effects of the remaining peers. The effect of the worst (best) student is 31 percent (21 percent) of the magnitude of the effect of the remaining peers. ${ }^{71}$

The evidence presented in table 4 contradicts the "shining lights" model and is consistent with the idea that one "bad apple" reduces class learning. Taking together, this means that if a class inherits fewer outliers in terms of ability, overall student achievements are marginally higher. One explanation of this finding is that if the best and worst students have an ability closer to the class mean, teachers might be better able to tailor their teaching style and content fitting to the needs of their students.

\section{7 | Conclusion}

We have investigated classroom peer effects in large sample of university students where assignment to classes within a course is random conditional on scheduling constraints. We find small in size but statistically significant peer effects on student grades in the linear-in-means specification. These effects seem particularly small since the Problem Based Learning teaching method which is used at the School of Business and Economics at Maastricht University is arguably more group intensive compared to traditional classroom instruction. These average effects hide some heterogeneity. It is especially the low ability students that benefit from high ability peers. Further, it is not only the average peer quality that matters for student outcomes. Confirming the "one bad apple" model, we show that especially low ability peers have an adverse effect on student grades. Surprisingly, we find that students' grades are also negatively affected by particularly high ability peers. Although all effects are very small and the economic importance of classroom peers may be limited our findings point to an underlying mechanism that suggests that the shining light of the brightest classmate blinds more than that it illuminates other students.

71 In columns (4), (5) and (6), the variable GPA of the remaining peers is the peer GPA excluding the GPA of the best, worst and best and worst student respectively. 


\section{Appendix}

\section{A.1 Additional Figures and tables}

Figure F1: Screenshot of the scheduling program used by the SBE Scheduling Department

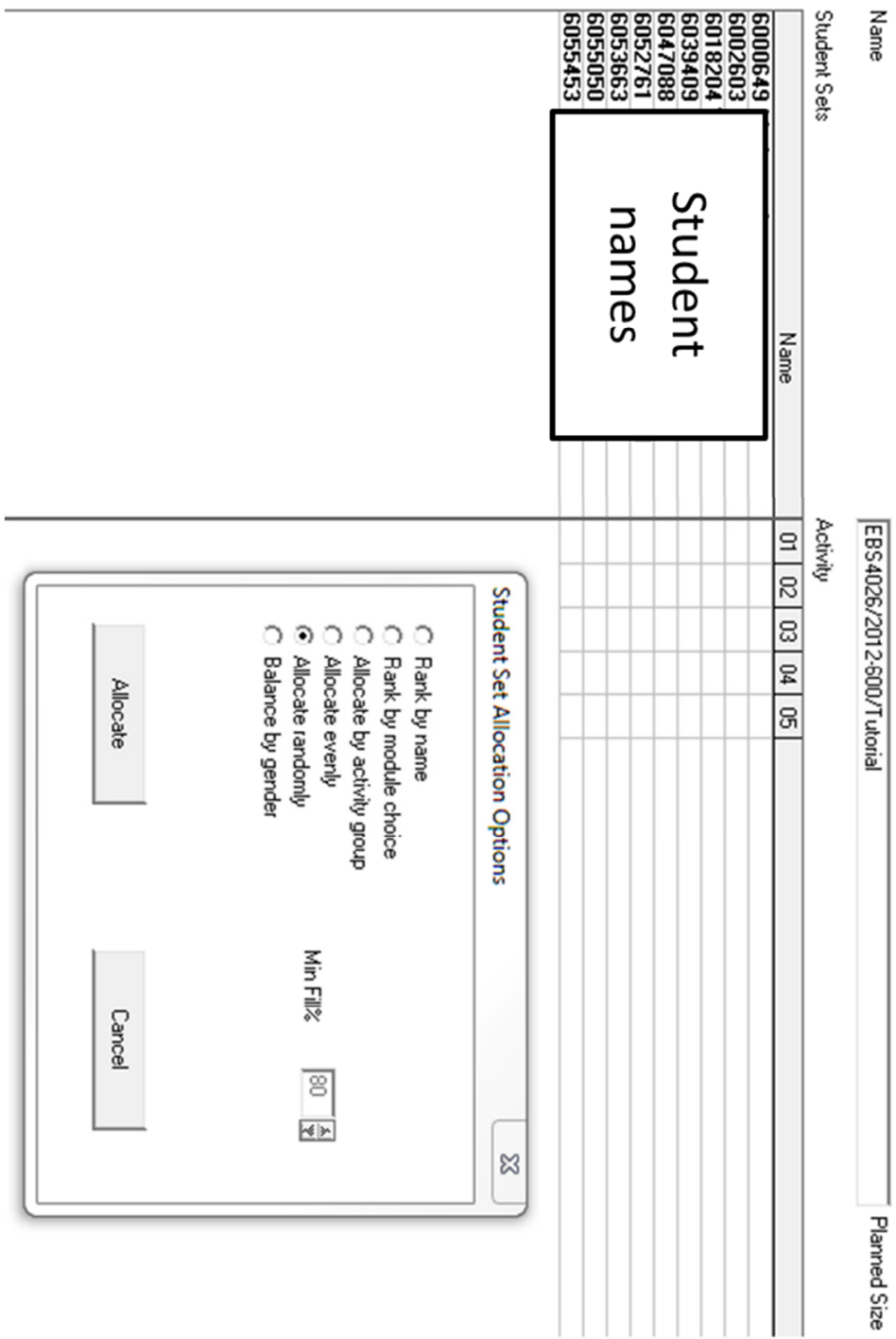

Note: This screenshot shows the program Plus Enterprise Timetable $\odot$. 
Table A1: OLS estimation: Student grades and class peer quality

\begin{tabular}{lcccc}
\hline & $(1)$ & $(2)$ & $(3)$ & $(4)$ \\
& Std. Grade & Std. Grade & Std. Grade & Std. Grade \\
\hline \multirow{3}{*}{ Standardized peer GPA } & $0.0112^{* *}$ & $0.0104^{*}$ & $0.0131^{* *}$ & $0.0123^{* *}$ \\
& $(0.005)$ & $(0.006)$ & $(0.005)$ & $(0.006)$ \\
Standardized GPA & $0.5446^{* * *}$ & $0.5439^{* * *}$ & $0.5475^{* * *}$ & $0.5467^{* * *}$ \\
& $(0.007)$ & $(0.007)$ & $(0.007)$ & $(0.007)$ \\
& & & & \\
Observations & 41,962 & 41,962 & 41,962 & 41,962 \\
R-squared & 0.421 & 0.430 & 0.438 & 0.446 \\
Course FE & YES & YES & YES & YES \\
Staff FE & NO & YES & NO & YES \\
Other course FE & NO & NO & YES & YES \\
\hline
\end{tabular}

Note: Robust standard errors clustered at the class level are in parentheses; *** $\mathrm{p}<0.01, * * \mathrm{p}<0.05, * \mathrm{p}<0.1$. This table is based on a OLS regressions with standardized grade as dependent variable. All specifications include dummies for day and time of the sessions, German, Dutch, exchange student status and late registration status. 


\section{A.2 Randomization check}

We use the following empirical specification for our tests. Take $y_{i}$ as a $1 x \mathrm{~N}_{i}$ vector of pre-treatment characteristics of students in course $i$. The pretreatment characteristics we look at are GPA, age, gender, or student ID rank.72 $T=\left(t_{1}, \ldots t_{n}\right)$ is a $n \times N_{i}$ matrix of class dummies (where each of the class dummies $t_{k}$ is of size $\left.1 x N_{i}\right), Z$ is a matrix which includes dummies for other course taken at the same time, and dummies for day and time of the sessions, German, Dutch, exchange student status and late registration status, and $\varepsilon_{i}$ a $1 \times N_{i}$ vector of zero-mean independent error terms.

Our randomization tests consist of running, for each course, the following regression:

$$
y_{i}=\alpha+T \beta+Z \gamma+\varepsilon_{i}
$$

Under the null-hypothesis of (conditionally) random assignment to classes within each course, $\beta_{1}=\beta_{2}=\cdots=\beta_{n}=0$. That means that the class assignment does not systematically relate to students' pre-treatment characteristic holding scheduling and stratification indicators constant. Therefore, we expect the F-test to be significant at the 5 percent level in around 5 percent of the cases, at 1 percent in around 1 percent of the cases, and at 0.1 percent in around 0.1 percent of the cases. Table A.2 shows in how many cases the F-test actually rejected the null hypothesis at the respective levels. Column (7) shows the total number of courses for each dependent variable for which we ran the regression specified in equation 1. Column (2) shows that the actual rejection rates at the 5 percent level are close to the expected rejection rates under random assignment. The F-tests for the regressions with the dependent variables GPA and age are rejected slightly more often than 5 percent, the rejection rates for the dependent variables gender and ID rank are rejected slightly less often than 5 percent. Columns (4) and (6) show the actual rejection rates at the 1 percent and 0.1 percent level. Also these rejection rates as a whole are close to

\footnotetext{
72 In Maastricht University, ID numbers are increasing in tenure at the university. ID rank is the rank of the ID number. We use ID rank instead of actual ID because the SBE recently added a new digit to the ID numbers, which creates a discrete jump in the series.
} 
the expected under random assignment, with the exception of age where the rejection rates is only slightly higher than we expected.

Table A.2: Randomization check of class assignment

\begin{tabular}{|c|c|c|c|c|c|c|c|}
\hline & (1) & (2) & (3) & (4) & (5) & (6) & (7) \\
\hline $\begin{array}{l}\text { Joined F-test signifi- } \\
\text { cant: }\end{array}$ & \multicolumn{2}{|c|}{$\begin{array}{c}\text { Number } \\
\text { significant at the } \\
5 \text { percent level }\end{array}$} & \multicolumn{2}{|c|}{$\begin{array}{c}\text { Number } \\
\text { significant at the } \\
1 \text { percent level }\end{array}$} & \multicolumn{2}{|c|}{$\begin{array}{c}\text { Number } \\
\text { significant at the } \\
0.1 \text { percent level }\end{array}$} & $\begin{array}{c}\text { Total number } \\
\text { of courses }\end{array}$ \\
\hline \multicolumn{8}{|l|}{ Dependent variable } \\
\hline$\overline{\mathrm{GPA}}$ & 25 & $5.80 \%$ & 8 & $1.86 \%$ & 2 & $0.46 \%$ & 431 \\
\hline Age & 28 & $6.57 \%$ & 11 & $2.58 \%$ & 4 & $0.94 \%$ & 426 \\
\hline Gender & 16 & $3.79 \%$ & 3 & $0.71 \%$ & 0 & $0.00 \%$ & 422 \\
\hline ID rank & 21 & $4.86 \%$ & 8 & $1.85 \%$ & 2 & $0.46 \%$ & 432 \\
\hline
\end{tabular}

Note: This table is based on separate OLS regressions with past GPA, age, gender and ID rank as dependent variables. Explanatory variables are a set of class dummies, dummies for other course taken at the same time, and dummies for day and time of the sessions, German, Dutch, exchange student status and late registration status. Column (1) shows the total number of separate regressions. Columns (2), (4) and (6) show in how many regressions the F-test rejected the null and the 5 percent, 1 percent and 0.1 percent level respectively. Columns (3), (5) and (7) show what percentage of the regressions the F-test rejected the null at the respective levels. Differences in number of courses are due to missing observations for some of the variables.

In order to investigate this issue more closely we look at the distribution of $\mathrm{p}$ values. Under the null hypothesis of conditionally random assignment, we would expect the $\mathrm{p}$-values of all the regressions to closely fit a $\mathrm{U}[0,1]$ uniform distribution with a mean of 0.5 (Murdoch et al., 2008). Figure F.2 shows histograms of the p-values of all four specifications, all of which are roughly uniformly distributed. ${ }^{73}$

\footnotetext{
${ }^{73}$ We choose to visually inspect the distribution of the p-values rather than formally testing them with non-parametric tests, such as the Kolmogorov-Smirnov test, because such tests are known to over-reject the null hypothesis in large samples (Kvam and Vidakovic, 2007).
} 
Columns (2) of table A.3 show the mean of the p-value over all regressions reported in table A.2. The mean p-values range from 0.48 to 0.52 . In column (3) we report p-values of a t-test, which tests whether the mean of the p-values reported in column (2) is significantly different from 0.5. None of the four t-tests rejects the null hypothesis.

Table A.3: Randomization check: Mean p-values

\begin{tabular}{lccc}
\hline & $(1)$ & $(2)$ & $(3)$ \\
\cline { 2 - 4 } Dependent variable: & $\begin{array}{c}\text { Total number of } \\
\text { courses }\end{array}$ & Mean of p-value & $\begin{array}{c}\text { p-value of t-test } \\
\text { (H0: Mean = 0.5) }\end{array}$ \\
\hline GPA & 431 & 0.48 & 0.112 \\
Age & 426 & 0.48 & 0.112 \\
Gender & 422 & 0.51 & 0.386 \\
ID rank & 432 & 0.52 & 0.119 \\
\hline
\end{tabular}

Note: This table is based on the regressions reported in table 2. Column (2) show the means of the p-values, Column (3) shows the p-values of t-tests testing whether the mean of the p-values in Column (3) is equal to 0.5. 
Figure F.2: Distribution of F-test $p$-values of $\beta$ from Equation (1) as reported in Table A.2

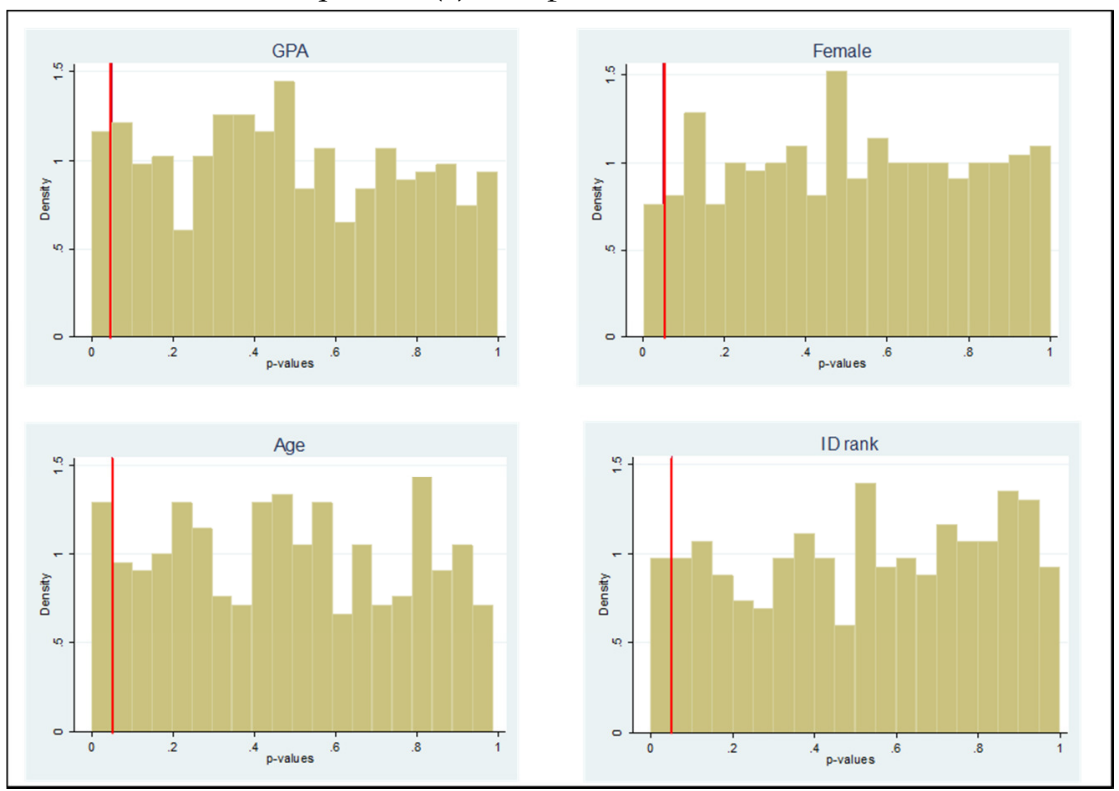

Note: These are histograms with p-values from all the regressions reported in table 2 . The vertical line in each histogram shows the 0.05 significance level. 

Chapter 7

Conclusions 



\section{1 | Summary of the main findings}

This thesis investigates the nature and consequences of school choice. Chapter two reviews the literature on school choice. Chapter three shows that parents prefer primary schools that perform better on school quality indicators. Higher educated families put higher weights on quality measured by the assessment of the Inspectorate of Education and school average test results. At the same time other school characteristics such as the schools' denomination and teaching concept play an additional important role in the choice process. Chapter four reveals that children benefit when their parents send them to a school that performs better on quality characteristics. Schools with higher average test scores cause a better development of cognitive abilities in the age group of four to six year old children. The observed effect is heterogeneous: lower ability children benefit more from attending a higher achieving school. Taking together the findings of chapters three and four, we can conclude that those children who would benefit most from attending a quality school come from the socioeconomic group that has the weakest preferences for school quality. One potential reason for these suboptimal educational choices could be that lower educated parents have less access to information about school quality and therefore make less informed choices. In chapter five we therefore propose an experiment in which we provide parents with information about test scores and other school characteristics that have been found to be important for school choice. The experiment that we describe and that we are conducting in the city of Rotterdam has the potential to improve the quality of school choice, increase the student-school match and also might raise student achievements in the long run.

One potential channel for the effects of school quality on cognitive development that we identify in chapter four could be that at better schools, students have better peers. Better peers could increase student achievements through spillovers in learning, less disruptive behavior or by generating an atmosphere of generally higher aims and aspirations. With the currently available data it is empirically not possible to disentangle peer effects in primary school from selection effects. We therefore study the nature of classroom peer effects in the different setting of Maastricht University where classes are conditionally randomly assigned. We show that average peer effects are very small, but find that other moments of the peer distribution matter for student grades. The ability of 
the worst student in class has, as compared to the size of the average peer effect, a relatively large influence on student grades. Put differently, "bad apples" seem to reduce student learning. At the other end of the peer distribution we surprisingly find that "shining lights" - particularly high performing students also have a negative effect on other students. One explanation for this finding is that if the best and worst students have abilities closer to the class mean, teachers might be better able to tailor their teaching style and content to the needs of their students.

\section{2 | Policy implications and recommendations}

The first part of this thesis has shown that parental preferences for school quality, measured as CITO scores and the "trusted" assessment of the Inspectorate of Education are relatively weak and decrease with the education level of the parents. We have also shown that low ability children, who are more likely to have lower educated parents, benefit more from attending a higher quality school. Since this could be due to a lack of information, one obvious policy recommendation would be to inform parents about the different school options that they face. Besides the approach that we describe in chapter five, one could also think about an intervention where parents from disadvantaged backgrounds receive personal advice on school choice from a school counselor.

The results we present in chapter four show that schools with a higher average CITO score enhance the early cognitive development of children. This finding provides support for the approach of the Inspectorate of Education, which uses CITO scores as a part of their school assessment process. Our findings support the policy that schools performing poorly in terms of school average CITO scores should be monitored more closely since children at these schools develop less cognitive abilities at the beginning of their school career. If the development of cognitive skills is complementary over time as formulated by the model of Heckman and coauthors $(2010 ; 2008$; 1999) our findings are particularly alarming since schools with poor quality delay the cognitive development in the earlier, more sensitive periods. 


\section{3 | Future research}

Hoxby (2002) suggested that school choice could be a tide that lifts all boats. Although we present evidence that parents seem to care about school quality and that children actually benefit from a high quality school, it is not that clear whether increased school competition actually raises schools' quality standards. One way of investigating this question would be to look at the effect of school openings or closings on the value-added of the surrounding schools. Shrinking student numbers in some areas of the Netherlands would provide an excellent research environment for investigating school competition effects.

Based on the findings in chapter three on parental school choice behavior it would be interesting to study selection into schools further. One factor that may be of potential importance for schools choice could be the personality of a child. For example, do parents with neurotic children send their children to different schools than parents with less neurotic children? How far are parents willing to travel to get access to a school that may be more specialized on the needs of their children? Providing more evidence on these points could improve our understanding of whether parents are trying to compensate for a lack of a particular personality trait by choosing special school types. It is also not clear whether parental preferences are aligned with student preferences. Mismatches might also be due to particular parental traits.

Given the findings in chapter four on early cognitive development one could also investigate the effects of school quality on the development of personality traits. Since panel data on non-cognitive skills are available, the next logical step would be to assess which school characteristics foster for example conscientiousness, openness to experiences or the degree of neuroticism. This evidence could potentially contribute to explaining how the formation of non-cognitive skills is affected by the school environment.

One interpretation of the findings we present in chapter three is that school competition and increased transparency about school quality may not only raise schools academic standards, but also lead to increased specialization in the long run. Although we present no direct evidence on this issue, one could think of the following mechanism that could be empirically investigated: When facing increased school competition in the domain of educational quality, a natural 
response of the schools would be to either raise their standards or, if that is not possible or wanted, to specialize on specific socio-economic subgroups that value other school characteristics beyond test scores.

Considering the findings of chapter six on peer effects it is yet unclear whether our results on peer effects at the university level would be generalizable to the setting of primary and secondary education. One potential identification strategy could be to exploit school admission lotteries exiting in some areas of the Netherlands that generate exogenous variation in peer quality. One other open key question in the literature on peer effects is through which channels peer effects work. Using data on course evaluations could provide insights on whether teachers adjust their teaching style with respect to the class composition and whether students' preparation effort increases when exposed to good peers. 


\section{References}

Abdulkadiroglu, A., Angrist, J. D., Dynarski, S. M., Kane, T. J. and Pathak, P. (2011). "Accountability and Flexibility in Public Schools: Evidence from Boston's Charters and Pilots." Quarterly Journal of Economics 126, 699-748.

Angrist, J. P, Parag, A. and Walters, C. R. (2011). "Explaining Charter School Effectiveness.” NBER Working Paper No. 17332.

Bajari, P., Fox, J., and Ryan, S. (2007). "Linear Regression Estimation of Discrete Choice Models with Nonparametric Distributions of Random Coefficients." American Economic Review (Papers and Proceedings) 97(2), 459-463.

Barro, L. (2002). "School Choice Through Relocation: Evidence from the Washington, D.C. Area." Journal of Public Economics 86, 155-189.

Blomeyer, D., Coneus, K., Laucht, M. and Pfeiffer, F. (2009). "Initial Risk Matrix, Home Resources, Ability Development and Children's Achievement." Journal of the European Economic Association 7(2-3), 638-648.

Booker, K., Gilpatric, S. M., Gronberg, T. and Jansen, D. (2007). "The Impact of Charter School Attendance on Student Performance." Journal of Public Economics 91(5-6), 849-876.

Borghans, L., Duckworth, A. L., Heckman, J. and ter Weel, B. (2008). "The Economics and Psychology of Personality Traits.", Journal of Human Resources 43(4), 972-1059.

Brunello, G., De Paola, M., and Scoppa, V. (2010). "Peer Effects in Higher Education: Does the Field of Study Matter?” Economic Inquiry 48(3), 621-634.

Burke, M. A., and Sass, T. R. (2013). "Classroom Peer Effects and Student Achievement." Journal of Labor Economics 31(1), 51-82.

Card, D. (1995). "Using Geographic Variation in College Proximity to Estimate the Return to Schooling." In Christofides, N., Grant, E. and Swidinsky, R. (eds). "Aspects of Labor Market Behaviour: Essays in Honour of John Vanderkamp." Toronto: University of Toronto Press. 
Carneiro, P., Crawford, C., and Goodman, A. (2007). "Impact of Early Cognitive and Non-Cognitive Skills on Later Outcomes." London, UK: London School of Economics Centre for the Economics of Education. CEE Discussion paper 92.

Carrell, S. E., Fullerton, R. L., and West, J. E. (2009). "Does Your Cohort Matter? Measuring Peer Effects in College Achievement." Journal of Labor Economics, 27(3).

Chetty, R., Friedman, J., Hilger, N., Saez, E., Whitmore Schanzenbach, D. and Yagan, D. (2010). "How Does Your Kindergarten Classroom Affect Your Earnings? Evidence From Project STAR.” Quarterly Journal of Economics 126(4), 1593-1660.

Cullen, J., Jacob, B. and Levitt, S. (2006). "The Effect of School Choice on Participants: Evidence from Randomized Lotteries.” Econometrica 74(6), 1191-1230.

Cullen, J., Jacob, B., and Levitt, S. (2005). "The Impact of School Choice on Student Outcomes: an Analysis of the Chicago Public Schools.” Journal of Public Economics 89 (5-6), 729-760.

Cunha, F. and Heckman, J. (2008). "Formulating, Identifying and Estimating the Technology of Cognitive and Noncognitive Skill Formation.” Journal of Human Resources 43(4), 738-782.

Cunha, F., Heckman, J. and Schennach, S. (2010). "Estimating the Technology of Cognitive and Noncognitive Skill Formation." Econometrica 78(3), 883-931.

Denessen, E., Driessen, G. and Sleegers, P. (2005). "Segregation by Choice? A Study of Group-Specific Reasons for School Choice." Journal of Education Policy 20(3), 347-368.

De Paola, M., and Scoppa, V. (2010). "Peer Group Effects on the Academic Performance of Italian Students.” Applied Economics, 42(17), 2203-2215.

Duflo, E., Dupas, P., and Kremera, M. (2011). "Peer Effects, Teacher Incentives, and the Impact of Tracking: Evidence from a Randomized Evaluation in Kenya." The American Economic Review, 101(5), 1739-1774. 
Friedman, M. (1955). "The Role of Government in Education." in Robert A. Solo, ed., Economics and the public interest. New Brunswick, NJ: Rutgers University Press, 44-123.

Glazerman, S. (1998). "School Quality and Social Stratification: The Determinants and Consequences of Parental School Choice." Unpublished manuscript.

Hanushek, E. A., Kain, J. F., Rivkin, S. G. and Branch, G. F. (2007). "Charter School Quality and Parental Decision Making with School Choice." Journal of Public Economics, 91(5-6) 823-848.

Hastings, J. S., Neilson, C. A. and Zimmerman, S. D. (2012). "The Effect of School Choice on Intrinsic Motivation and Academic Outcomes." NBER Working Paper Series 18324

Hastings, J., Kane, T. and Staiger, D. (2010). "Heterogeneous Preferences and the Efficacy of Public School Choice.” NBER Working Paper Series 2145.

Hastings, J., and Weinstein, J. (2008). "Information, School Choice, and Academic Achievement: Evidence from Two Experiments." Quarterly Journal of Economics, 123, 1373-1414.

Hastings, J. S., Van Weelden, R. and Weinstein, J. (2007). "Preferences, Information and Parental Choice Behavior in Public School Choice." NBER Working Paper Series, 12995.

Heckman, J. (2000). "Policies to Foster Human Capital." Research in Economics 54, 3-56.

Howell, W. G., Wolf, P. J., Campbell, D. E., and Peterson. (2002). "School Vouchers and Academic Performance: Results from Three Randomized Field Trials." Journal of Policy Analysis and Management, 21, 191-217.

Hoxby, C. (2002). "Would School Choice Change the Teaching Profession?" Journal of Human Resources 38(4), 846-891.

Hoxby, Caroline M. (2002). "School Choice and School Productivity (or Could School Choice Be a Tide That Lifts All Boats?)." NBER Working Paper 8873. 
Hoxby, Caroline M. (2000). "Does Competition Among Public Schools Benefit Students and Taxpayers?" American Economic Review 90(5), 1209-38.

Hanushek, E., Kain, J., Rivkin, S. and Branch, G. (2007). "Charter school Quality and Parental Decision Making with School Choice." Journal of Public Economics 91(5-6), 823-848.

Jacob, B., and Lefgren, L. (2007). "What do Parents Value in Education? An Empirical Investigation of Parents' Revealed Preferences for Teachers.", Quarterly Journal of Economics, 122 (4): 1603-1637.

Karsten, S., Ledoux, G., Roeleveld, J., Felix, C. and Elshof, D. (2003). "School Choice and Ethnic Ssegregation." Educational Policy, 17, 452-477.

Knudsen, E., Heckman, J., Cameron, J. and Shonkoff, J. (2006). "Economic, Neurobiological, and Behavioral Perspectives on Building America's Future Workforce." Proceedings of the National Academy of Sciences 103(27), 10155-10162.

Koning, P. and Van der Wiel, K. (2013). "Ranking the Schools: How Quality Information Affects School Choice in the Netherlands." Journal of the European Economic Association 11(2) 466-493.

Koning, P. and Van der Wiel, K. (2012). "School Responsiveness to Quality Rankings: An Empirical Analysis of Secondary Education in the Netherlands." De Economist 160(4), 339-355.

Kvam, P. H., and Vidakovic, B. (2007). Nonparametric Statistics with Applications to Science and Engineering. (Vol. 653): Wiley-Interscience.

Ladd, Helen F., Edward B. Fiske and Nienke Ruijs. (2010). "Parental Choice in the Netherlands: Growing Concerns about Segregation." Sanford Working Paper Series, SAN10-02.

Lyle, D. S. (2007). "Estimating and Interpreting Peer and Role Model Effects from Randomly Assigned Social Groups at West Point." The Review of Economics and Statistics, 89(2), 289-299.

Manski, C. F. (1993). "Identification of Endogenous Social Effects: The Reflection Problem." The Review of Economic Studies, 60(3), 531-542.

Martins, P. and Walker, I. (2006). "Student Achievement and University Classes: Effects of Attendance, Size, Peers, and Teachers." IZA Discussion Paper 2490. 
Murdoch, D. J., Tsai, Y.-L. and Adcock, J. (2008). "P-values are Random Variables." The American Statistician, 62(3).

Rouse, C. E. (1998). "Private School Vouchers and Student Achievement: An Evaluation of the Milwaukee Parental Choice Program." The Quarterly Journal of Economics 113 (2).

Ruijs, N., Oosterbeek, H. (2012). "School Choice in Amsterdam. Which Schools do Parents Prefer When School Choice is Free?" Unpublished Manuscript, University of Amsterdam.

Sacerdote, B. (2001). "Peer Effects with Random Assignment: Results for Dartmouth Roommates." The Quarterly Journal of Economics, 116(2), 681704.

Train, K. (2009). Discrete Choice Methods with Simulation (Second Edition). New York: Cambridge University Press.

Zimmerman, D. J. (2003). "Peer Effects in Academic Outcomes: Evidence from a natural experiment." Review of Economics and Statistics, 85(1), 9-23. 


\section{Dutch Summary (Samenvatting)}

Het doel van dit proefschrift is om de determinanten van schoolkeuzes te identificeren en om te analyseren welke aspecten van de schoolomgeving cognitieve ontwikkeling en schoolprestaties stimuleren.

Hoofdstuk 2 geeft een samenvatting van de literatuur aangaande de redenen om een school te kiezen en de consequenties van het kiezen van een bepaalde school. Studies op basis van cross-sectionele data van de VS laten zien dat het volgen van onderwijs aan een beter presterende school lijkt te leiden tot betere uitkomsten. Andere studies schrijven deze hogere scores echter toe aan zelfselectie in de scholen. Daarnaast tonen empirische resultaten op basis van experimenten en natuurlijke experimenten (plaatsing in scholen op basis van loting) aan dat informatie over de kwaliteit van scholen het keuzegedrag van ouders beïnvloedt.

In hoofdstuk 3 analyseren we hoe Nederlandse ouders scholen kiezen en laten we zien hoe voorkeuren voor de kwaliteit van een school, de nabijheid van de school en het schooltype geïdentificeerd kunnen worden. Voorkeuren voor schoolkwaliteit blijken te verschillen tussen sociaal-economische groeperingen. Daarnaast hebben bepaalde ouders een sterke voorkeur voor gespecialiseerde scholen met een specifiek onderwijsconcept. Zo lijken gezinnen van een lagere sociaal-economische komaf gemiddeld vaker scholen van mindere kwaliteit te kiezen. In bredere zin onderschrijven onze resultaten het idee dat vrije schoolkeuze niet alleen competitie onder scholen stimuleert, maar ook scholen kan aanzetten om zich te specialiseren en zo te voldoen aan de vraag naar scholing in een heterogene maatschappij. 
Hoofdstuk 4 analyseert het effect van de kwaliteit van kleuterscholen op de cognitieve ontwikkeling van kinderen. De resultaten van dit hoofdstuk geven aan dat de cognitie van kinderen in scholen met een hoge onderwijskwaliteit sneller ontwikkelt dan die van kinderen in scholen met een lagere onderwijskwaliteit. Onze resultaten tonen ook aan dat dit effect heterogeen is. Kinderen met een lager initieel cognitief niveau profiteren meer van een school met hoge onderwijskwaliteit.

Hoofdstuk 5 geeft het ontwerp van een veldexperiment dat gebruikt kan worden om te analyseren of het geven van informatie over scholen een effect heeft op de schoolkeuze van ouders. Het beschikbaar stellen van informatie over scholen zou een beleidsmiddel kunnen zijn om schoolkwaliteit transparanter te maken. Het zou op korte termijn kunnen leiden tot een rationelere schoolkeuze van ouders. Op langere termijn zou dit dan weer kunnen leiden tot betere schoolprestaties.

Hoofdstuk 6 bestudeert of klasgenoten leerprestaties kunnen beïnvloeden. In het primair onderwijs is het bijna onmogelijk om de effecten van klasgenoten te onderscheiden van selectie-effecten. Daarom analyseren we de effecten van klasgenoten in een andere omgeving, namelijk in onderwijsgroepen van Maastricht University. De resultaten tonen aan dat het volgen van onderwijs in een klas met goed presterende klasgenoten weinig meerwaarde heeft voor de leerprestaties. Bovendien laten we zien dat het leren niet gestimuleerd wordt door een zeer goede klasgenoot, maar wel gehinderd wordt door een zeer slecht presterende klasgenoot. 



\section{Acknowledgements}

Lex Borghans and Bart Golsteyn have been perfect supervisors. Throughout all phases of my $\mathrm{PhD}$ you gave me the freedom to develop my own ideas and provided me with valuable feedback. Working together with you showed me how to think as an economist and how to be a good researcher. Thank you both!

This thesis has largely benefited from many discourses with friends and colleagues within and outside Maastricht University. I truly enjoyed the many discussions with Bart L., Bene, Eva, Franzi, Jan, Margriet, Maria, Nico, and Tyas. In particular I would like to thank Nina for her patience and for listening to my good and bad ideas. Thank you all! I also thank my parents Radka and Winfried for their support during the last 28 years. You have helped me in every way you could. It means everything.

Ulf Zölitz, Bonn, December 2013 


\section{Curriculum Vitae}

Ulf Nikolaus Zölitz was born in Engelskirchen, Germany on September 19, 1985. He graduated from high school (Gymnasium) at the Antonius Kolleg Neunkirchen in 2005. He studied economics at the University of Bonn from 2005 to 2010. During his studies he worked as a research assistant at the Institute for Applied Microeconomics from 2008 to 2010. His master thesis analyzed the relationship between life satisfaction and consumption behavior.

In September 2010 Ulf started his dissertation research at Maastricht University. The results of his research as a $\mathrm{PhD}$ candidate are collected in this doctoral thesis. His research has been presented at various international workshops and conferences.

Since October 2013 Ulf holds the position of a postdoctoral researcher at the Department of Economics at Maastricht University. In 2014 Ulf is a visiting scholar at Northwestern University, Chicago. 


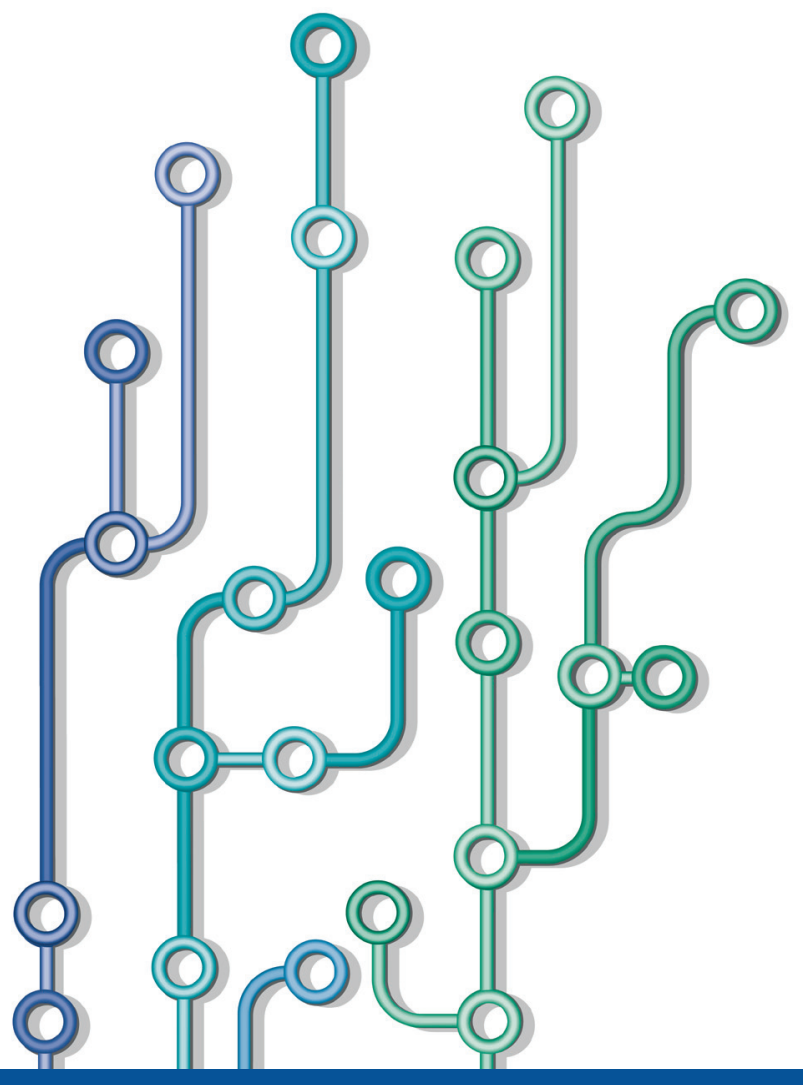

